SORAIA CRISTINA FELIX DA SILVA

\title{
GASEIFICAÇÃO DE VINHAÇA EM ÁGUA SUPERCRÍTICA
}

Dissertação apresentada à Escola Politécnica da Universidade de São Paulo para obtenção do título de Mestre em Engenharia

Área de Concentração:

Engenharia Química

Orientador:

Prof. Dr. Reinaldo Giudici 
SORAIA CRISTINA FELIX DA SILVA

\section{GASEIFICAÇÃO DE VINHAÇA EM ÁGuA SUPERCRÍTICA}

Dissertação apresentada à Escola Politécnica da Universidade de

São Paulo para obtenção do título de Mestre em Engenharia 
SORAIA CRISTINA FELIX DA SILVA

\section{GASEIFICAÇÃO DE VINHAÇA EM ÁGUA SUPERCRÍTICA}

Dissertação apresentada à Escola Politécnica da Universidade de

São Paulo para obtenção do título de Mestre em Engenharia

Área de Concentração:

Engenharia Química

Orientador:

Prof. Dr. Reinaldo Giudici 
Catalogação-na-publicação

Silva, Soraia Cristina Felix da

Gaseificação de Vinhaça em Água Supercrítica / S. C. F. Silva -- São Paulo, 2016. $102 \mathrm{p}$.

Dissertação (Mestrado) - Escola Politécnica da Universidade de São Paulo. Departamento de Engenharia Química.

1.Gaseificação em água supercrítica 2.Biomassa I.Universidade de São Paulo. Escola Politécnica. Departamento de Engenharia Química II.t. 


\section{AGRADECIMENTOS}

Ao Professor Doutor Reinaldo Giudici, pela confiança, orientação e assinaturas de última hora.

Ao Professor Doutor Song Won Park, por toda a orientação, cafés e piadas durante a execução deste trabalho.

Aos meus familiares e amigos, pelo carinho, paciência e apoio durante toda a jornada.

À Promon Engenharia, pelo apoio com crédito educativo e referências técnicas. 


\section{RESUMO}

A gaseificação utiliza o conteúdo intrínseco de carbonos e hidrogênios das matérias primas sólidas ou líquidas na geração de uma mistura de hidrogênio $\left(\mathrm{H}_{2}\right)$, monóxido de carbono (CO), dióxido de carbono $\left(\mathrm{CO}_{2}\right)$ e metano $\left(\mathrm{CH}_{4}\right)$. Tal mistura pode ser utilizada como matéria prima na síntese de novos produtos ou como combustível. A gaseificação pode ser utilizada no processamento de uma gama variada de produtos, independentemente de suas características ou estado físico. A utilização de biomassa como insumo da gaseificação vem sendo cada vez mais explorada e estudada, já que apresenta benefícios não somente na esfera ambiental, mas também em âmbitos econômicos e sociais. A vinhaça é um subproduto do processo de produção de álcool, que contém grandes concentrações de nutrientes e matéria orgânica em sua composição. A sua utilização hoje está limitada a fertirrigação e a aplicações isoladas em biodigestão e outros, que não são suficientes para 0 consumo da produção anual crescente do resíduo. Seu uso na gaseificação permitiria o aproveitamento do conteúdo orgânico da mesma e a produção de gases de alto valor agregado. Como a umidade do insumo interfere negativamente na eficiência da gaseificação clássica, a aplicação da mesma para matérias primas com alto teor de líquidos não é recomendada. Uma alternativa viável seria a utilização do meio gaseificante supercrítico, que resulta em rendimentos constantes, independentemente da umidade da corrente de entrada do reator. $O$ presente trabalho consiste no projeto de um módulo de gaseificação de vinhaça em água supercrítica, a ser instalado como uma unidade anexa a usinas de açúcar e álcool. Ele compreende o projeto conceitual e análise de viabilidade deste módulo, incluindo estimativas de CAPEX (Capital Expenditure) e OPEX (Operation Expenditure) e uma análise de sensibilidade dos mesmos. O estudo apresenta ainda o estado da arte do conhecimento e da tecnologia de gaseificação com água supercrítica (SCWG), relacionando os gargalos a serem resolvidos, assim como os ganhos intrínsecos da definição conceitual do projeto.

Palavras-Chave: SCWG. Água Supercrítica. Gaseificação. Vinhaça. Biomassa. Projeto. CAPEX. OPEX. 


\begin{abstract}
The gasification process uses the carbon and hydrogen content in a given solid or liquid feedstock to produce a gaseous mixture of hydrogen $\left(\mathrm{H}_{2}\right)$, carbon monoxide (CO), carbon dioxide $\left(\mathrm{CO}_{2}\right)$ and methane $\left(\mathrm{CH}_{4}\right)$. This mixture can be used as a precursor in the synthesis of new products or directly as a fuel. The gasification can be used in the processing of a wide range of materials, regardless of its characteristics or physical state. The use of vinasse as a gasification feedstock has been increasingly explored and studied, since its appeal lies not only on the environmental sphere, but as well on economic and social scope. Vinasse is a byproduct of the ethanol/ sugar producing process and contains large concentrations of nutrients and carbon organic matter in its protein-rich composition. The use of this fluid is limited today to fertirrigation and isolated applications, that are not enough for the consumption of its growing production. The possibility of gasifying the vinasse would allow a more profitable use of the fluid. In the classical gasification, the moisture content of the product being gasified impairs the yield of the reaction. So, for liquid feedstock its use is not recommended. One viable alternative for this case would be the use of the supercritical water as a reaction medium, which results in constant yields regardless of the moisture content of the raw material. This work consists on the design of module for vinasse gasification in supercritical water, to be installed as a unit, attached to an alcohol/ sugar plant. It comprises the conceptual design and feasibility study of the module, including CAPEX and OPEX estimates, plus a sensitivity analysis. The study also presents the state of the art of the knowledge associated to SCWG technology, relating bottlenecks to be solved, as well as the intrinsic gains from conceptual design definition.
\end{abstract}

Keywords: SCWG. Supercritical Water. Gasification. Vinasse. Biomass. Project. CAPEX. OPEX. 


\section{LISTA DE ILUSTRAÇÕES}

Figura 1: Rotas para conversão de biomassa em energia. ............................... 7

Figura 2: Diagrama de fases da água.........................................................11

Figura 3: Reações consideradas no modelo cinético de Guan; Wei e Savage.......19

Figura 4: Etapas de reação do modelo cinético segundo Resende e Savage........23

Figura 5: Mecanismo de reação do modelo de decomposição segundo Goodwin e Rorrer.

Figura 6: Mecanismo de reação do modelo de gaseificação segundo Goodwin e Rorrer.

Figura 7: Etapas de reação do modelo cinético segundo Goodwin e Rorrer. .28

Figura 8: Fluxograma de Processo do sistema de Gaseificação de Vinhaça em Água Supercrítica proposto.

Figura 9: Simulação de gaseificação de vinhaça em água supercrítica. .59

Figura 10: Fluxograma de Processo do sistema de Gaseificação de Vinhaça em Água Supercrítica proposto - completo.

Figura 11: Módulo de gaseificação de vinhaça em água supercrítica, com a inclusão da turbina. 


\section{LISTA DE TABELAS}

Tabela 1: Composição média da vinhaça.

Tabela 2: Comparação entre gaseificadores comerciais.

Tabela 3: Classes de estimativas de investimento segundo a AACE.

Tabela 4: Resultados da simulação para o módulo de gaseificação de vinhaça em água.

Tabela 5: Lista de Equipamentos com as principais características dos equipamentos do módulo de gaseificação de vinhaça em água supercrítica.

Tabela 6: Estimativa de custo para os equipamentos do módulo de gaseificação de vinhaça em água supercrítica.

Tabela 7: Estimativa de OPEX do módulo de gaseificação de vinhaça em água supercrítica.

Tabela 8: Resultados da simulação para o módulo de gaseificação de vinhaça em água supercrítica com a temperatura de operação de $600^{\circ} \mathrm{C}$ no gaseificador.

Tabela 9: Estimativa de OPEX do módulo de gaseificação de vinhaça em água supercrítica com a temperatura de operação de $600^{\circ} \mathrm{C}$ no gaseificador.

Tabela 10: Resultados da simulação para o módulo de gaseificação de vinhaça em água supercrítica para vinhaça com $12 \%$ de concentração de sólidos.

Tabela 11: Estimativa de OPEX do módulo de gaseificação de vinhaça em água supercrítica para vinhaça com $12 \%$ de concentração de sólidos.

Tabela 12: Resultados da simulação para o módulo de gaseificação de vinhaça em água supercrítica, com a inclusão da turbina.

Tabela 13: Estimativa de CAPEX do módulo de gaseificação de vinhaça em água supercrítica com turbina.

Tabela 14: Estimativa de OPEX do módulo de gaseificação de vinhaça em água supercrítica com turbina. 


\title{
LISTA DE ABREVIATURA E SIGLAS
}

\author{
AACE Association for the Advancement of Cost Engineering \\ ASPEN Plus Software de simulação de processos \\ CAPEX Capital Expenditure \\ CFD Computational Fluid Dynamics \\ DDGS Dried Distillers Grains with Solubles \\ Matlab Software de cálculo numérico \\ NREL National Renewable Energy Laboratory \\ OPEX Operation Expenditure \\ RGIBBS Bloco do simulador ASPEN Plus, representativo de um modelo \\ de reator \\ RK-SOAVE Equação de estado de Soave Redlich-Kwong \\ RYIELD Bloco do simulador ASPEN Plus, representativo de um modelo \\ de reator \\ SCWG Supercritical Water Gasification \\ SRKMHV2 Equação de estado Soave Redlich-Kwong, modificada por \\ Huron-Vidal \\ TCPDU Termochemical Process Development Unit
}




\section{SUMÁRIO}

1 INTRODUÇÃO

1.1 Desafios do manuseio da vinhaça na indústria de açúcar e álcool ..... 1

1.2 Objetivos do trabalho ...................................................................... 4

1.3 Estrutura da dissertação .......................................................... 4

2 DESCRIÇÃO DOS OBJETOS DO ESTUDO ......................................... 6

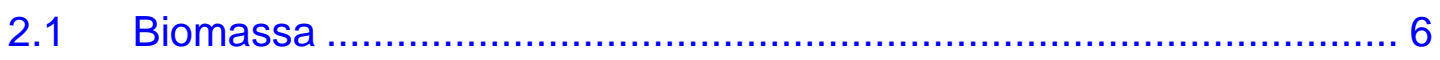

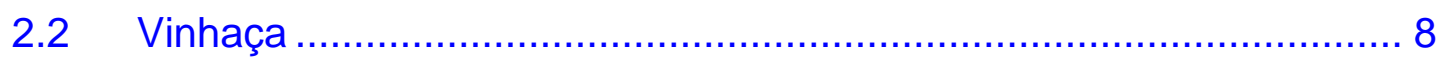

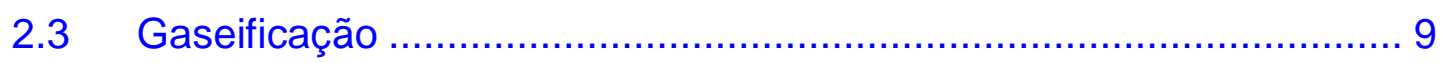

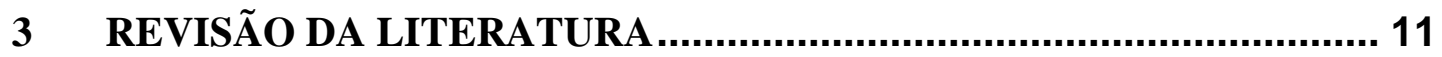

3.1 Gaseificação em água supercrítica ............................................... 11

3.2 Influência da Temperatura ...................................................... 12

3.3 Tipos de Gaseificadores........................................................... 13

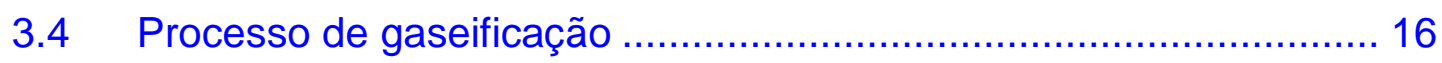

3.5 Modelos de gaseificação .......................................................... 18

3.5.1 Estudos de Yakaboylu et al. (2013) .................................................................. 18

3.5.2 Modelo cinético segundo Guan; Wei e Savage. (2012) ………………………...... 19

3.5.3 Modelo cinético segundo Resende e Savage (2010) .............................................. 21

3.5.4 Modelo cinético segundo Castello e Fiori (2012) .................................................. 24

3.5.5 Modelo cinético segundo Goodwin e Rorrer (2010) ……................................. 25

3.5.6 Modelo termodinâmico segundo Tang e Kitagawa (2005) ...................................... 29

3.5.7 Modelo termodinâmico segundo Yan; Guo e Lu (2006) ........................................ 31

3.5.8 Modelo termodinâmico segundo Freitas e Guirardello (2012).................................. 32

3.5.9 Simulação e modelagem segundo Tisdale (2004) ……………………………….... 34

3.5.10 Modelagem e simulação segundo Kumar et al. (2009) ………………………........ 36

3.5.11 Análise segundo Withag et al. (2012) ..................................................................

3.5.12 Análise segundo Fiori; Valbusa; Castello (2012) ................................................. 38

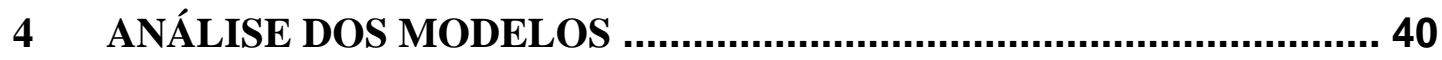

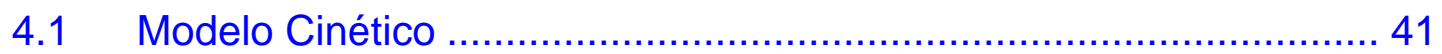

4.2 Modelo Termodinâmico ................................................................ 42

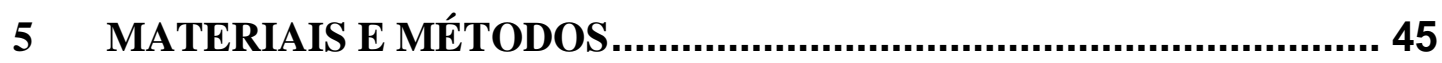

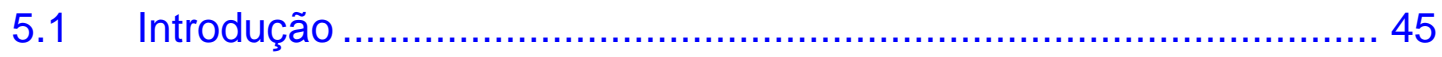

5.2 Descrição simplificada da execução de um projeto conceitual ......... 47 
5.3 Estimativas de investimento de projetos ..................................... 49

5.4 Método de Lang ................................................................... 50

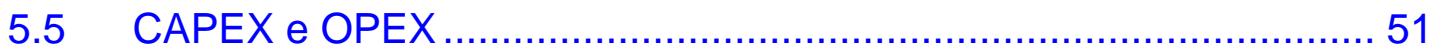

5.6 ASPEN Plus ......................................................................... 51

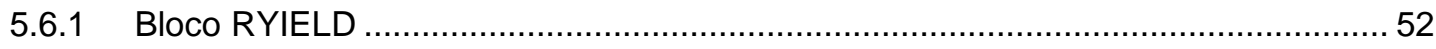

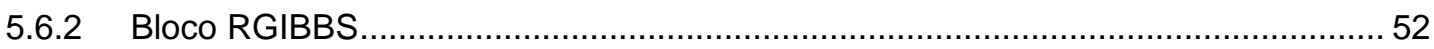

5.7 Fluxograma de Gaseificação de Vinhaça em Água Supercrítica ...... 55

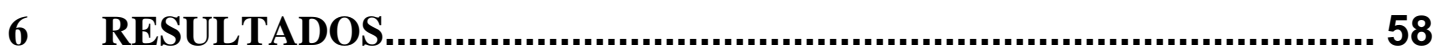

6.1 Balanço de massa e energia do caso de projeto .......................... 58

6.2 Descrição dos equipamentos ............................................. 63

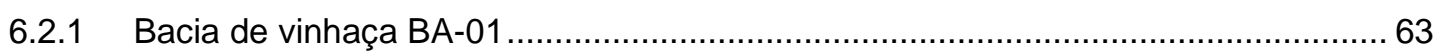

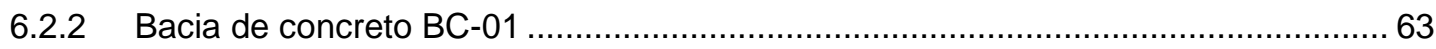

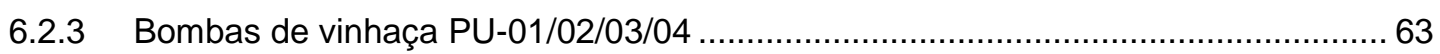

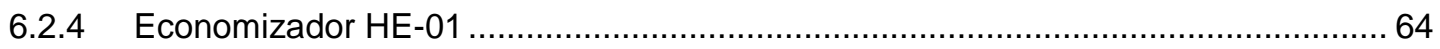

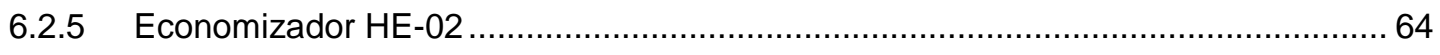

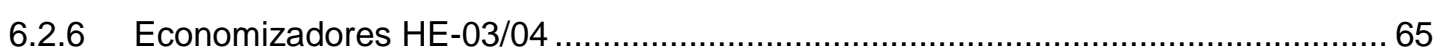

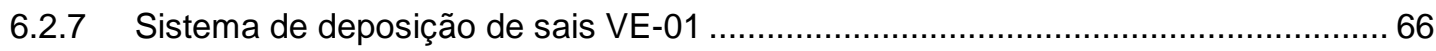

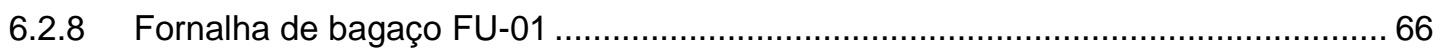

6.2.9 Sistema de alimentação de bagaço e chaminé BI-01, BE-01/02 e CH-01 ............... 66

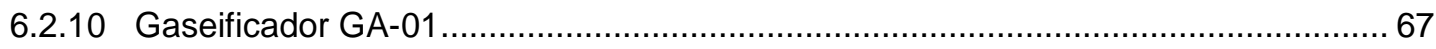

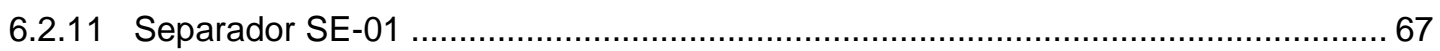

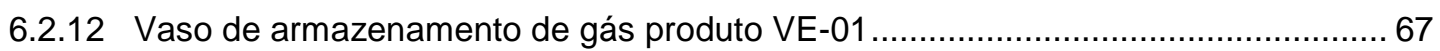

6.2.13 Tanque de água recuperada TK-01 e válvulas redutoras de pressão ...................... 67

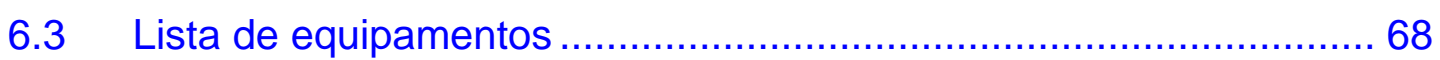

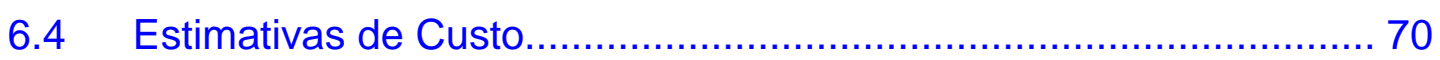

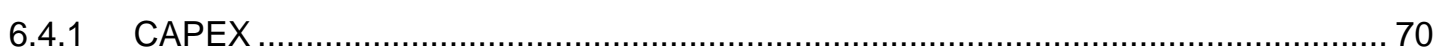

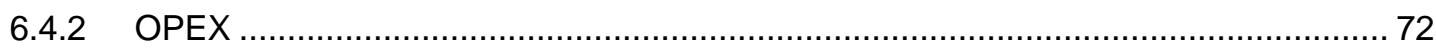

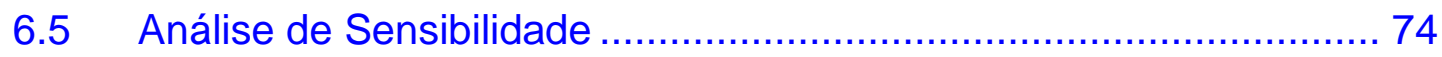

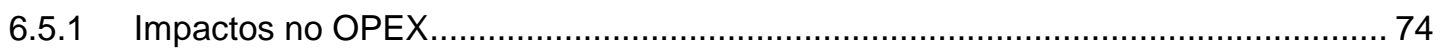

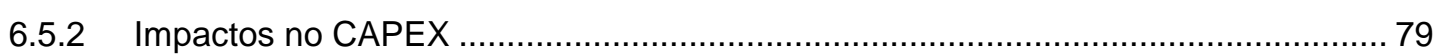

6.6 Análise Geral da Sensibilidade ............................................... 84

6.7 Análise Geral do Projeto ........................................................ 87

7 CONCLUSÃO E RECOMENDAÇÕES ........................................... 94

8 REFERÊNCIAS BIBLIOGRÁFICAS ............................................. 96 


\section{INTRODUÇÃO}

\subsection{Desafios do manuseio da vinhaça na indústria de açúcar e álcool}

A vinhaça é um resíduo gerado pela destilação de mostos fermentados, que pode ser obtido a partir de diversas matérias-primas, dependendo da localidade e do produto sendo fabricado (açúcar ou álcool). Na Europa, a produção de açúcar e álcool utiliza como matéria-prima principal a beterraba, que gera uma vinhaça de características semelhantes às da vinhaça gerada a partir da cana-de-açúcar. Para cada litro de etanol de beterraba são produzidos 11,6 litros de vinhaça[1]. No caso dos Estados Unidos, a produção de etanol é feita a partir de grãos, sendo o mais utilizado o milho. No Brasil, a matéria prima mais utilizada é a cana-de-açúcar, para a qual em média, são produzidos de 10 a 15 litros de vinhaça[2] para cada litro de etanol.

De acordo com o Plano Decenal de Expansão de Energia 2022[3], publicado pela Empresa de Pesquisa Energética do Ministério de Minas e Energia, é estimado um crescimento da ordem de $11,2 \%$ ao ano na demanda de etanol anidro no Brasil para os próximos 10 anos, podendo atingir os 32,8 bilhões de litros em 2022. Projetando a produção de etanol anidro para o caso da vinhaça, teríamos então uma produção de 426,4 bilhões de litros de vinhaça no ano de 2022.

Estes dados são um indicativo da latência do tema, e da necessidade de se encontrar meios alternativos para a utilização da vinhaça. Ainda mais porque a utilização da vinhaça como um combustível ou como um precursor para novos produtos pode aumentar a eficiência energética do processo de produção do etanol, bem como reduzir sua pegada de carbono.

\footnotetext{
${ }^{1}$ Informação extraída de RIBAS, M. M. F. "Tratamento de vinhaça em reator anaeróbio operado em batelada sequencial contendo biomassa imobilizada sob condições termofílicas e mesofílicas". Universidade de São Paulo, São Carlos. 2006.

${ }^{2}$ Ver CHRISTOFOLETTI, C.; ESCHER, A.; CORREIA, J.; MARINHO, J.; FONTANETTI, C. "Sugarcane vinasse: Environmental implications of its use". Waste Management 33 (2013) 2752-2761.

${ }^{3}$ Ministério de Minas e Energia. Empresa de Pesquisa Energética. Plano Decenal de Expansão de Energia 2022. Brasília: MME/EPE, 2013. http://www.epe.gov.br/Estudos/Documents/PDE2022.pdf
} 
A utilização da vinhaça tem sido estudada por diversos pesquisadores (ROCHA, 2009; MORAES et al., 2014; TIAN et al., 2013; MELO e SILVA, 2011; PRADA et al., 1997;), e sua aplicação mais comum, hoje, é na fertirrigação. Segundo Melo e Silva (2001), a cana fertirrigada é mais produtiva que a cana que não recebeu a fertirrigação, independentemente de qual o corte. Ademais, os ganhos de produtividade aumentam com o número de cortes.

Uma aplicação alternativa da vinhaça é a sua utilização na biodigestão anaeróbica para a produção de metano. Esse processo tem sido muito estudado por diversos pesquisadores (MORAES et al., 2014; BAEZ-SMITH et al., 2006), pois trata simultaneamente da utilização de um resíduo com alto potencial poluidor e pode gerar energia com a queima do metano. No entanto, de acordo com Tian et al. (2013), as reações de despolimerização dos polissacarídeos presentes na vinhaça podem gerar subprodutos indesejáveis, com potencial de inibir o crescimento microbiano, necessário para a biodigestão.

A utilização da vinhaça hoje não é suficiente para o consumo da produção anual crescente deste resíduo. Uma potencialidade seria a gaseificação da vinhaça, o que permitiria o aproveitamento do conteúdo orgânico da mesma e a produção de gases de alto valor agregado.

A gaseificação pode ser entendida como um processo de despolimerização de materiais de origem carbonácea, que utiliza o conteúdo intrínseco de carbonos e hidrogênios dos mesmos para a geração de uma mistura de hidrogênio $\left(\mathrm{H}_{2}\right)$, monóxido de carbono $(\mathrm{CO})$, dióxido de carbono $\left(\mathrm{CO}_{2}\right)$ e metano $\left(\mathrm{CH}_{4}\right)$. Tal mistura pode ser utilizada como matéria prima na síntese de novos produtos ou como combustível. A gaseificação pode ser utilizada no processamento de uma gama variada de produtos, independentemente de suas características ou estado físico. A utilização de biomassa como insumo da gaseificação vem sendo cada vez mais explorada e estudada, já 
que seu apelo gira não somente na esfera ambiental, mas também em âmbitos econômicos e sociais.

O rendimento da gaseificação clássica depende de diversos fatores que serão discutidos posteriormente, dentre eles a umidade do composto que está sendo alimentado no gaseificador. Ela interfere diretamente no rendimento da reação, quanto maior a umidade do composto, pior o rendimento. Uma alternativa viável seria a utilização do meio gaseificante supercrítico, que resulta em rendimentos constantes, independentemente da umidade da corrente de entrada do reator (BASU, 2010).

O presente trabalho consiste no projeto de um módulo de gaseificação de vinhaça em água supercrítica, a ser instalado como uma unidade anexa a usinas de açúcar e álcool. Dessa maneira, são reduzidos os custos com o transporte da matéria prima, que é produzida em grandes quantidades diariamente pelas usinas. Outro aspecto positivo é a possibilidade de se aproveitar a estrutura existente da usina, que reduziria parte dos custos de investimento.

Este trabalho compreende uma análise sistemática para preencher um espaço de conhecimento aberto entre as pesquisas laboratoriais/ teóricas e as unidades reais de produção de gases por gaseificação em água supercrítica (SCWG, do inglês Supercritical Water Gasification), que sejam comercialmente atrativas de ponto de vista da eficiência energética. Este projeto conceitual e de viabilidade, enquadrado na Classe 4 da classificação da AACE (Association for the Advancement of Cost Engineering), apresenta fluxograma, requisitos dos equipamentos projetados e os custos de capital e de operação.

As vantagens de integração das correntes de processos estão dentro do escopo de um projeto de pesquisa de ampla integração de biomassa por gaseificação em água supercrítica (Magdeldin et al., 2015). 


\subsection{Objetivos do trabalho}

O presente trabalho tem como objetivo apresentar um projeto de unidade de gaseificação de vinhaça em água supercrítica em escala comercial.

Apesar do alto grau de interesse da indústria sucroalcooleira pelo tema, estudos laboratoriais com vinhaça em água supercrítica ainda são incipientes. Há raras publicações de projetos de engenharia em SCWG, com a exceção de propostas de unidades de demonstração/ piloto multipropósito.

A importância deste projeto, como ponte entre as pesquisas de laboratório e a engenharia de projetos, ademais de seu caráter inovador e único, fundamenta-se no seu poder impulsionador de estudos na área da gaseificação em água supercrítica, mostrando a relevância e a viabilidade do processo. Ao mesmo tempo, ele apresenta o estado da arte do conhecimento e da tecnologia, relacionando os gargalos a serem resolvidos, assim como os ganhos intrínsecos da definição conceitual do projeto.

\subsection{Estrutura da dissertação}

A Dissertação foi desenvolvida de acordo com a estrutura indicada a seguir:

Capítulo 2: Descrição dos objetos do presente estudo, ou seja, biomassa, vinhaça e sua gaseificação.

Capítulo 3: Revisão da Literatura; que apresenta o cenário da utilização de biomassas como fonte de energia, as características da biomassa escolhida para o projeto - a vinhaça - e os conceitos gerais de gaseificação em água supercrítica, abordando os processos físico e químico, assim como modelos cinéticos e de equilíbrio termodinâmico. 
Capítulo 4: Uma breve análise dos modelos cinéticos e termodinâmicos de gaseificação em água supercrítica, separada do presente texto do Capítulo 3, referente à revisão bibliográfica, por ser um ponto de vista da autora, embora baseada na leitura das publicações.

Capítulo 5: Materiais e Métodos; que se subdivide nas definições básicas para a elaboração de projetos conceituais/ análises de investimento, na apresentação do fluxograma simulado de processos, e na descrição sumária dos equipamentos do projeto, possibilitando avaliação das correntes de operação do processo.

Capítulo 6: Resultados; que apresenta o projeto de gaseificação de vinhaça em água supercrítica, com seu CAPEX (Capital Expenditure) e OPEX (Operation Expenditure), incluindo três análises de sensibilidade e seus resultados.

Capítulo 7: Conclusão e Recomendações; definidas a partir do presente estudo, à luz de sua característica inovadora. Inclui as dificuldades/gargalos tecnológicos, que são os impulsionadores de estudos futuros.

Capítulo 8: Referências; que lista a bibliografia utilizada no presente trabalho.

Durante o desenvolvimento do presente trabalho foram publicadas:

1. Soraia Cristina Felix da Silva, Reinaldo Giudici, Song Won Park. "Process design for supercritical water gasification of sugar vinasse". ECCE10 (10th European Congress of Chemical Engineering) Nice. France. Sep, $27^{\text {th }}-$ Oct, $1^{\text {st }} \cdot 2015$.

2. Soraia Cristina Felix da Silva, Reinaldo Giudici, Song Won Park. "Gaseificação de Vinhaça em Água Supercrítica". COBEQ XXI Congresso Brasileiro de Engenharia Química.25-29 Setembro, 2016. (submetido) 


\section{DESCRIÇÃO DOS OBJETOS DO ESTUDO}

\subsection{Biomassa}

Dentre todas as fontes renováveis de energia, a biomassa se destaca por ser a única capaz de prover calor, energia, alimento, fibras, combustíveis e produtos químicos em um único recurso. Sua distribuição no planeta é razoavelmente homogênea, quando em comparação com os combustíveis fosseis, permitindo a descentralização dos recursos energéticos, o que é fundamental no desenvolvimento da autossuficiência em níveis locais, regionais e até mesmo nacionais (TISDALE, 2004).

A biomassa pode ser facilmente usada como fonte primária de obtenção de energia e calor. No entanto, sua forma volumosa e desajeitada prejudica seu transporte e armazenamento, independentemente de seu estado físico. Isso representa uma grande motivação na conversão desta matéria-prima em combustíveis ou intermediários de manuseio mais favorável, como gases e líquidos, de menor volume e maior poder calorífico.

A biomassa absorve dióxido de carbono da atmosfera durante a fotossíntese, liberando-o de volta ao ambiente, após a sua combustão. Devido a este balanço, pode-se concluir que a biomassa é neutra com relação ao $\mathrm{CO}_{2}$, o que a torna um recurso energético favorável e preferencial do ponto de vista ambiental (NIKOO e MAHINPEY, 2008). Ainda, segundo Resende e Savage (2010), “a oxidação eventual dos átomos de carbono contidos na biomassa não aumenta o conteúdo líquido de $\mathrm{CO}_{2}$ na atmosfera".

Além disso, também existem as vantagens relacionadas ao seu aspecto renovável, quando em comparação aos combustíveis fósseis, aos benefícios ambientais, principalmente se aliados à geração de créditos de carbono, e 
sociopolíticos, visando o desenvolvimento de economias regionais e a segurança da produção, que é menos afetada com flutuações de preço e questões políticas, quando se tem uma geração de matéria prima pulverizada (TISDALE, 2004).

A conversão da biomassa em energia, combustíveis ou produtos químicos pode ser realizada de diversas maneiras, seguindo duas grandes vertentes: bioquímica ou termoquímica. A rota bioquímica engloba a fermentação, a digestão e a hidrólise. Nela, as moléculas de biomassa são quebradas em moléculas menores por intermédio de bactérias, enzimas e até mesmo ácidos, na presença ou ausência de oxigênio.

$\mathrm{Na}$ rota termoquímica, a biomassa é convertida em gases, que podem ser usados como intermediários químicos, ou diretamente para queima e geração de energia térmica. Os principais exemplos desta rota são a combustão, pirólise, gaseificação e liquefação.

A Figura 1 mostra, esquematicamente, as rotas mencionadas (BASU, 2010).

Figura 1: rotas para conversão de biomassa em energia.

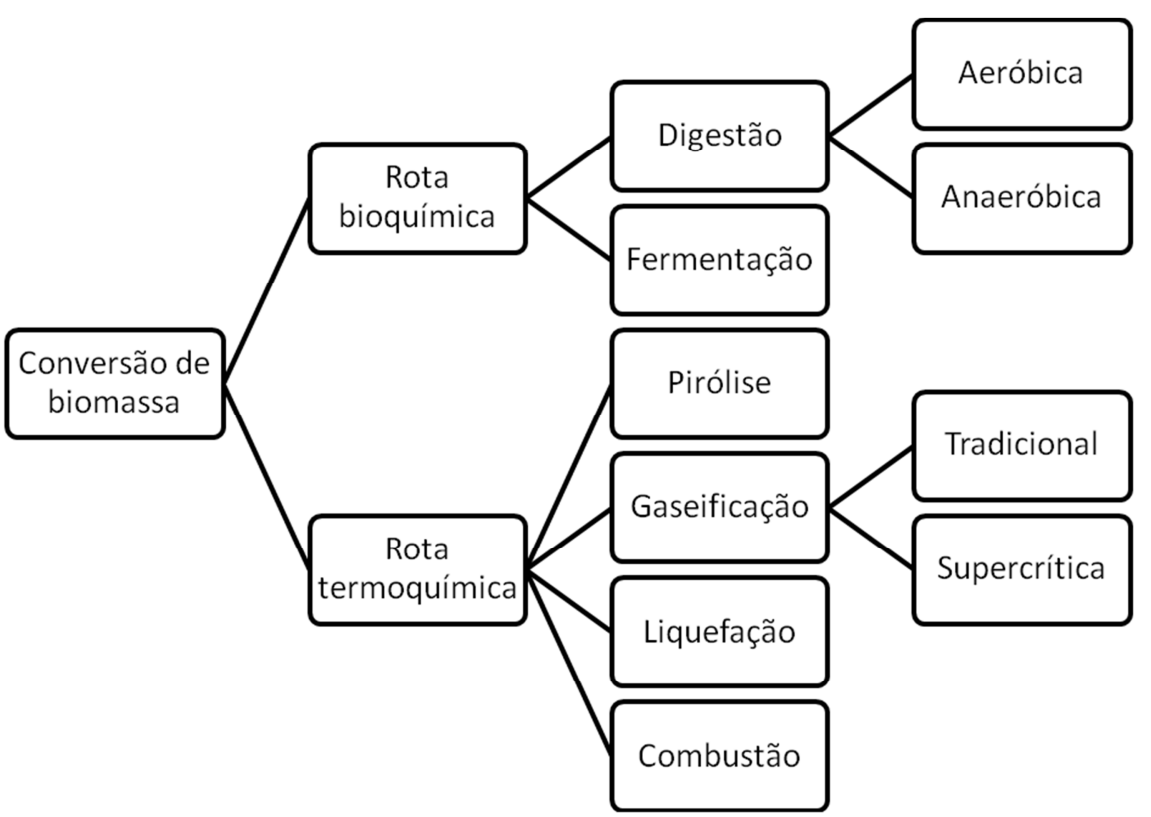

Fonte: BASU, 2010. 


\subsection{Vinhaça}

A vinhaça contém altas concentrações de fosfatos, ácidos orgânicos e nitrogênio, que pode ser encontrado em sua maioria na forma orgânica, tendo como origem as proteínas do caldo e restos de leveduras da fermentação (GARCÍA-JARANA et al., 2008).

A Tabela 1 mostra a composição média da vinhaça, a partir de diferentes mostos. Mostos são líquidos com alto teor de açúcares, prontos para serem fermentados. Dois exemplos de mostos de cana-de-açúcar são o melaço e o caldo de cana, sendo que o melaço é obtido a partir da evaporação do caldo de cana.

Tabela 1: composição média da vinhaça.

\begin{tabular}{|c|c|c|c|}
\hline \multirow{2}{*}{ Elementos } & \multicolumn{3}{|c|}{ Vinhaça de mosto } \\
\hline & melaço & caldo & misto \\
\hline $\mathrm{pH}$ & $4,2-5,0$ & $3,7-4,6$ & $4,4-4,6$ \\
\hline Temperatura $\left({ }^{\circ} \mathrm{C}\right)$ & $80-100$ & $80-100$ & $80-100$ \\
\hline $\mathrm{DBO}\left(\mathrm{mg} \mathrm{L}^{-1} \mathrm{O}_{2}\right)$ & 25.000 & $6.000-16.500$ & 19.800 \\
\hline $\mathrm{DQO}\left(\mathrm{mg} \mathrm{L}^{-1} \mathrm{O}_{2}\right)$ & 65.000 & $15.000-33.000$ & 45.000 \\
\hline Sólidos totais $\left(\mathrm{mg} \mathrm{L}^{-1}\right)$ & 81.500 & 23.700 & 52.700 \\
\hline Sólidos voláteis ( $\left.\mathrm{mg} \mathrm{L}^{-1}\right)$ & 60.000 & 20.000 & 40.000 \\
\hline Sólidos fixos $\left(\mathrm{mg} \mathrm{L}^{-1}\right)$ & 21.500 & 3.700 & 12.700 \\
\hline$N\left(M_{G} L^{-1} N\right)$ & $450-1.610$ & $150-700$ & $480-710$ \\
\hline $\mathrm{P}_{2} \mathrm{O}_{5}\left(\mathrm{mg} \mathrm{L}^{-1}\right)$ & $100-290$ & $10-210$ & $9-200$ \\
\hline $\mathrm{K}_{2} \mathrm{O}\left(\mathrm{mg} \mathrm{L}^{-1}\right)$ & $3.740-7.830$ & $1.200-2.100$ & $3.340-4.600$ \\
\hline $\mathrm{CaO}\left(\mathrm{mg} \mathrm{L}^{-1}\right)$ & $450-5.180$ & $130-1.540$ & $1.330-4.570$ \\
\hline $\mathrm{MgO}\left(\mathrm{mg} \mathrm{L}^{-1}\right)$ & $420-1.520$ & $200-490$ & 580.700 \\
\hline $\mathrm{SO}_{4}\left(\mathrm{mg} \mathrm{L}^{-1}\right)^{\prime}$ & 6.400 & $600-760$ & $3.700-3.730$ \\
\hline$C\left(M G L^{-1}\right)$ & $11.200-22.900$ & $5.700-13.400$ & $8.700-12.100$ \\
\hline Relação C/N & $16-16,27$ & $19,7-21,07$ & $16,4-16,43$ \\
\hline Matéria orgânica $\left(\mathrm{mg} \mathrm{L}^{-1}\right)$ & 63.400 & 19.500 & 3.800 \\
\hline Subst. redutoras $\left(\mathrm{mg} \mathrm{L}^{-1}\right)$ & 9.500 & 7.900 & 8.300 \\
\hline
\end{tabular}

Fonte: PRADA et al., 1998.

Segundo Huelsman (2014), estudos de gaseificação de materiais com alta concentração de proteínas resultaram em rendimentos mais baixos do que os esperados para biomassas sem conteúdo proteico. Isso se deve à inibição pelas proteínas das reações radicalares em cadeia que levariam à gaseificação. A presença de sais alcalinos na solução reacional combate 
este efeito das proteínas, mantendo os rendimentos dentro dos níveis esperados. Para o caso da vinhaça, que apresenta conteúdo proteico remanescente das leveduras do processo de fermentação, o efeito de inibição dos mecanismos radicalares seria anulado pela alta concentração de sais na mesma.

\subsection{Gaseificação}

A gaseificação pode ser entendida como um processo de despolimerização de materiais de origem carbonácea, que utiliza o conteúdo intrínseco de carbonos e hidrogênios dos mesmos para a geração de uma mistura de hidrogênio $\left(\mathrm{H}_{2}\right)$, monóxido de carbono $(\mathrm{CO})$, dióxido de carbono $\left(\mathrm{CO}_{2}\right)$ e metano $\left(\mathrm{CH}_{4}\right)$.

Tal mistura pode ser utilizada como combustível ou como precursora de novos produtos (KAMM; GRUBER e KAMM, 2006; BASU, 2010). A escolha de um combustível a ser utilizado no processo de gaseificação pode ser influenciada por diversos fatores, como sua umidade, reatividade, tamanho e distribuição granulométrica, estado físico, entre outros. No entanto, o fator fundamental é o poder calorífico do combustível, que é um indicativo da viabilidade da operação de gaseificação, do ponto de vista energético.

Outro item importante é a definição do meio reacional. Segundo Ahmed et al. (2012), a escolha de um meio reacional, e por consequência de um agente gaseificante, influencia diretamente no poder calorífico do gás gerado na gaseificação. Dentre os agentes gaseificantes conhecidos, encontram-se o oxigênio puro, ar, nitrogênio, dióxido de carbono, misturas gasosas, vapor de água e a água em estado supercrítico.

Para o caso da gaseificação tradicional, a eficiência térmica é reduzida consideravelmente com o aumento de umidade no combustível utilizado. No 
entanto, para o caso de combustíveis com teor de umidade alto (entre 90 e 95\%), a utilização de água supercrítica como meio reacional tem se mostrado uma alternativa promissora (AHMED et al., 2012), na qual não há variação de eficiência térmica com a variação da umidade. 


\section{REVISÃO DA LITERATURA}

\subsection{Gaseificação em água supercrítica}

A utilização da água supercrítica como meio de reação favorece a obtenção de altas taxas de reação e torna desnecessária a secagem/ evaporação do combustível a ser gaseificado, quando o mesmo apresenta altos teores de umidade (YOSHIDA; OSHIMA e MATSUMURA, 2004). A água encontra-se em estado supercrítico quando apresenta temperatura e pressão acima do ponto crítico, $374,15^{\circ} \mathrm{C}$ e 220,64 bar. Neste estado, sua constante dielétrica é reduzida, assim como o número de ligações de hidrogênio, tornando a água um bom solvente para compostos não polares e gases, basicamente um ótimo meio para reações de gaseificação (ZHANG, 2008). A Figura 2 mostra um diagrama de fases esquemático, no qual pode ser observada a região supercrítica da água.

Figura 2: diagrama de fases da água.

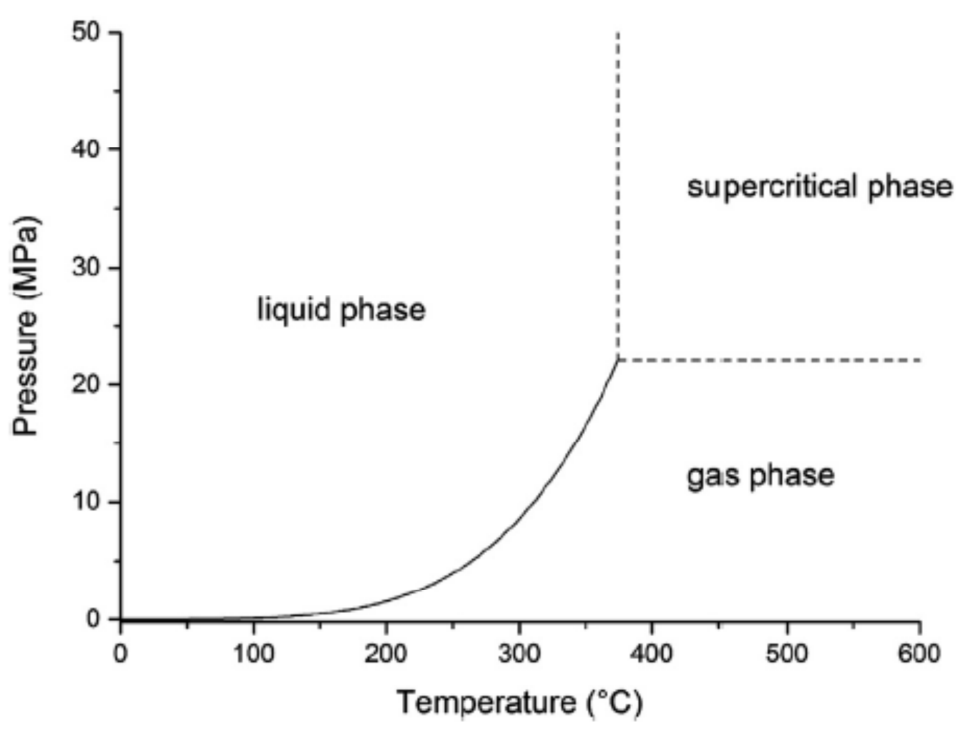

Fonte: YAKABOYLU et al., 2013. 
Outra vantagem da utilização de água supercrítica como meio reacional é que a mesma pode ser utilizada também como reagente, simultaneamente. Segundo Manzour (2012), a barreira de transferência de massa entre diferentes fases não existe para reações em água supercrítica. Isso alinhado à densidade da água supercrítica, que dependendo das condições de temperatura e pressão pode variar entre 100 e $600 \mathrm{~kg} / \mathrm{m}^{3}$, tornam a tecnologia com água supercrítica promissora para matérias primas líquidas diluídas.

A presença de água supercrítica no meio reacional auxilia a gaseificação isolando os reagentes uns dos outros, dificultando as reações de segunda ordem de formação de alcatrões e carvão (HUELSMAN, 2012).

\subsection{Influência da Temperatura}

Segundo Kamler e Soria (2012), a temperatura pode ser considerada a variável mais sensível em processos de gaseificação em água supercrítica, sendo que a temperatura de $600^{\circ} \mathrm{C}$ é tida como ponto ótimo desejado, sendo associada a altas taxas de conversão.

Em altas temperaturas $\left(500\right.$ a $\left.800^{\circ} \mathrm{C}\right)$ o mecanismo de radicais livres domina a reação de gaseificação. Nessa condição, as reações da pirólise, que liberam uma grande quantidade de gases, são fortemente favorecidas, assim como a reação de deslocamento água-gás, favorecendo altos rendimentos em hidrogênio no produto final (HUELSMAN, 2014).

Para reações de oxidação em meio supercrítico, em condições de temperatura acima de $600^{\circ} \mathrm{C}$ é possível atingir altas eficiências de destruição de orgânicos (acima de 99,9\%) em baixos tempos de residência (menores que 1 minuto). $\mathrm{Na}$ ausência de catalisadores ou oxidantes para auxiliar o processo de gaseificação, para garantir baixos tempos de reação, ou a 
conversão rápida, é necessário operar com temperaturas em torno de $800^{\circ} \mathrm{C}$ (KAMLER e SORIA, 2012).

\subsection{Tipos de Gaseificadores}

Existem diversos tipos de gaseificadores em geral, não especifico à supercrítica, que podem ser classificados de acordo com as características específicas do processo, como o meio reacional e o tipo de contato entre os fluidos dentro do equipamento. Dentre as classificações possíveis encontram-se a de gaseificador de leito de arraste (entrained bed), leito fluidizado (fluidized bed), que pode ser borbulhante ou circulante, leito de jorro (spouted bed) ou leito fixo (fixed bed) (BASU, 2006). Cada gaseificador tem seus pontos fortes e fracos para cada tipo de aplicação. A escolha de um determinado tipo de gaseificador leva em conta a escala de produção, o material a ser alimentado, nível de produção de alcatrão, perfil de temperatura, dentre outros. A Tabela 2 mostra uma comparação entre os gaseificadores supracitados.

Tabela 2: Comparação entre gaseificadores comerciais.

\begin{tabular}{|c|c|c|c|}
\hline Parâmetros & Leito Fixo & Leito Fluidizado & Leito de Jorro \\
\hline Tamanho da alimentação & $<51 \mathrm{~mm}$ & $<6 \mathrm{~mm}$ & $<0,15 \mathrm{~mm}$ \\
\hline Tolerância a finos & Limitado & Boa & Excelente \\
\hline $\begin{array}{c}\text { Tolerância a grossos } \\
\text { saída }\end{array}$ & Muito boa & Boa & Baixa \\
\hline $\begin{array}{c}\text { Temperatura do gás de } \\
\text { Carvão de } \\
\text { baixa } \\
\text { especificação }\end{array}$ & $\begin{array}{c}8050^{\circ} \mathrm{C} \\
\begin{array}{c}\text { Carvão de } \\
\text { baixa } \\
\text { especificação e } \\
\text { excelente para } \\
\text { biomassa }\end{array}\end{array}$ & $\begin{array}{c}\text { Qualquer } \\
\text { carvão, } \\
\text { incluindo o } \\
\text { aglutinante, } \\
\text { mas } \\
\text { inadequado } \\
\text { para biomassa }\end{array}$ \\
\hline Requisitos para oxidação & Baixo & Moderado & Alto \\
\hline $\begin{array}{c}\text { Temperatura da zona de } \\
\text { reação }\end{array}$ & $1090^{\circ} \mathrm{C}$ & $800-1000^{\circ} \mathrm{C}$ & $1990^{\circ} \mathrm{C}$ \\
\hline Requisito de vapor & Alto & Moderado & Baixo \\
\hline $\begin{array}{c}\text { Natureza das cinzas } \\
\text { produzidas }\end{array}$ & Seca & Seca & Escória \\
\hline Eficiência de gás-frio & $80 \%$ & $89 \%$ & $80 \%$ \\
\hline
\end{tabular}




\begin{tabular}{|c|c|c|c|} 
Utilização & $\begin{array}{c}\text { Capacidades } \\
\text { pequenas }\end{array}$ & $\begin{array}{c}\text { Unidades de } \\
\text { tamanho médio }\end{array}$ & $\begin{array}{c}\text { Grandes } \\
\text { capacidades }\end{array}$ \\
\hline Problemas & $\begin{array}{c}\text { Produção de } \\
\text { alcatrão e } \\
\text { utilização de } \\
\text { finos }\end{array}$ & $\begin{array}{c}\text { Conversão de } \\
\text { carbono }\end{array}$ & $\begin{array}{c}\text { Resfriamento } \\
\text { do gás produto }\end{array}$ \\
\hline
\end{tabular}

Fonte: adaptado de BASU, 2006.

Em gaseificadores de leito fixo, o insumo ou combustível sólido a ser gaseificado é suportado em uma grelha e se move na direção do fundo do reator em um fluxo pistonado. Apesar do baixo custo de construção, devido à menor quantidade de partes móveis, tanto a mistura quanto a transferência de calor são ruins, dificultando o controle de composição e temperatura do gás gerado. Para o caso de combustíveis que tendem a se aglomerar, o potencial de aglomeração dentro deste tipo de gaseificador é grande, e, portanto, sua utilização deve ser evitada (BASU, 2010). Para gaseificadores de leito fluidizado, este problema não ocorre, já que os mesmos são conhecidos pela boa distribuição e uniformidade nas temperaturas ao longo do reator. Os mesmos apresentam vantagens no âmbito da transformação de biomassa em energia, o que se deve ao alto grau de turbulência, aliado ao grande contato entre as fases, o que melhora o controle da temperatura, e permite um maior armazenamento energético.

Os gaseificadores de leito fluidizado têm seu leito formado por partículas sólidas, que são mantidas em uma condição de semi-suspensão, caracterizada pelo estado fluidizado (BASU, 2010). Para a obtenção deste estado, gás é passado no sentido ascendente por um determinado leito de partículas, em uma razão vazão/ velocidade suficiente para que a força exercida pelo peso das partículas se iguale à força do arraste do gás. Neste ponto, as partículas começam a se descolar umas das outras, ficando suspensas (GUALBERTO, 2002). Os gaseificadores de leito fluidizado podem ser diferenciados pela velocidade com que um certo material atravessa o leito, sendo ele borbulhante ou circulante. A principal diferença entre eles está na hidrodinâmica, conforme Basu (2010): 
- Para leitos circulantes, os sólidos estão dispersos por toda a região do tubo de subida (riser) e a alta velocidade de fluidização, da ordem de 3,5 a $5,5 \mathrm{~m} / \mathrm{s}$, permite uma recirculação contínua de sólidos, que são retornados à base do tubo;

- Para leitos borbulhantes, a velocidade de fluidização é mais baixa, ficando entre 0,5 e 1,0 m/s. O aparecimento das bolhas, assim como para leitos circulantes, deve-se a um incremento na velocidade do gás do meio reacional acima da velocidade mínima de fluidização. As bolhas aumentam de tamanho ao subirem no tubo, devido ao decréscimo na pressão e ao coalescimento com outras bolhas. As partículas arrastadas podem ser coletadas por um dispositivo de limpeza de gases na saída do reator, como um ciclone.

Leitos circulantes proporcionam um maior tempo de residência, sendo propícios para a gaseificação de biomassa, principalmente para o caso de insumos com alta volatilidade.

A gaseificação em leito borbulhante fluidizado pode ser usada para o caso de biomassas com diferentes teores de umidade, inclusive os altos. Segundo Lim e Alimuddin (2008), isso se deve à presença do material inerte, que permite uma mistura turbulenta e cheia de bolhas da biomassa, sob a força de empuxo do agente fluidificante utilizado. Devido às condições de escoamento e a alta taxa de contato entre os sólidos, as partículas de biomassa conseguem reagir, liberando os componentes voláteis.

Gaseificadores por arraste são, em sua essência, reatores co-corrente de fluxo pistonado, nos quais tanto o combustível quanto o gás reacional são alimentados no mesmo sentido e percorrem todo o reator para a produção de gás. Tais reatores são muito utilizados para aplicações com carvão, coque de petróleo e outros resíduos de refinarias. Para o caso de combustíveis com altos teores de umidade, como biomassas em geral, este gaseificador não é indicado. Devido ao seu pequeno tempo de residência, os 
insumos alimentados têm que ser muito finos, o que é difícil de obter com biomassas em geral, sem um grande custo para preparo das mesmas.

Para gaseificação em água supercrítica, ainda em escala de laboratório utilizam-se reatores de Batelada, CSTR (continuous stirred tank reactor), e Tubular com ou sem leito fixo (BASU e METTANANT, 2009). Para escalas de reatores maiores, tem-se desde reator de leito fixo até fluidizado. (YAKABOYLU et al., 2015, MATUSMURA e MINOWA, 2004)

\subsection{Processo de gaseificação}

Segundo Basu (2006), o processo de gaseificação clássica ocorre em três etapas principais: pirólise ou devolatilização, combustão e a gaseificação em si. Durante a etapa de pirólise, os componentes termicamente instáveis são decompostos por meio da inserção de calor no meio e evaporam em conjunto com outros componentes mais voláteis. Esta etapa gera gases leves (hidrogênio, monóxido de carbono, dióxido de carbono, metano e vapor de água), alcatrão (líquido composto por moléculas pesadas orgânicas e inorgânicas) e carvão (resíduo carbonáceo). A Reação 3.1 ilustra de forma genérica a quebra de um substrato de origem carbonácea.

$$
\mathrm{C}_{n} \mathrm{H}_{m} \mathrm{O}_{p}+\text { Calor } \rightarrow \sum \mathrm{C}_{\mathrm{a}} \mathrm{H}_{\mathrm{b}} \mathrm{O}_{\mathrm{c}} \text { (líquido) }+\sum \mathrm{C}_{\mathrm{x}} \mathrm{H}_{\mathrm{y}} \mathrm{O}_{z} \text { (gás) }+\sum \mathrm{C} \text { (sólido) }
$$

(Reação 3.1)

A próxima etapa é a de combustão, que conta com duas reações exotérmicas que geram calor para todas as reações endotérmicas subsequentes do processo. Uma delas é a de combustão do carvão produzido na pirólise, gerando $\mathrm{CO}_{2}$ (Reação 3.2) e a outra é a oxidação do hidrogênio, produzindo vapor de água (Reação 3.3).

$\mathrm{C}+\mathrm{O}_{2} \leftrightarrow \mathrm{CO}_{2} ; \quad \Delta \mathrm{H}=+393,77 \mathrm{~kJ} / \mathrm{mol}$ carbono

(Reação 3.2)

$\mathrm{H}_{2}+1 / 2 \mathrm{O}_{2} \leftrightarrow \mathrm{H}_{2} \mathrm{O} ; \quad \Delta \mathrm{H}=+742 \mathrm{~kJ} / \mathrm{mol} \mathrm{H}_{2}$

(Reação 3.3) 
Finalmente tem-se a gaseificação, que pode ser dividida em quatro subprocessos: a reação água-gás, a reação de Boudouard, a substituição (shift conversion) e a metanação. Todos esses passos são endotérmicos e utilizam o calor proveniente da combustão para ocorrer. A reação água-gás é a oxidação parcial do carbono pelo vapor da água presente no meio reacional, gerando hidrogênio e monóxido de carbono, conforme indicado na Reação 3.4.

$\mathrm{C}+\mathrm{H}_{2} \mathrm{O} \leftrightarrow \mathrm{CO}+\mathrm{H}_{2} ; \quad \Delta \mathrm{H}=-131,38 \mathrm{~kJ} / \mathrm{kg}$ mol carbono $\quad$ (Reação 3.4)

A reação de Boudouard (Reação 3.5),ocorre entre o carvão restante e o $\mathrm{CO}_{2}$, gerando $\mathrm{CO}$.

$\mathrm{C}+\mathrm{CO}_{2} \leftrightarrow 2 \mathrm{CO} ; \quad \Delta \mathrm{H}=-172,58 \mathrm{~kJ} / \mathrm{mol}$ carbono

(Reação 3.5)

Na etapa de substituição (shift conversion), o vapor d'água é reduzido pelo monóxido de carbono para produzir hidrogênio (Reação 3.6). Esta reação é responsável pelo aumento da razão hidrogênio/ monóxido de carbono no gás, que é determinante na fabricação de gás de síntese. Quanto maior esta razão, melhor a qualidade do gás produzido, para quando o objetiva-se a produção de hidrogênio.

$\mathrm{CO}+\mathrm{H}_{2} \mathrm{O} \leftrightarrow \mathrm{CO}_{2}+\mathrm{H}_{2} ; \quad \Delta \mathrm{H}=-41,98 \mathrm{~kJ} / \mathrm{mol}$ carbono $\quad$ (Reação 3.6)

O último passo é a metanação, na qual metano é formado a partir da reação entre o carvão e o hidrogênio (3.7). Esta reação pode ser catalisada por catalisadores a base de níquel, mas estudos também mostram a utilização de $\mathrm{KOH}, \mathrm{Na}_{2} \mathrm{CO}_{3}, \mathrm{~K}_{2} \mathrm{CO}_{3}$ e carbono ativado (YANIK et al., 2008).

$\mathrm{C}+2 \mathrm{H}_{2} \leftrightarrow \mathrm{CH}_{4} ; \quad \Delta \mathrm{H}=+74,90 \mathrm{~kJ} / \mathrm{mol}$ carbono

(Reação 3.7) 


\subsection{Modelos de gaseificação}

Existem na literatura poucos modelos desenvolvidos para a gaseificação em água supercrítica. Alguns autores sugerem modelos com base no equilíbrio químico das espécies e na derivação dos balanços de massa (LETTELIER et al., 2010), na análise do equilíbrio termodinâmico com foco na minimização da energia livre de Gibbs (TANG e KITAGAWA, 2005; BARATIERI et al., 2008). Outros trabalham com a aproximação cinética, considerando as reações que podem ocorrer em cada passo do processo de gaseificação e também o balanço no gaseificador, que pode ter seu comportamento aproximado ao de um reator do tipo CSTR ou PFR.

De acordo com Lettelier et al. (2010), a hipótese de equilíbrio químico só pode ser utilizada para temperaturas acima de $740^{\circ} \mathrm{C}$, posto que abaixo deste valor a cinética da gaseificação é tão baixa que a duração da reação como um todo não é suficiente para a verificação da hipótese de equilíbrio.

Os modelos termodinâmicos de equilíbrio podem ser divididos em modelos estequiométricos e não estequiométricos. Para o caso de modelos estequiométricos, faz-se necessário o conhecimento do mecanismo da reação envolvida, enquanto para modelos não estequiométricos, os únicos parâmetros que devem ser informados são a pressão e temperatura da reação e a composição elementar da matéria a ser gaseificada. As duas aproximações são equivalentes (SMITH e MISSEN, 1982 apud YAN; GUO e LU, 2006).

\subsubsection{Estudos de Yakaboylu et al. (2013)}

Yakaboylu et al. (2013) estudaram o comportamento de equilíbrio de alguns componentes durante a gaseificação supercrítica de esterco de porcos e gado, na porcentagem de $50 \%$ cada. O estudo considerou o intervalo de temperatura de 100 a $580^{\circ} \mathrm{C}$, com pressão de $24 \mathrm{MPa}$. Para os cálculos do equilíbrio, usou-se a premissa de que para um sistema fechado, o equilíbrio pode ser definido como um estado no qual a energia livre de Gibbs se aproxima de um valor mínimo, com relação a todas as possíveis mudanças 
de pressão e temperatura. Chegou-se à conclusão de que a presença de solutos e gases no meio reacional aumenta o ponto pseudo crítico da água e que, na região subcrítica, compostos de cálcio, magnésio, fósforo e silicone são estáveis na forma sólida, enquanto compostos de cloretos, potássio e sódio são estáveis na forma gasosa.

\subsubsection{Modelo cinético segundo Guan; Wei e Savage. (2012)}

A biomassa é constituída por um conjunto de macromoléculas, que são rapidamente decompostas em moléculas menores em meio supercrítico, para então serem convertidas em produtos gasosos. Guan; Wei e Savage (2012) notaram em seus estudos de gaseificação de microalgas em água supercrítica que algumas moléculas menores eram gaseificadas mais rapidamente, enquanto moléculas contendo anéis aromáticos eram mais resistentes à transformação. $O$ modelo cinético com as reações estudadas tem como primeiros passos a geração de dois intermediários genéricos a partir das microalgas. Os passos seguintes preveem a transformação dos intermediários em produtos gasosos via reforma a vapor ou via decomposição.

Figura 3: Reações consideradas no modelo cinético de Guan; Wei e Savage.

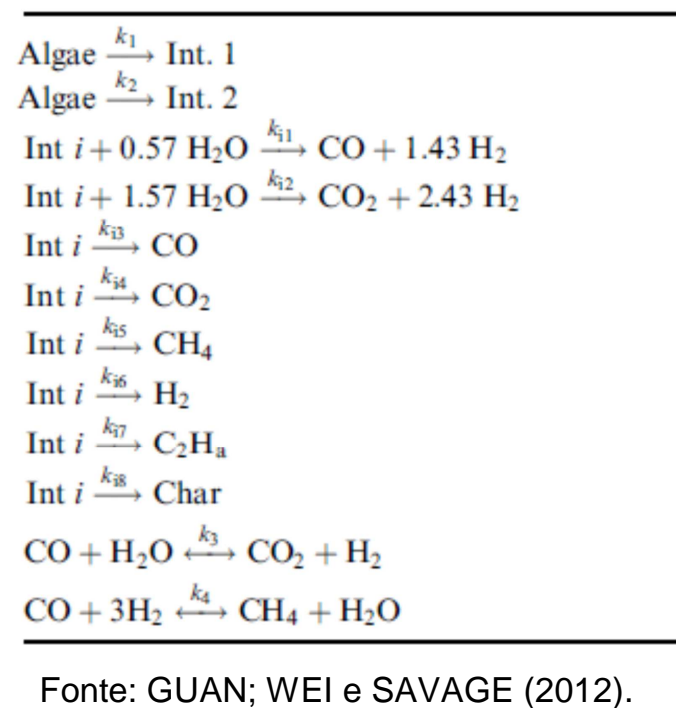

Fonte: GUAN; WEI e SAVAGE (2012). 
A reforma a vapor produz então $\mathrm{CO}$ e $\mathrm{H}_{2}$ ou $\mathrm{CO}_{2}$ e $\mathrm{H}_{2}$. Os dados experimentais obtidos pelo grupo indicaram energias de ativação muito diferentes para o $\mathrm{H}_{2}$ e para o $\mathrm{CO}_{2}$, um indicativo de que somente a reforma a vapor não seria suficiente para descrever o modelo. Portanto, foram incluídas as contribuições de formação direta dos gases $\mathrm{H}_{2}, \mathrm{CO}, \mathrm{CO}_{2}, \mathrm{CH}_{4} \mathrm{e}$ $\mathrm{C}_{2}$ a partir dos intermediários. O modelo prevê também uma etapa de formação de sólidos a partir dos intermediários, como o carvão. Para a simplificação do modelo, foi considerado que o carvão formado é estável, um produto final. Por fim, são previstas as reações de substituição água-gás (water-gas shift) e de metanação. A Figura 3 mostra um quadro-resumo das reações consideradas.

Para a determinação do modelo cinético a partir das reações citadas, Guan; Wei e Savage (2012) determinaram as taxas de reação para todos os passos, a partir de simplificações de ordem (considerando todas as reações de primeira ordem com relação ao reagente) e também definiram um tipo de reator para a obtenção de equações diferenciais de balanço de massa. As equações, do formato dC/dt, apresentam os parâmetros $\mathrm{k}_{1}, \mathrm{k}_{2}, \mathrm{k}_{3}, \mathrm{k}_{4}, \mathrm{k}_{i 1 \sim i 8}$ (vide Figura 3), cujos valores foram obtidos a partir de um ajuste do modelo com os dados experimentais para diversas temperaturas. Para o caso de $k_{3}$ e $k_{4}$, constantes da substituição e da metanação, respectivamente, foi utilizada a hipótese de equilíbrio e os dados foram obtidos a partir do software ASPEN Plus[4].

A hipótese de formação de dois grupos de intermediários foi validada pelo modelo, um se forma mais lentamente e um mais rapidamente, dando indícios ainda de que o grupo intermediário mais rápido seria o responsável pela formação do carvão.

O modelo pode ser utilizado para prever efeitos qualitativos do carregamento de matéria-prima no gaseificador, para obter o efeito da densidade da água

\footnotetext{
${ }^{4}$ Aspen Technology, Inc. ASPEN Plus Ver. 10.2 User Guide.

http://web.ist.utl.pt/ist11038/acad/Aspen/AspUserGuide10.pdf
} 
nos rendimentos dos gases individuais e até mesmo para prever a composição do gás no equilíbrio. Os resultados de equilíbrio obtidos pelo modelo foram comparados com as composições obtidas ao se rodar o bloco RGIBBS do ASPEN Plus, que determina a composição dos componentes a partir da minimização da energia livre de Gibbs para o sistema. A comparação mostrou que os resultados do modelo estão de acordo com os resultados do software comercial. Logo, as simplificações de quantidade de reações e as constantes associadas são adequadas para descrever o modelo de gaseificação de microalgas em água supercrítica. $O$ mesmo pode ser observado para lignina e celulose, em estudos anteriores do grupo (GUAN; WEI e SAVAGE, 2012).

\subsubsection{Modelo cinético segundo Resende e Savage (2010)}

O modelo desenvolvido por Resende e Savage (2010) abrange a gaseificação de microcelulose cristalina e lignina organodissolvida (organosolv).

Tal modelo foi baseado nos caminhos de reação propostos pela literatura para gaseificadores com tecnologia supercrítica e é focado na simplificação de reações que apresentam compostos intermediários de cadeia longa, pela definição de uma espécie genérica intermediária de menor tamanho.

A primeira etapa da gaseificação prevista por Resende e Savage (2010) é a hidrólise, que ocorre de maneira rápida. Ela se dá com a solvatação das biomacromoléculas simultaneamente com o ataque hidrolítico nas estruturas macromoleculares, gerando oligômeros mais simples. Tais oligômeros podem ser hidrolisados sequencialmente até a formação de monômeros simples. Neste modelo, supõe-se que a etapa de hidrólise gere somente monômeros, sem a formação de oligômeros intermediários. A segunda etapa abrange a formação de intermediários a partir dos monômeros gerados pelo passo anterior. Esses intermediários podem ser produtos de diversas reações, como isomerizações, desidratação, condensação retro-aldol e 
outras. No entanto, para o modelo de Resende e Savage (2010), todos os possíveis intermediários formados são tratados como um único composto, do tipo $\mathrm{C}_{x} \mathrm{H}_{\mathrm{y}} \mathrm{O}_{z}$, que representa os gases não permanentes originários da biomassa, e que podem continuar reagindo para formar outros gases. A terceira e a quarta etapa representam a reforma a vapor dos intermediários, formando $\mathrm{CO}$ e $\mathrm{H}_{2}$ ou $\mathrm{CO}_{2}$ e $\mathrm{H}_{2}$, dependendo da estequiometria da reação. As etapas subsequentes englobam a decomposição do intermediário genérico $\mathrm{C}_{\mathrm{x}} \mathrm{H}_{\mathrm{y}} \mathrm{O}_{z}$ nos produtos principais da gaseificação: $\mathrm{CO}, \mathrm{CO}_{2}, \mathrm{CH}_{4}, \mathrm{H}_{2}$ e carvão (incluindo os intermediários que seriam transformados em carvão ao final da reação), independentemente da reforma a vapor. O monóxido de carbono produzido pode reagir com o hidrogênio gasoso presente no meio, via reação de metanação, produzindo metano e vapor de água. O CO pode também reagir com o vapor de água, formando hidrogênio e dióxido de carbono, na reação que é conhecida como substituição água-gás. As reações de metanação e de substituição água-gás são as únicas reações reversíveis previstas no modelo. As reações de Boudouard e a hidrogenação não foram previstas para este modelo, devido às condições de temperatura utilizadas $\left(500\right.$ a $\left.600^{\circ} \mathrm{C}\right)$.

Uma vez definidas as etapas, para a obtenção do modelo, foram levantadas as equações de balanço ( $\mathrm{dC} / \mathrm{dt}$ ) para todos os componentes, assumindo-se que todas as reações fossem de primeira ordem com relação à concentração de cada uma das espécies. O reator considerado para o balanço de massa foi do tipo descontínuo, isotérmico de volume constante.

As equações geraram parâmetros de velocidade do tipo $k_{i}$, de $k_{2}$ a $k_{8}$ para 0 caso da celulose, incluindo as constantes $\mathrm{k}_{10 r}$ e $\mathrm{k}_{11 r}$ para as reações reversíveis. As mesmas foram obtidas experimentalmente, com exceção das constantes das reações reversas, que foram obtidas pela aplicação do bloco reator REQUIL do ASPEN Plus, com a premissa de equilíbrio.

O modelo cinético se adequou aos dados experimentais obtidos pelos autores para o caso de microcelulose cristalina e lignina organodissolvida e 
mostrou que pode predizer resultados de experimentos para uma variedade de carregamentos de biomassa e densidades de entrada.

A Figura 4 mostra as etapas de reação consideradas no modelo.

Figura 4: Etapas de reação do modelo cinético segundo Resende e Savage.

\begin{tabular}{|c|c|}
\hline \multicolumn{2}{|l|}{ Reaction 1. Hydrolysis } \\
\hline For Cellulose : $\quad\left(\mathrm{C}_{6} \mathrm{H}\right.$ & $\left(\mathrm{C}_{6} \mathrm{H}_{10} \mathrm{O}_{5}\right)_{\mathrm{n}}+\mathrm{n} \mathrm{H}_{2} \mathrm{O} \stackrel{\mathrm{k}_{1}}{\longrightarrow} \mathrm{nC}_{6} \mathrm{H}_{12} \mathrm{O}_{6}$ \\
\hline For Lignin : $\quad\left(\mathrm{C}_{10} \mathrm{H}_{1}\right.$ & $\left(\mathrm{C}_{10} \mathrm{H}_{10} \mathrm{O}_{3}\right)_{\mathrm{n}}+\mathrm{n} \mathrm{H}_{2} \mathrm{O} \stackrel{\mathrm{k}_{1}}{\longrightarrow} \mathrm{nC}_{10} \mathrm{H}_{12} \mathrm{O}_{4}$ \\
\hline \multicolumn{2}{|c|}{ Reaction 2. Intermediate Formation. } \\
\hline \multicolumn{2}{|c|}{ Monomer $\stackrel{\mathrm{k}_{2}}{\longrightarrow} \mathrm{C}_{\mathrm{x}} \mathrm{H}_{\mathrm{y}} \mathrm{O}_{\mathrm{z}}$} \\
\hline \multicolumn{2}{|c|}{ Reactions 3 and 4. Steam-Reforming. } \\
\hline \multicolumn{2}{|c|}{ Steam-Reforming I } \\
\hline \multicolumn{2}{|c|}{$\mathrm{C}_{\mathrm{x}} \mathrm{H}_{\mathrm{y}} \mathrm{O}_{\mathrm{z}}+(\mathrm{x}-\mathrm{z}) \mathrm{H}_{2} \mathrm{O} \stackrel{\mathrm{k}_{3}}{\longrightarrow} \mathrm{x} \mathrm{CO}+(\mathrm{x}-\mathrm{z}+\mathrm{y} / 2) \mathrm{H}_{2}$} \\
\hline \multicolumn{2}{|c|}{ Steam-Reforming II } \\
\hline \multicolumn{2}{|c|}{$\mathrm{C}_{\mathrm{x}} \mathrm{H}_{\mathrm{y}} \mathrm{O}_{\mathrm{z}}+(2 \mathrm{x}-\mathrm{z}) \mathrm{H}_{2} \mathrm{O} \stackrel{\mathrm{k}_{4}}{\longrightarrow} \mathrm{xCO}_{2}+(2 \mathrm{x}-\mathrm{z}+\mathrm{y} / 2) \mathrm{H}_{2}$} \\
\hline \multicolumn{2}{|c|}{ Reactions 5 to 8 . Intermediate Decomposition. } \\
\hline CO from Intermedia & e $\quad \mathrm{C}_{\mathrm{x}} \mathrm{H}_{\mathrm{y}} \mathrm{O}_{\mathrm{z}} \stackrel{\mathrm{k}_{5}}{\longrightarrow} \mathrm{CO}+\mathrm{C}_{\mathrm{x}} \mathrm{H}_{\mathrm{y}} \mathrm{O}_{\mathrm{z}}$ \\
\hline $\mathrm{CO}_{2}$ from intermedi: & $\mathrm{C}_{\mathrm{x}} \mathrm{H}_{\mathrm{y}} \mathrm{O}_{\mathrm{z}} \stackrel{\mathrm{k}_{6}}{\longrightarrow} \mathrm{CO}_{2}+\mathrm{C}_{\mathrm{x}} \mathrm{H}_{\mathrm{y}} \mathrm{O}_{\mathrm{z}}$ \\
\hline $\mathrm{CH}_{4}$ from intermedic & $\mathrm{C}_{\mathrm{x}} \mathrm{H}_{\mathrm{y}} \mathrm{O}_{\mathrm{z}} \stackrel{\mathrm{k} 7}{\longrightarrow} \mathrm{CH}_{4}+\mathrm{C}_{\mathrm{x}} \mathrm{H}_{\mathrm{y}} \mathrm{O}_{\mathrm{z}}$ \\
\hline $\mathrm{H}_{2}$ from intermedia & $\mathrm{C}_{\mathrm{x}} \mathrm{H}_{\mathrm{y}} \mathrm{O}_{\mathrm{z}} \stackrel{\mathrm{k}_{8}}{\longrightarrow} \mathrm{H}_{2}+\mathrm{C}_{\mathrm{x}} \mathrm{H}_{\mathrm{y}} \mathrm{O}_{\mathrm{z}}$ \\
\hline \multicolumn{2}{|c|}{ Reaction 9. Char Generation. } \\
\hline \multicolumn{2}{|c|}{$\mathrm{C}_{\mathrm{x}} \mathrm{H}_{\mathrm{y}} \mathrm{O}_{\mathrm{z}} \stackrel{\mathrm{k}_{9}}{\longrightarrow}$ Char } \\
\hline \multicolumn{2}{|c|}{ Reactions 10 and 11. Gas species interconversion. } \\
\hline Water-Gas Shift & $\mathrm{CO}+\mathrm{H}_{2} \mathrm{O} \leftrightarrow \mathrm{CO}_{2}+\mathrm{H}_{2}$ \\
\hline Methanation & $\mathrm{CO}+3 \mathrm{H}_{2} \leftrightarrow \mathrm{CH}_{4}+\mathrm{H}_{2} \mathrm{O}$ \\
\hline
\end{tabular}

Fonte: RESENDE e SAVAGE (2010). 


\subsubsection{Modelo cinético segundo Castello e Fiori (2012)}

Castello e Fiori (2012) estudaram três modelos diferentes para gaseificação de metanol em água supercrítica. Os modelos abordados foram o GRIMECH 3.0 (SMITH et al., 2000; BROCK e SAVAGE, 1995; e WEBLEY e TESTER, 1991). Nestes modelos parte-se de mecanismos de reações gasosas radicalares, já que devido ao produto iônico da água estar muito baixo em condições supercríticas, o mesmo pode ser ignorado. $\mathrm{O}$ modelo GRI-Mech 3.0 foi desenvolvido para descrever a aplicação de combustão de misturas contendo ar e metano, mas pode também incluir a combustão de outros hidrocarbonetos leves. Ao ser aplicado para a gaseificação supercrítica, ele comporta 215 reações e 34 componentes diferentes (com a exclusão de reações contendo nitrogênio). O modelo de Brock e Savage (1995) descreve a oxidação do metano, hidrogênio e compostos $C_{1}$ em água supercrítica. Ele inclui 148 reações e 22 componentes diferentes. $O$ modelo de Webley e Tester (1991) também descreve a oxidação do metano em água supercrítica e prevê 66 reações para 17 componentes diferentes. Os modelos foram implementados em MatLab[5], gerando uma série de equações que foram resolvidas pela rotina ODE15S.

Cada modelo era composto de um número $j$ de componentes e um número $i$ de reações elementares. Para todas as reações diretas eram conhecidos os valores da energia de ativação $\left(E_{a c t, i}\right)$, fator pré-exponencial da Equação de Arrhenius $\left(\mathrm{k}_{0, i}\right)$ e do expoente de dependência da temperatura na Equação de Arrhenius $\left(m_{i}\right)$. Essas constantes permitiram o cálculo das constantes cinéticas, $\mathrm{k}_{i}$, para cada uma das reações, de acordo com a Equação de Arrhenius modificada, Equação 3.1:

$$
k_{i}=k_{0, i} T^{m_{i}} \exp \left(-\frac{E_{a c t, i}}{R T}\right)
$$

${ }^{5}$ Mathworks, Inc. Matlab Primer R2015b. www.mathworks.com 
Para o cálculo das constantes de equilíbrio das reações reversas utilizam-se condições termodinâmicas facilitadoras, como a suposição de equilíbrio, que, após alguns desenvolvimentos, permite o cálculo das mesmas a partir da energia livre de Gibbs entre os produtos, a pressão de referência $(101,325 \mathrm{~Pa})$, e das constantes das reações diretas.

$$
k_{-i}=\frac{k_{i}}{Y_{i}}
$$

(Equação 3.2)

$Y_{i}=\prod_{j} C_{j}^{v_{j, i}}=\left(\frac{P_{0}}{R T}\right)^{\sum_{j} v_{j, i}} \exp \left(-\frac{\Delta G^{0}}{R T}\right)$

A comparação dos três modelos para o caso do metanol levou à conclusão de que o modelo de Webley e Tester foi o que mais se aproximou dos dados experimentais da gaseificação deste produto.

\subsubsection{Modelo cinético segundo Goodwin e Rorrer (2010)}

O estudo de Goodwin e Rorrer (2010) envolveu a determinação de dois modelos cinéticos, um a partir do mecanismo de reação de gaseificação de xilose em água supercrítica e o outro a partir de sua decomposição em água supercrítica. O mecanismo de reação do modelo de decomposição encontrase na Figura 5, enquanto o mecanismo de reação do modelo de gaseificação encontra-se na Figura 6.

O modelo de decomposição só engloba intermediários e produtos finais com mais de $1 \%$ do carbono total presente na corrente de alimentação (com exceção de hidrogênio e formiato de metila). Para os casos da metanação e substituição água-gás, foi suposto equilíbrio termodinâmico baseado na lei dos gases ideais.

O modelo de gaseificação é uma simplificação do modelo de decomposição, no qual a hipótese de equilíbrio termodinâmico para a metanação e substituição água-gás também foi assumida, com a inclusão do componente 
de fugacidade baseado na equação de estado de Peng-Robinson[6] para cada fluido reagindo, devido a sua não idealidade.

Figura 5: Mecanismo de reação do modelo de decomposição segundo Goodwin e Rorrer.

$\mathrm{CH}_{4}+3 \mathrm{CO}+3 \mathrm{H}_{2}+\mathrm{CO}_{2}$

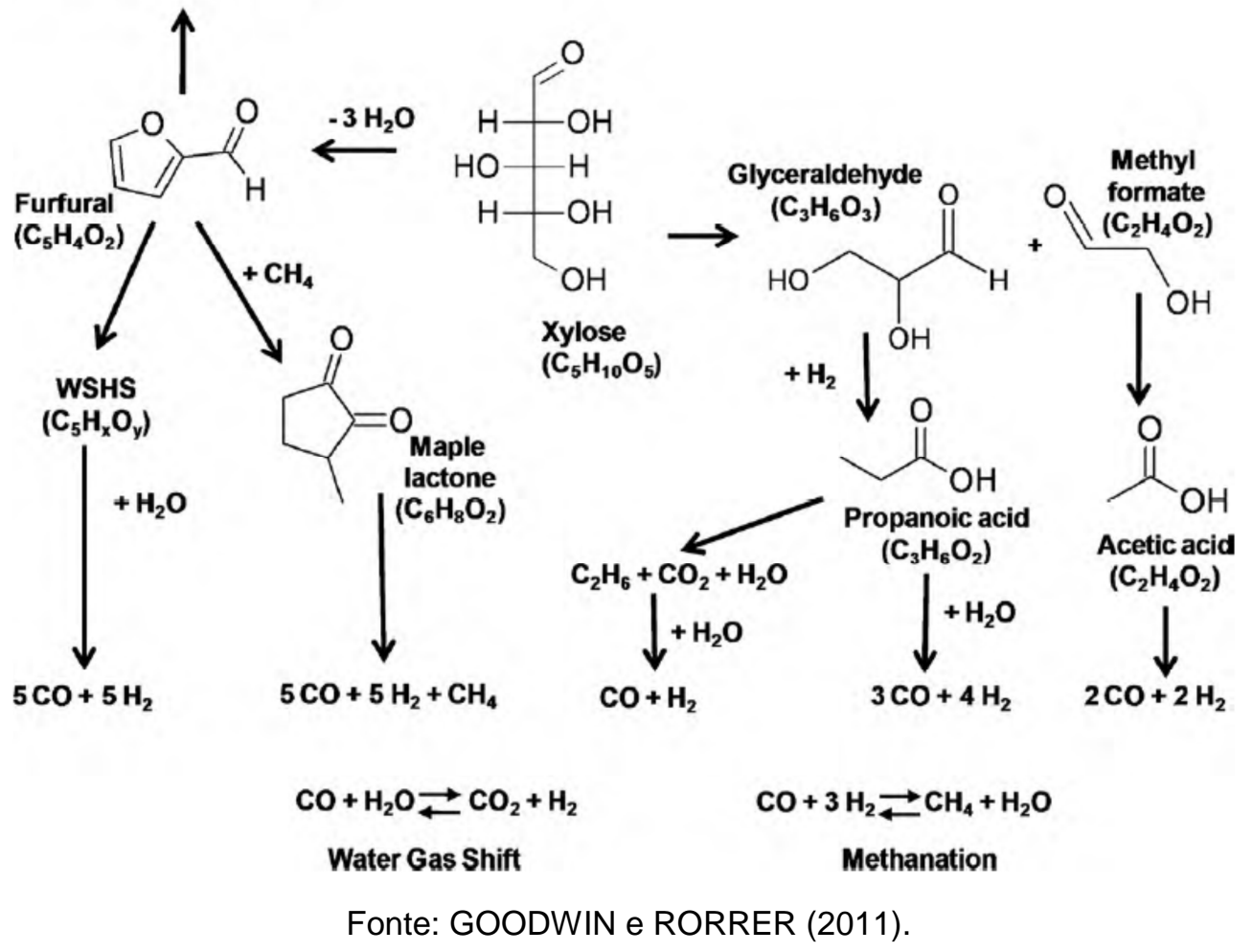

\footnotetext{
${ }^{6}$ As equações de estado e suas análises podem ser encontradas, por exemplo, em Michael Modell and Robert C. Reid. Thermodynamics and its Applications, $2^{\text {nd }}$ ed. Prentice-Hall. NJ. 1983 e Stanley I. Sandler. Chemical, Biochemical, and Engineering Thermodynamics. $4^{\text {th }}$ ed. Wiley. 2006;
} 
Figura 6: Mecanismo de reação do modelo de gaseificação segundo Goodwin e Rorrer.

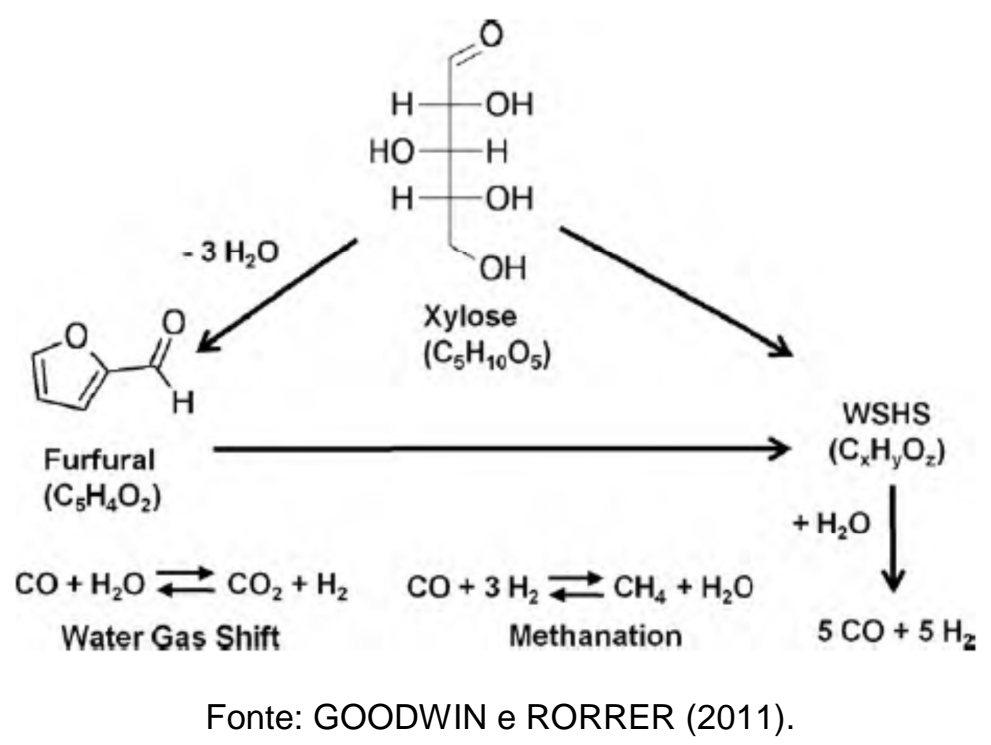

Foram feitas diversas suposições para os dois modelos, indicadas a seguir:

- Isotermia do fluido reagindo no gaseificador;

- Concentração de água constante na temperatura e pressão do reator, para o modelo de decomposição. Tal concentração foi usada na determinação de valores do equilíbrio para as reações de metanação e substituição água-gás e incluída nas constantes de velocidade das outras reações, permitindo a proposição de que elas fossem reações de pseudo primeira ordem. Para o modelo de gaseificação, a concentração foi assumida como variável.

- As reações de decomposição e gaseificação dos líquidos no meio reacional foram consideradas irreversíveis e de primeira ordem ou pseudo primeira ordem com relação a seus reagentes. Todas as reações na fase gasosa foram consideradas reversíveis e em equilíbrio termodinâmico;

- A relação entre as constantes de velocidade e a temperatura pode ser expressa pela Relação de Arrhenius. 
As reações descritas pelos autores encontram-se a seguir, na Figura 7:

Figura 7: etapas de reação do modelo cinético segundo Goodwin e Rorrer.

$$
\begin{aligned}
& \mathrm{C}_{5} \mathrm{H}_{10} \mathrm{O}_{5}(\mathrm{Xy}) \stackrel{k_{1}}{\longrightarrow} \mathrm{C}_{2} \mathrm{H}_{4} \mathrm{O}_{2}(\mathrm{MF})+\mathrm{C}_{3} \mathrm{H}_{6} \mathrm{O}_{3}(\mathrm{Gly}) \quad r_{1}=k_{1} C_{\mathrm{Xy}} \\
& \mathrm{C}_{5} \mathrm{H}_{10} \mathrm{O}_{5}(\mathrm{Xy}) \stackrel{k_{2}}{\longrightarrow} \mathrm{C}_{5} \mathrm{H}_{4} \mathrm{O}_{2}(\mathrm{FF})+3 \mathrm{H}_{2} \mathrm{O} \quad r_{2}=k_{2} \mathrm{C}_{\mathrm{Xy}} \\
& \mathrm{C}_{3} \mathrm{H}_{6} \mathrm{O}_{3}(\mathrm{Gly})+\mathrm{H}_{2} \stackrel{k_{3}}{\longrightarrow} \mathrm{C}_{3} \mathrm{H}_{6} \mathrm{O}_{2}(\mathrm{PA})+\mathrm{H}_{2} \mathrm{O} \quad r_{3}=k_{3} C_{\mathrm{Gly}} C_{\mathrm{H}_{2}} \\
& \mathrm{C}_{2} \mathrm{H}_{4} \mathrm{O}_{2}(\mathrm{MF}) \stackrel{k_{4}}{\longrightarrow} \mathrm{C}_{2} \mathrm{H}_{4} \mathrm{O}_{2}(\mathrm{AA}) \quad r_{4}=k_{4} \mathrm{C}_{\mathrm{MF}} \\
& \mathrm{C}_{5} \mathrm{H}_{4} \mathrm{O}_{2} \text { (FF) } \stackrel{k_{5}}{\longrightarrow} \mathrm{C}_{x} \mathrm{H}_{y} \mathrm{O}_{z} \text { (WSHS) } \quad r_{5}=k_{5} C_{\text {WSHS }} \\
& \mathrm{C}_{5} \mathrm{H}_{4} \mathrm{O}_{2}(\mathrm{FF})+\mathrm{CH}_{4} \stackrel{k_{6}}{\longrightarrow} \mathrm{C}_{6} \mathrm{H}_{8} \mathrm{O}_{2}(\mathrm{ML}) \quad r_{6}=k_{6} \mathrm{C}_{\mathrm{FF}} \mathrm{C}_{\mathrm{CH}_{4}} \\
& \mathrm{C}_{3} \mathrm{H}_{6} \mathrm{O}_{3}(\mathrm{PA})+\mathrm{H}_{2} \stackrel{k_{7}}{\longrightarrow} \mathrm{C}_{2} \mathrm{H}_{6}+\mathrm{H}_{2} \mathrm{O}+\mathrm{CO}_{2} \quad r_{7}=k_{7} \mathrm{C}_{\mathrm{PA}} \mathrm{C}_{\mathrm{H}_{2}} \\
& \mathrm{C}_{2} \mathrm{H}_{4} \mathrm{O}_{2}(\mathrm{AA}) \stackrel{k_{8}}{\longrightarrow} 2 \mathrm{CO}+2 \mathrm{H}_{2} \quad r_{8}=k_{8} \mathrm{C}_{\mathrm{Eth}} \\
& \mathrm{C}_{3} \mathrm{H}_{6} \mathrm{O}_{2}(\mathrm{PA})+\mathrm{H}_{2} \mathrm{O} \stackrel{k_{9}}{\longrightarrow} 3 \mathrm{CO}+4 \mathrm{H}_{2} \quad r_{9}=k_{9} \mathrm{C}_{\mathrm{PA}} \\
& \mathrm{C}_{5} \mathrm{H}_{4} \mathrm{O}_{2}(\mathrm{FF})+3 \mathrm{H}_{2} \mathrm{O} \stackrel{k_{10}}{\longrightarrow} \mathrm{CO}_{2}+\mathrm{CH}_{4}+3 \mathrm{CO}+3 \mathrm{H}_{2} \quad r_{10}=k_{10} C_{\mathrm{FF}} \\
& \mathrm{C}_{x} \mathrm{H}_{y} \mathrm{O}_{z}(\text { WSHS })+w \mathrm{H}_{2} \mathrm{O} \stackrel{k_{11}}{\longrightarrow} 5 \mathrm{CO}+5 \mathrm{H}_{2} \quad r_{11}=k_{11} C_{\text {WSHS }} \\
& \mathrm{C}_{6} \mathrm{H}_{8} \mathrm{O}_{2}(\mathrm{ML})+3 \mathrm{H}_{2} \mathrm{O} \stackrel{k_{12}}{\longrightarrow} \mathrm{CH}_{4}+5 \mathrm{CO}+5 \mathrm{H}_{2} \quad r_{12}=k_{12} C_{\mathrm{ML}} \\
& \mathrm{C}_{2} \mathrm{H}_{6}+\mathrm{H}_{2} \mathrm{O} \stackrel{k_{13}}{\longrightarrow} 2 \mathrm{CO}+5 \mathrm{H}_{2} \quad r_{13}=k_{13} C_{\mathrm{Eth}} \\
& \mathrm{CO}+\mathrm{H}_{2} \underset{k_{15}}{\stackrel{k_{14}}{\rightleftarrows}} \mathrm{H}_{2}+\mathrm{CO}_{2} \quad r_{14}=k_{14} C_{\mathrm{CO}} C_{\mathrm{H}_{2} \mathrm{O}}-k_{15} C_{\mathrm{H}_{2}} C_{\mathrm{CO}_{2}} \\
& \mathrm{CO}+3 \mathrm{H}_{2} \underset{k_{17}}{\stackrel{k_{16}}{\rightleftarrows}} \mathrm{CH}_{4}+\mathrm{H}_{2} \mathrm{O} \quad r_{15}=k_{16} C_{\mathrm{CO}} \mathrm{C}_{\mathrm{H}_{2}}^{3}-k_{17} C_{\mathrm{CH}_{4}} C_{\mathrm{H}_{2} \mathrm{O}}
\end{aligned}
$$

Fonte: GOODWIN e RORRER (2011).

Os valores previstos no modelo foram comparados com resultados experimentais, usando-se reatores microtubulares de Hastelloy C-276, operando com pressão de 250 bar e temperaturas variando entre $450^{\circ} \mathrm{C}$ e $650^{\circ} \mathrm{C}$. O modelo de decomposição descreve a quebra da xilose em intermediários líquidos e é relevante na análise da gaseificação da hemicelulose em água supercrítica a temperaturas baixas e na produção de químicos a partir da xilose. Já o modelo de gaseificação é mais apropriado para modelar e otimizar a gaseificação em água supercrítica de correntes ricas em hemicelulose, onde as condições de gaseificação são dominantes. 
$\mathrm{Na}$ continuação dos estudos, Goodwin e Rorrer (2011) testaram a gaseificação com reatores de microcanais de Hastelloy C-276 a $650^{\circ} \mathrm{C}$ e 250 bar. O modelo de gaseificação proposto foi avaliado através de estudos de simulação em CFD (Computational Fluid Dynamics) de duas dimensões, usando a suposição de utilização de um único canal do reator (um microreator). Isso pode ser um facilitador do scale-up, já que as características físicas dos canais de um reator industrial continuariam as mesmas de um microreator de bancada, indicando que a performance do aparato de gaseificação não seria afetada por seu aumento. Os resultados da análise em CFD indicam que as reações endotérmicas da gaseificação da xilose não têm grande influência na temperatura do meio reacional. No entanto, a configuração em canais do reator testado faz com que a temperatura do meio reacional seja influenciada pelo tempo de residência do fluido, devido ao gradiente de temperatura do período de aquecimento do mesmo.

\subsubsection{Modelo termodinâmico segundo Tang e Kitagawa (2005)}

Tang e Kitagawa (2005) formularam um modelo termodinâmico baseado na minimização da energia livre de Gibbs, a fim de prever a composição de equilíbrio de biomassas submetidas à gaseificação em água supercrítica.

O primeiro passo na determinação do modelo é o de estimar as quantidades das espécies no equilíbrio. Para tal, o processo de gaseificação foi extrapolado pelas reações a seguir, supondo-se que a quantidade das espécies contendo 2 e 3 carbonos era mínima:

$$
\begin{aligned}
& \mathrm{CH}_{x} \mathrm{O}_{y}+(1-y) \mathrm{H}_{2} \mathrm{O} \leftrightarrow \mathrm{CO}+(\mathrm{x} / 2+1-\mathrm{y}) \mathrm{H}_{2} \\
& \mathrm{CO}+\mathrm{H}_{2} \mathrm{O} \leftrightarrow \mathrm{CO}_{2}+\mathrm{H}_{2} \\
& \mathrm{CO}+3 \mathrm{H}_{2} \leftrightarrow \mathrm{CH}_{4}+\mathrm{H}_{2} \mathrm{O}
\end{aligned}
$$

Devido às características apolares da água no estado supercrítico, os hidrocarbonetos e gases leves pertencentes à biomassa encontram-se 
solubilizados na água, gerando um sistema homogêneo. Para a determinação do comportamento termodinâmico de cada uma das espécies presentes neste sistema, foi usada a equação de estado de Peng-Robinson, com a adição do fator de compressibilidade. A mesma foi reescrita como um polinômio de terceira ordem. Foi feita a extensão da equação de estado para misturas, com a incorporação da teoria de mistura clássica de Van der Waals, sendo que os parâmetros de interação adicionais foram estimados a partir dos segundos coeficientes viriais de mistura.

A partir das definições de potencial químico e fugacidade (incluindo a equação de estado), foi estabelecida uma equação em termos de Energia livre de Gibbs. No equilíbrio, a energia livre deve ser mínima, respeitando os balanços de massa e os requerimentos de estequiometria. A equação final encontra-se abaixo, bem como suas restrições.

$$
\begin{aligned}
& G=\sum_{i}^{i=K} n_{i}\left[R T\left(\ln \left(\frac{\phi_{i} P}{P_{0}}\right)+\ln \left(X_{i}\right)\right)+G_{i}^{0}\left(T, P_{0}\right)\right] \\
& \sum_{\mathrm{i}}^{\mathrm{k}} \beta_{\mathrm{ei}} \mathrm{n}_{\mathrm{i}}=\beta_{\mathrm{e}} \quad(\mathrm{e}=1,2,3, \ldots, \mathrm{M}) \\
& 0 \leq n_{i} \leq n_{i t} \quad(i=1,2,3, \ldots, K)
\end{aligned}
$$

O modelo foi aplicado na análise de processos de gaseificação em água supercrítica de glucose, celulose e biomassa "real", que incluía resíduos de lixões municipais e recursos agrícolas. Para o modelo de gaseificação da glucose foram incluídas outras reações ao modelo, representadas a seguir.

$$
\begin{aligned}
& \text { Glucose } \rightarrow \mathrm{CO}+\mathrm{H}_{2}+\mathrm{CH}_{4}+\mathrm{H}_{2} \mathrm{O} \\
& \mathrm{CH}_{4}+\mathrm{H}_{2} \mathrm{O} \rightarrow \mathrm{CO}+3 \mathrm{H}_{2}
\end{aligned}
$$

Após a verificação do modelo para este componente, chegou-se à conclusão de que a reação de gaseificação da glucose pode ser representada pela reação abaixo. 


$$
2 \mathrm{C}_{6} \mathrm{H}_{12} \mathrm{O}_{6} \rightarrow 9 \mathrm{CO}+3 \mathrm{H}_{2}+3 \mathrm{CH}_{4}+3 \mathrm{H}_{2} \mathrm{O}
$$

(Reação 3.13)

\subsubsection{Modelo termodinâmico segundo Yan; Guo e Lu (2006)}

Com o objetivo de determinar a produção de hidrogênio na gaseificação de biomassa em água supercrítica, Yan; Guo e Lu(2006) desenvolveram um modelo de equilíbrio não estequiométrico baseado na minimização da energia livre de Gibbs.

Para a solução do problema de otimização restrito, formado pelo sistema de minimização da energia livre de Gibbs, em conjunto com os balanços de massa, foram adotados multiplicadores de Lagrange, removendo assim as restrições.

Foi utilizada a equação de estado de Duan[], que possui exatidão para temperaturas acima da crítica (até $2000 \mathrm{~K}$ ) e para pressões entre 0 e 2500 bar. A equação está representada a seguir:

$$
\begin{aligned}
& \mathrm{Z}=\frac{\mathrm{P}_{\mathrm{m}} V_{\mathrm{m}}}{R T_{\mathrm{m}}}=1+\frac{\mathrm{a}_{1}+\frac{\mathrm{a}_{2}}{\mathrm{~T}_{\mathrm{m}}^{2}}+\frac{\mathrm{a}_{3}}{\mathrm{~T}_{\mathrm{m}}^{3}}}{\mathrm{~V}_{\mathrm{m}}}+\frac{\mathrm{a}_{4}+\frac{\mathrm{a}_{5}}{\mathrm{~T}_{\mathrm{m}}^{2}}+\frac{\mathrm{a}_{6}}{\mathrm{~T}_{\mathrm{m}}^{3}}}{\mathrm{~V}_{\mathrm{m}}^{2}}+\frac{\mathrm{a}_{7}+\frac{\mathrm{a}_{8}}{T_{\mathrm{m}}^{2}}+\frac{\mathrm{a}_{9}}{\mathrm{~T}_{\mathrm{m}}^{3}}}{\mathrm{~V}_{\mathrm{m}}^{4}}+ \\
& +\frac{\mathrm{a}_{10}+\frac{\mathrm{a}_{11}}{\mathrm{~T}_{\mathrm{m}}^{2}}+\frac{\mathrm{a}_{12}}{\mathrm{~T}_{\mathrm{m}}^{3}}}{\mathrm{~V}_{\mathrm{m}}^{5}}+\frac{\mathrm{a}_{13}}{\mathrm{~T}_{\mathrm{m}}^{3} V_{\mathrm{m}}^{2}}\left(1+\frac{\mathrm{a}_{14}}{V_{\mathrm{m}}^{2}}\right) \exp \left(-\frac{a_{14}}{V_{\mathrm{m}}^{2}}\right)
\end{aligned}
$$

A determinação da composição de equilíbrio foi feita com base na hipótese de que as únicas reações relevantes na gaseificação da biomassa em estudo (glucose) são as reações representadas pelas equações 3.8, 3.9 e 3.10 .

\footnotetext{
${ }^{7}$ Citado em Yan; Guo; Lu (2006) como: Duan Z, Moller N, Weare JH. A general equation of state for supercritical fluid mixture and molecular dynamics simulation of mixture PVTX properties. Geochimica et CosmochimicaActa, Vol. 60,No. 7, pp. 1209-1216, 1996 ;http://gcmodel.kl-

edi.ac.cn/archives/publications/21-GCA1996-60.pdf
} 
Foram desconsideradas as frações molares de $\mathrm{C}_{2} \mathrm{H}_{4}, \mathrm{C}_{2} \mathrm{H}_{6}$ e $\mathrm{C}_{6} \mathrm{H}_{12} \mathrm{O}_{6}$, devido às pequenas quantidades presentes no meio reacional final (da ordem de $10^{-7}$ ), assim como a formação de alcatrão e os conteúdos de nitrogênio e enxofre.

O modelo foi aplicado para diversas condições: temperaturas entre 650 e $1050 \mathrm{~K}$, pressões entre 20 e $35 \mathrm{MPa}$ e concentrações (composição elementar da biomassa alimentada no sistema) entre 0,1 e 1,0 M. Os resultados obtidos a partir dos cálculos com o modelo se aproximam bastante daqueles obtidos experimentalmente para a glucose. Observou-se também que a temperatura do meio reacional e a concentração da biomassa alimentada têm mais influência no comportamento da reação que a pressão:

- Temperaturas altas favorecem a formação de hidrogênio;

- A eficiência da gaseificação e a eficiência do gás frio aumentam com o aumento de temperatura;

- O aumento da concentração na biomassa alimentada diminui os rendimentos na produção de gases, assim como as eficiências da gaseificação e do gás frio, mesmo que a alta concentração seja interessante em termos industriais;

- Matérias-primas com alta relação Carbono/Oxigênio oferecem altas taxas teóricas de formação de hidrogênio.

\subsubsection{Modelo termodinâmico segundo Freitas e Guirardello (2012)}

Freitas e Guirardello (2012) estudaram a gaseificação de glucose e celulose em água supercrítica, com um modelo de minimização da energia livre de Gibbs à pressão e temperatura constantes, para a determinação das composições de equilíbrio e maximização da entropia à pressão e entalpia constantes, para a determinação da temperatura final da reação. A formulação do modelo foi feita a partir de programação não linear de modo a 
assegurar a obtenção do ótimo global sem a necessidade de uma estimativa inicial, devido à sua convexidade.

Para a formulação segundo a minimização da energia livre de Gibbs, foi considerada a equação clássica para sistemas multicomponentes, em conjunto com as restrições de balanço de massa e de não negatividade do número de mols dos componentes em cada fase, conforme indicado abaixo.

$$
\begin{aligned}
& \min G=\sum_{i=1}^{N C} n_{i}^{g} \cdot \mu_{i}^{g}+\sum_{i=1}^{N C} n_{i}^{l} \cdot \mu_{i}^{l}+\sum_{i=1}^{N C} n_{i}^{S} \cdot \mu_{i}^{S} \\
& n_{i}^{g}, n_{i}^{l}, n_{i}^{S} \geq 0 \\
& \sum_{i=1}^{N C} a_{m i}\left(n_{i}^{g}+n_{i}^{l}+n_{i}^{S}\right)=\sum_{i=1}^{N C} a_{m i} \cdot n_{i}^{0}, m=1, \ldots N E
\end{aligned}
$$

A determinação do coeficiente de fugacidade foi feita a partir de equação de estado, truncada no segundo coeficiente virial, conforme a Equação 3.11. 0 cálculo dos coeficientes viriais foi feito a partir da correlação de Pitzer e Curl, modificada por Tsonopoulos[8].

$$
\ln \widehat{\phi}_{\iota}=\left[2 \sum_{j}^{m} y_{j} \cdot B_{i j}-B\right] \frac{P}{R T}
$$

Para a formulação do problema de maximização da entropia foi utilizada a equação 3.12, a qual deve satisfazer as restrições de balanço e de não negatividade do número de mols dos componentes em cada fase, assim como o balanço de entropia indicado na sequência.

$$
\begin{aligned}
& \max S=\sum_{i=1}^{N C} n_{i}^{g} \cdot S_{i}^{g}+\sum_{i=1}^{N C} n_{i}^{l} \cdot S_{i}^{l}+\sum_{i=1}^{N C} n_{i}^{S} \cdot S_{i}^{S} \\
& \sum_{i=1}^{N C}\left(n_{i}^{g} \cdot H_{i}^{g}+n_{i}^{l} \cdot H_{i}^{l}+n_{i}^{S} \cdot H_{i}^{S}\right)=\sum_{i=1}^{N C}\left(n_{i}^{0} \cdot H_{i}^{0}\right)=H
\end{aligned}
$$

\footnotetext{
${ }^{8}$ As equações de estado e correlações de Pitzer e Curl, e de Tsonopoulos, podem ser encontradas, por exemplo, em Hong Wei Xiang. The Corresponding-States Principle and its Practice: Thermodynamic, Transport and Surface Properties of Fluids.Elsevier Science. 2005.
} 
Para a resolução do problema foram feitas análises para temperaturas entre 703,15 e 1073,15 K; pressões entre 250 e 350 atm e concentração de glucose/ celulose de 2,5 a $20 \%$ (em porcentagem mássica).

A metodologia usada mostrou-se confiável nas análises termodinâmicas da glucose e da celulose. Os dados obtidos a partir do modelo proposto foram comparados com dados experimentais e a aproximação foi satisfatória. Foi verificado que baixas concentrações na corrente de alimentação e altas temperaturas aumentam a eficiência da produção de hidrogênio em todos os casos estudados, independentemente do substrato.

\subsubsection{Simulação e modelagem segundo Tisdale (2004)}

No trabalho de Tisdale (2004) foi realizada a simulação da Unidade de Desenvolvimento de Processos Termoquímicos (TCPDU - Termochemical Process Development Unit) da NREL (National Renewable Energy Laboratory), para propósitos de otimização. O modelo inclui três partes, uma de gaseificação/ quebra térmica, uma de remoção de sólidos e um sistema de condensação.

A etapa de gaseificação conta com um sistema de leito fluidizado com aquecimento indireto. A autora indica que este tipo de gaseificador (leito fluidizado) tem mostrado grande potencial na gaseificação de biomassa.

O gaseificador foi simulado usando o modelo de reator RYIELD do ASPEN Plus. Tal modelo foi escolhido devido à falta de dados cinéticos para as biomassas gaseificadas no estudo, no caso madeira e cama de frango. Os valores de rendimento necessários como entradas nos cálculos foram obtidos a partir de experimentos realizados anteriormente na unidade (TCPDU). As reações de gaseificação consideradas no modelo encontramse a seguir (HIGMAN; VAN DER BURGT, 2003 apud TISDALE, 2004): 
Reações de oxidação:

$$
\begin{array}{lll}
\mathrm{C}+1 / 2 \mathrm{O}_{2} \leftrightarrow \mathrm{CO} ; & \Delta \mathrm{H}=-111 \mathrm{~kJ} / \mathrm{kmol} & \text { (Reação 3.14) } \\
\mathrm{CO}+1 / 2 \mathrm{O}_{2} \leftrightarrow \mathrm{CO}_{2} ; & \Delta \mathrm{H}=-283 \mathrm{~kJ} / \mathrm{kmol} & \text { (Reação 3.15) } \\
\mathrm{H}_{2}+1 / 2 \mathrm{O}_{2} \leftrightarrow \mathrm{H}_{2} \mathrm{O} ; & \Delta \mathrm{H}=-242 \mathrm{~kJ} / \mathrm{kmol} & \text { (Reação 3.16) }
\end{array}
$$

Reação de Boudouard:

$$
\mathrm{C}+\mathrm{CO}_{2} \leftrightarrow 2 \mathrm{CO} ; \quad \Delta \mathrm{H}=-+172 \mathrm{MJ} / \mathrm{kmol} \quad \text { (Reação 3.17) }
$$

Reação água-gás:

$$
\mathrm{C}+\mathrm{H}_{2} \mathrm{O} \leftrightarrow \mathrm{CO}+\mathrm{H}_{2} ; \quad \Delta \mathrm{H}=-+131 \mathrm{MJ} / \mathrm{kmol} \quad \text { (Reação 3.18) }
$$

Reação de metanação:

$$
\mathrm{C}+2 \mathrm{H}_{2} \leftrightarrow \mathrm{CH}_{4} ; \quad \Delta \mathrm{H}=--75 \mathrm{MJ} / \mathrm{kmol} \quad \text { (Reação 3.19) }
$$

Tais reações podem ser combinadas em uma única equação genérica, que descreve o consumo dos hidrocarbonetos durante a gaseificação, neste caso com o agente gaseificante sendo o oxigênio.

$$
\mathrm{C}_{\mathrm{n}} \mathrm{H}_{\mathrm{m}}+\mathrm{n} / 2 \mathrm{O}_{2} \leftrightarrow \mathrm{nCO}+\mathrm{m} / 2 \mathrm{H}_{2}
$$

O uso de tais equações implica na hipótese de uma quantidade estequiométrica de vapor, assim como uma reação de deslocamento águagás completa, o que nem sempre representa o comportamento real no gaseificador. 
O método base escolhido para calcular o modelo foi o Redlich-Kwong-Soave (RK-SOAVE) ${ }^{[9]}$. A autora indica que o mesmo é adequado para aplicações de processamento de hidrocarbonetos e regiões de altas pressões e temperaturas, inclusive extrações supercríticas.

O modelo obtido foi capaz de prever a composição dos gases em diversos casos, apresentando resultados similares aos obtidos experimentalmente para a etapa de gaseificação.

\subsubsection{Modelagem e simulação segundo Kumar et al. (2009)}

O modelo para gaseificação de biomassa proposto por Kumar et al. (2009) considera a combinação dos módulos RYIELD e RGIBBS do software ASPEN Plus. Nessa abordagem a biomassa é inicialmente decomposta como carbono, $\mathrm{CH}_{4}, \mathrm{CO}, \mathrm{CO}_{2}, \mathrm{H}_{2}, \mathrm{H}_{2} \mathrm{O}$, cinzas, $\mathrm{NH}_{3}$, enxofre, umidade e cinzas, que são basicamente os principais produtos possíveis já citados em literatura para gaseificação. Tal aproximação difere razoavelmente de outros estudos envolvendo simulação de gaseificação, que consideram que a biomassa é decomposta em elementos individuais, como $\mathrm{C}, \mathrm{O}_{2}, \mathrm{H}_{2}, \mathrm{~N}_{2}$, $\mathrm{S}$ e cinzas. Essa abordagem permite a incorporação do carvão e de alcatrões no sistema.

Os rendimentos necessários para a alimentação do bloco RYIELD foram obtidos a partir da reação a seguir, que considera globalmente a transformação da biomassa nos elementos intermediários.

$$
\mathrm{CH}_{\mathrm{x}} \mathrm{O}_{\mathrm{y}} \mathrm{N}_{\mathrm{z}} \mathrm{S}_{\mathrm{s}} \rightarrow \mathrm{aC}+\mathrm{bCO}+\mathrm{cCO}_{2}+\mathrm{dH}_{2}+\mathrm{eCH}_{4}+\mathrm{fNH}_{3}+\mathrm{gS}+\mathrm{CH}_{1,55} \mathrm{O}_{0,55}
$$

(Reação 3.21)

Os valores dos coeficientes da reação acima foram obtidos a partir de análises químicas das biomassas estudadas, no caso palha de milho e grãos

\footnotetext{
${ }^{9}$ As equações de estado e suas análises podem ser encontradas, por exemplo, em Michael Modell and Robert C. Reid. Thermodynamics and its Applications, $2^{\text {nd }}$ ed. Prentice-Hall. NJ. 1983 e Stanley I. Sandler. Chemical, Biochemical, and Engineering Thermodynamics. $4^{\text {th }}$ ed. Wiley. 2006;
} 
secos de destilaria com solúveis (DDGS - Dried Distillers Grains with Solubles), e dos balanços de massa para cada elemento.

O bloco RGIBBS foi usado para calcular a concentração de todos os possíveis produtos da gaseificação com base na minimização da energia livre de Gibbs, considerando a hipótese de que as reações de gaseificação atingiram o equilíbrio.

Foram incluídos no modelo módulos de aproveitamento energético, separadores e outros itens necessários, a fim de se comparar os resultados do modelo com aqueles obtidos na unidade experimental.

Os resultados do modelo mostram que a temperatura do leito do gaseificador impacta diretamente nos rendimentos de $\mathrm{H}_{2}$ e do gás total, enquanto os rendimentos de $\mathrm{CO}$ e $\mathrm{CO}_{2}$ são influenciados pela temperatura da borda livre do gaseificador (freeboard). $O$ modelo permite o ajuste das composições gasosas desejadas a partir da estimativa das condições de operação da gaseificação.

\subsubsection{Análise segundo Withag et al. (2012)}

Withag et al. (2012) fizeram uma análise do estado da arte da modelagem de gaseificação em água supercrítica, a fim de entender o efeito dos parâmetros de processo na eficiência térmica da gaseificação. $O$ estudo resultou no levantamento de alguns comportamentos constantes da gaseificação em água supercrítica, apresentados a seguir:

- O conteúdo de monóxido de carbono no gás produzido é muito baixo;

- O rendimento em hidrogênio aumenta com o aumento de temperatura, principalmente acima de $600^{\circ} \mathrm{C}$, enquanto o rendimento em metano aumenta em menores que $600^{\circ} \mathrm{C}$. 
- Com o aumento da concentração de biomassa na corrente de alimentação, o rendimento em hidrogênio decresce, enquanto o rendimento em metano aumenta.

- A pressão não tem influência significativa no processo global.

A simulação do modelo de Withag et al. (2012) considerou como biomassa no estado líquido uma mistura de água e metanol. O modelo foi dividido em seções, englobando todas as transformações do fluido, desde a pressurização da corrente de entrada, troca de calor entre a corrente de saída e a de entrada, o reator de gaseificação em si e a separação do gás final. Para o cálculo da composição final do gás produto, foi considerada a hipótese de equilíbrio químico, com a minimização da energia livre de Gibbs.

Os autores fizeram uma análise extensiva dos possíveis métodos de cálculo das propriedades termodinâmicas e de transporte do sistema químico e optaram pelo uso das equações de estado, com o modelo de Soave RedlichKwong, modificado por Huron-Vidal (SRKMHV2). Os resultados obtidos indicam que a composição do gás de saída pode ser adaptada para uma condição desejada, variando-se os parâmetros de entrada e temperatura do reator. A eficiência do trocador de calor (que permite a troca entre a corrente de gás produto e a alimentação líquida) tem um efeito determinante na eficiência térmica do processo. Sob o aspecto de eficiência térmica de produção do gaseificador, concluiu-se que um processo otimizado para a produção de metano tem maior eficiência térmica que um processo otimizado para a produção de hidrogênio.

\subsubsection{Análise segundo Fiori; Valbusa; Castello (2012)}

Os estudos feitos por Fiori; Valbusa e Castello (2012) envolvem a gaseificação de biomassas em água supercrítica, para a obtenção de hidrogênio para posterior uso em células a combustível.O processo determinado pelos autores considera a queima do gás produto, já separado 
do hidrogênio, para o aquecimento do gaseificador. O processo foi simulado em ASPEN Plus, para diversas biomassas, como glicerol, fenol, microalga Spirulina, lodo de esgoto e bagaço de uvas (resíduo da produção de vinho). Para as simulações, foram variados os seguintes parâmetros: temperatura $\left(500,700\right.$ e $\left.900^{\circ} \mathrm{C}\right)$, pressão $(250,300$ e 350 bar) e concentração da biomassa (biomassas entre 5 e 35\%, sendo o restante água).

Para as biomassas mais simples, como o glicerol e o fenol, o gaseificador foi modelado como um trocador de calor, seguido de um reator do tipo RGIBBS. O trocador de calor permite que a biomassa atinja a condição de temperatura pré-determinada para o sistema, enquanto o bloco RGIBBS pressupõe a condição de equilíbrio, fornecendo a composição da mistura no gás produto.

Para as moléculas mais complexas, o gaseificador foi modelado no ASPEN Plus como uma combinação do bloco trocador de calor e do bloco RGIBBS, com um bloco RYIELD entre eles. O bloco RYIELD age como um devolatilizador, transformando as moléculas mais complexas (bagaço, lodo e microalga) em moléculas simples, que conseguem ser processadas pelo bloco RGIBBS.

Os resultados obtidos com a simulação mostram que o processo de gaseificação em água supercrítica de biomassas pode chegar a uma produção de energia entre 145 e $157 \mathrm{kWe}$ por $1000 \mathrm{~kg} / \mathrm{h}$ de biomassa alimentada no sistema (desconsiderando perdas). Tal resultado fornece uma visão do potencial da gaseificação de biomassas em água supercrítica. 


\section{ANÁLISE DOS MODELOS}

A maioria dos trabalhos atuais de gaseificação supercrítica tem como foco a utilização de biomassa lignocelulósica, que consideram que os compostos chave desse tipo de material são a celulose, a hemicelulose e a lignina. São exploradas as formas mais simples, como glicose, xilanas e grupos fenólicos guaiacil, siringil e propanil. As fontes proteicas de biomassa são estudadas sob o ponto de vista de bioquímica e de estruturas celulares, em outras áreas de pesquisa, mas dificilmente haverá algum tipo de motivação para representá-las como fórmulas estruturais químicas, ou como compostos modelo para cinética de reação. É improvável que a glicina $\left(\mathrm{C}_{2} \mathrm{H}_{5} \mathrm{NO}_{2}\right)$ ou a prolina $\left(\mathrm{C}_{5} \mathrm{H}_{9} \mathrm{NO}_{2}\right)$, aminoácidos básicos, possam ser considerados como compostos modelo para biomassa proteica na mesma qualidade que a glicose é utilizada para a celulose, mesmo que estudos de decomposição de tais aminoácidos possam ajudar a entender as fontes proteicas para a gaseificação. Ou seja, uma determinação cinética rigorosa e a proposição de mecanismos de reação nesses compostos, quando puros, não tem aproveitamento direto na cinética de fontes proteicas. Ressalta-se que alguns materiais lignocelulósicos possuem partes proteicas, como é o caso das microalgas. Para estes casos, o estudo da cinética de decomposição do indol $\left(\mathrm{C}_{8} \mathrm{H}_{7} \mathrm{~N}\right)$, que é um composto heterocíclico aromático, pode elucidar a sua interação com outros compostos modelo.

A representação de modelos categorizados em modelos de taxas cinéticas e modelos termodinâmicos de equilíbrio não é uma criação da SCWG, de gaseificadores de biomassa, ou de gaseificação e de reatores de reforma de gás em geral. Entretanto, uma discussão entre as diferenças destes modelos é muito útil no caso da SCWG. 


\subsection{Modelo Cinético}

O modelo cinético tem como sua parte mais importante a proposição dos mecanismos cinéticos envolvidos durante a gaseificação da biomassa. Como a decomposição da biomassa deve ocorrer em escala de minutos para que a evolução cinética possa ser experimentalmente detectada nas condições atuais, as condições iniciais e o tempo de residência em cada condição são importantes para a determinação de dados cinéticos. Isso porque as rotas da decomposição de biomassa são diferentes para diferentes temperaturas e tempos de reação, e não é possível comprovar as rotas pela dificuldade de medição dos intermediários das reações. Para essa escala de tempo, as temperaturas de reação nos experimentos publicados estão nas faixas de $200-500^{\circ} \mathrm{C}$. O uso dos modelos cinéticos de SCWG em unidades industriais é muito restrito, já que os mesmos sempre contêm parâmetros que restringem a sua aplicação para diferentes substratos e condições de operação que não aquelas nas quais eles foram testados.

Não existem dados experimentais para a vinhaça na literatura. No entanto, é necessário lembrar que a SCWG com a vinhaça representa uma operação com matéria-prima extremamente diluída. Ao mesmo tempo em que a água é um componente das reações de "water gas shift", ela influi diretamente na metanação (por meio do $\mathrm{H}_{2}$ ). As duas reações são acopladas e estão em equilíbrio termodinâmico, por isso, conjectura-se aqui que o modelo cinético pode não refletir com segurança os dados experimentais em termos de $\mathrm{CH}_{4}$, frente à modelagem dos mecanismos das reações. Entretanto, os erros associados à determinação de parâmetros cinéticos geralmente são devidos à falta de medição de compostos em mecanismos de reações incompletas. Mesmo a abordagem dos modelos cinéticos mostra que seus resultados são melhores para temperaturas mais altas (na faixa de $200-500^{\circ} \mathrm{C}$ ), e isso se explica pelo fato de que as mudanças nas propriedades da água supercrítica podem afetar os experimentos. Uma das grandes fraquezas do modelo cinético ainda é o modelo de mecanismos e rotas de decomposição com seus intermediários, já que, ao mudar a operação de $350^{\circ} \mathrm{C}$ para $450^{\circ} \mathrm{C}$, 
$550^{\circ} \mathrm{C}$ e $650^{\circ} \mathrm{C}$, as rotas de mecanismos são diferentes. Ao operar na mesma temperatura, mas com tempos de contato diferentes, os mecanismos serão diferentes, mesmo para compostos modelo. Paradoxalmente, uma das principais justificativas para o uso de modelos cinéticos envolve a hipótese de que os mesmos modelam os intermediários, assim como os mecanismos para fins de dimensionamento dos equipamentos. Este contraste se explica com uma expectativa para o futuro: com o início da operação de novos reatores (experimentais ou não), os ganhos virão com a melhoria do desenho mecânico dos mesmos. Este tipo de melhoria requer a obtenção de modelos cinéticos mais precisos, que por sua vez, dependem de um melhor entendimento dos mecanismos de reação. Tal entendimento implica na integração de todos os compostos simples de matérias-primas, porque mesmo as reações menos importantes devem ser consideradas na modificação de rotas de uma reação principal. Com isso conclui-se que os estudos cinéticos ainda estão "na sua infância".

\subsection{Modelo Termodinâmico}

Os modelos termodinâmicos de equilíbrio para gaseificadores se dividem em estequiométricos e não estequiométricos. Em modelos estequiométricos, tem-se a proposição dos mecanismos das reações e das espécies envolvidas. Em uma abordagem não estequiométrica, nenhuma consideração em particular das rotas das reações é necessária, porque ela trabalha apenas com a análise imediata da composição da matéria-prima. Os resultados das duas abordagens são essencialmente os mesmos, com a diferença de que na primeira, a energia de Gibbs é analisada nas reações mais importantes, enquanto na segunda, a energia de Gibbs é analisada no sistema como um todo. Para fazer a ligação entre o modelo cinético e o modelo termodinâmico, a abordagem estequiométrica é mais interessante. 
Ao assumir que um reator tem produtos em equilíbrio químico na sua composição mais estável, a energia livre de Gibbs deve ser a mínima. No entanto, em função da temperatura de operação, esse equilíbrio termodinâmico pode não existir. Os experimentos da literatura mostram que os modelos de equilíbrio se adequam aos dados experimentais na faixa de $700-1000^{\circ} \mathrm{C}$. Para efeito de fluxograma de processos, deve-se lembrar de que os resultados de um modelo termodinâmico:

- Não levam em conta as Dimensões do equipamento,

- Não consideram as perdas de calor;

- Consideram que a mistura é perfeita e uniforme e que as taxas de reação são extremamente rápidas;

- Consideram que o tempo de residência é suficiente para atingir equilíbrio.

Além disso, esse tipo de modelo pode fornecer como resultado algumas espécies superestimadas, como $\circ \mathrm{CO}_{2}$ na composição final dos gases, devido às hipóteses e métodos de determinação de propriedades escolhidos.

Uma questão em modelos termodinâmicos envolve a apresentação da água em estado supercrítico. É sempre dito que ela é um solvente polar nessas condições, mas ao mesmo tempo, por seu alto poder de dissociação, apresenta altas quantidades de radicais de caráter básico e ácido. Mesmo assim, são utilizados modelos cinéticos e termodinâmicos similares àqueles usados para quando a água está nas suas características normais, o que é um paradoxo. Outra questão em aberto é o fato de não haver diferenciação de modelo para gaseificadores tradicionais e gaseificadores supercríticos, mesmo que as características de operação sejam tão distintas. 
Os dados quantitativos da literatura mostram que a maioria da cinética de casos de SCWG está dividida em duas etapas: uma de decomposição e outra de gaseificação em si, que tem efeito significativo em torno de 350$500^{\circ} \mathrm{C}$ (escala de minutos). Na faixa de temperatura de $600-800^{\circ} \mathrm{C}$ (escala de segundos) a gaseificação é muito rápida, sendo adequado o modelo de equilíbrio termodinâmico. Assume-se aqui que na faixa de alta temperatura os dois modelos dão resultados similares.

A adoção da faixa de alta temperatura no presente trabalho leva em conta não somente a rapidez das reações, mas também evita um problema. $\mathrm{Na}$ faixa de $350-500^{\circ} \mathrm{C}$ podem ocorrer mudanças abruptas nas propriedades físicas da água supercrítica (densidade, viscosidade, constante elétrica, etc.); podendo ocasionar até mesmo a geração de alcatrão, o que não é adequado para premissas de projeto. Assim, foi evitada a operação abaixo de $550^{\circ} \mathrm{C}$. 


\section{MATERIAIS E MÉTODOS}

\subsection{Introdução}

A inovação de produto é a introdução de um serviço ou produto tanto novo quanto significativamente melhorado enquanto a inovação de processo é a implementação de um método de produção novo (ou significativamente melhorado) e inclui alterações significativas nas técnicas e equipamentos. O presente trabalho contribui com uma combinação dos dois conceitos.

Síntese de processo é uma parte de um processo de inovação que inclui estágios desde a necessidade de identificação até a operação/ manutenção da unidade industrial. (PERTIWI; WEBB E SHARRATT, 2010). As áreas de maior interesse para a síntese de processo são a química básica/ detalhada, identificação das tarefas, operações unitárias, e engenharia básica. A abordagem sistemática à síntese de processo, como no presente caso, busca fornecer diretrizes para avaliação da viabilidade e flexibilidade do presente processo de SCWG de vinhaça, desenvolvendo as alternativas correspondentes a diferentes decisões de projeto e, principalmente, gerando as necessidades de pesquisas colaborativas em tecnologia básica e equipamentos.

Apesar de o presente trabalho fazer uso de publicações correntes em SCWG, a inovação através de síntese de processo não é apenas uma coleta de informação e tecnologias existentes, mas também a sua interpretação e desenvolvimento para a geração de novos conhecimentos diretamente relacionados à engenharia de projetos. Na medida em que a unidade industrial se torna mais complexa, ao integrar o processamento da vinhaça, é necessário olhar para o processo de um modo integrado, considerando todas as interfaces do projeto.

As principais etapas do presente processo de SCWG de vinhaça, tal como aceitas usualmente pelos pesquisadores, são: a fase de determinação de objetivos com a identificação e seleção de projetos, seguida da fase de desenvolvimento e produção da tecnologia, finalizando com a fase de difusão ao mercado. A expansão teórica 
desses conceitos pode ser vista em Lager (2011). Pelo fato do processamento da vinhaça em água supercrítica ser extremamente novo, essa inovação na síntese de processo não segue a classificação de inovação tradicional, mesmo aceitando e abarcando essa abordagem e sim a classificação de inovação estratégica. Essas classificações podem ser melhor entendidas em Palmer e Kaplan (2013).

O maior desafio na implantação de um processo de inovação é que não existem fluxogramas/ dados/ processos/ sistemas similares em operação, para se utilizar como base (benchmark), tal como tradicionalmente descrito por Turton et al. (2012). Isso significa que, tipicamente, diferentes fases de desenvolvimento de um processo inovativo vão requerer trabalhos adicionais, o que pode estender a duração do projeto, tendo impacto também nos custos (LAKSHMANAN; ROY e RAMACHANDRAN, 2016).

Na presente metodologia têm-se as seguintes etapas:

1. Desenvolvimento do fluxograma

Fluxograma é aqui considerado um roadmap, um guia, principalmente para processos inovativos. Sua elaboração gera uma lista de necessidades de estudos em escala de bancada, unidades piloto e unidades de demonstração, incluindo requisitos viabilidade econômica e ambiental, possibilitando uma vantagem competitiva em economia de conhecimento perante o mercado. $\mathrm{O}$ desenvolvimento de um fluxograma começa com a identificação de matérias primas e potenciais produtos, para assim desenvolver um projeto conceitual.

2. Detalhes de projeto dentro da Classe 4 da AACE

As considerações relacionadas à AACE (Association for the Advancement of Cost Engineering) serão explicadas ao longo do capítulo.

É necessário gerar um grau mínimo e confiança com relação aos custos de capital e operação, devido a complexidade do processo inovativo e seus equipamentos. 
3. Avaliação dos balanços de massa e energia

O fluxograma deve ser avaliado, baseado no balanço de processo, incluindo todas as operações unitárias e entendimento das reações químicas envolvidas. Com isso, o mesmo poderia ser futuramente utilizado em uma proposta Classe 3, que incluiria uma lista de todos os equipamentos, com todos os itens mecânicos, dimensões de equipamentos, materiais de construção, motores elétricos e outros itens.

4. Estimativa preliminar dos custos de capital e de operação

Essas estimativas são elaboradas para cada opção de processo.

5. Análise de Sensibilidade

São selecionados três casos para a análise de sensibilidade do projeto: uma para a condição de operação, outra para a condição de matéria prima e a terceira para a alternativa/ opção de processo, com o objetivo de demonstrar a robustez do presente trabalho.

\subsection{Descrição simplificada da execução de um projeto conceitual}

Não existem muitas linhas de pesquisa em como executar projetos de engenharia. As análises relacionadas a projetos se limitam a avaliar a gestão dos mesmos, assim como garantir padrões de qualidade em sua execução e precificação.

O presente estudo incluiu a criação de um projeto conceitual para um módulo de gaseificação de vinhaça em água supercrítica, que será discutido em todas suas etapas de avaliação e pontos de interesse.

Todo projeto se inicia com a definição de um problema ou necessidade, seja ela de produção de algum produto/ bem de consumo, ou de mitigação de uma condição adversa. $O$ apelo da definição do módulo deste estudo foi a utilização da vinhaça na 
gaseificação supercrítica. Em conjunto, tem-se a necessidade de preencher um espaço existente entre os pesquisadores e a indústria, que é colocar em prática e analisar a viabilidade daquilo que está sendo estudado em bancada.

Após a definição do problema a ser endereçado, são iniciados os estudos de estado da arte da tecnologia, que englobam o entendimento das tecnologias sendo utilizadas, com seus riscos e potenciais.

Após o entendimento da tecnologia, é proposto o processo em si. Nesta etapa é feito um fluxograma simplificado (flowsheet), que será a base para as simulações de processo, elas incluem os balanços de massa e energia. Para a execução da simulação, é necessária a definição das condições básicas do processo, por exemplo, das entradas e saídas das correntes principais. Essa definição depende de avaliações de demanda do produto a ser produzido, ou como no caso deste estudo, da quantidade de vinhaça sendo produzida por dia em uma usina típica. Para a execução dos balanços são feitas também as definições específicas de processo, que envolvem a determinação de temperaturas e pressões, qualidades de produtos e correntes de entrada e outros, sempre levando em consideração as limitações da tecnologia utilizada.

Com os balanços calculados, seja com a ajuda de um software de processo, ou com cálculos manuais, são pré-dimensionados os equipamentos principais da planta. Com as características destes itens, serão realizadas as estimativas de custo, que podem vir de cotações formais por fornecedores, ou informações de bancos de dados consolidados.

O levantamento de preços de equipamentos é acompanhado de uma estimativa para os outros itens da planta, que vão desde itens de tubulação e componentes elétricos, até a precificação da construtora que irá executar os serviços de construção e montagem. Em estimativas mais generalistas, podem ser utilizados fatores para o cálculo dos preços destes itens, como é o caso do fator de Lang, que será abordado com maiores detalhes na subseção 5.4 . 
A partir das estimativas de custo, o projeto pode ser avaliado com relação a sua continuidade e etapas futuras.

\subsection{Estimativas de investimento de projetos}

A AACE (Association for the Advancement of Cost Engineering) é uma agência sem fins lucrativos, que visa o auxiliar profissionais da gestão de custos nas áreas de coordenação de projetos, estimativas de riscos e escopo. Em sua prática recomendada No 18R-97[10], a mesma estabelece diretrizes para a classificação de estimativas de custos em projetos, com um sistema que mapeia as fases e estágios da estimativa de custos de projeto, com uma matriz genérica de qualidade e maturidade, que pode ser aplicada numa grande variedade de indústrias.

A partir das diretrizes da AACE é possível estabelecer cinco classes de estimativas, com base no nível de definição de um dado projeto. As características de cada classe são típicas para a maioria dos processos industriais, mas podem variar de aplicação para aplicação. A Tabela 3 mostra tais categorias e suas características.

Tabela 3: Classes de estimativas de investimento segundo a AACE.

\begin{tabular}{|c|c|c|c|c|c|}
\hline & $\begin{array}{l}\text { Característica } \\
\text { Primária }\end{array}$ & \multicolumn{4}{|c|}{ Características Secundárias } \\
\hline $\begin{array}{l}\text { CLASSE DA } \\
\text { ESTIMATIVA }\end{array}$ & $\begin{array}{c}\text { NÍVEL DE } \\
\text { DEFINIÇÃO DO } \\
\text { PROJETO } \\
\text { Expresso como } \\
\text { uma \% da } \\
\text { definição completa }\end{array}$ & $\begin{array}{l}\text { USO FINAL } \\
\text { Propósito típico } \\
\text { da estimativa }\end{array}$ & $\begin{array}{l}\text { METODOLOGIA } \\
\text { Método Típico da } \\
\text { estimativa }\end{array}$ & $\begin{array}{c}\text { INTERVALO DE } \\
\text { PRECISÃO } \\
\text { ESPERADO } \\
\text { Variação típica em } \\
\text { intervalos baixo e alto[a] }\end{array}$ & $\begin{array}{c}\text { ESFORÇO } \\
\text { PARA A } \\
\text { PREPARAÇÃO } \\
\text { Grau de esforço } \\
\text { típico relativo a } \\
\text { um índice de } \\
\text { custo de } 1[b]\end{array}$ \\
\hline Classe 5 & $0 \%$ a $2 \%$ & $\begin{array}{l}\text { Triagem de } \\
\text { conceito }\end{array}$ & $\begin{array}{c}\text { Capacidade } \\
\text { Consignada, Modelos } \\
\text { Paramétricos, Modelos } \\
\text { para Análise ou } \\
\text { Analogia }\end{array}$ & $\begin{array}{c}L:-20 \% \text { a }-50 \% \\
H:+30 \% \text { a }+100 \%\end{array}$ & 1 \\
\hline Classe 4 & $1 \%$ a $15 \%$ & $\begin{array}{l}\text { Estudo ou } \\
\text { viabilidade }\end{array}$ & $\begin{array}{c}\text { Equipamentos } \\
\text { Consignados ou } \\
\text { modelos paramétricos }\end{array}$ & $\begin{array}{c}L:-15 \% \text { a }-30 \% \\
H:+20 \% \text { a }+50 \%\end{array}$ & 2 a 4 \\
\hline
\end{tabular}

\footnotetext{
${ }^{10}$ AACE International Recommended Practice No. 18R-97. COST ESTIMATE CLASSIFICATION SYSTEM - AS APPLIED IN ENGINEERING, PROCUREMENT, AND CONSTRUCTION FOR THE PROCESS INDUSTRIES. TCM Framework: 7.3 - Cost Estimating and Budgeting. 2011. http://www.aacei.org/toc/toc_18R-97.pdf
} 


\begin{tabular}{|c|c|c|c|c|c|} 
Classe 3 & $10 \%$ a $40 \%$ & $\begin{array}{c}\text { Orçamento, } \\
\text { Autorização ou } \\
\text { Controle }\end{array}$ & $\begin{array}{c}\text { Custos unitários semi- } \\
\text { detalhados, com itens } \\
\text { de tubulação montados }\end{array}$ & $\begin{array}{c}\mathrm{L}:-10 \% \text { a }-20 \% \\
\mathrm{H}:+10 \% \text { a }+30 \%\end{array}$ & 3 a 10 \\
\hline Classe 2 & $30 \%$ a $70 \%$ & $\begin{array}{c}\text { Controle ou } \\
\text { Proposta }\end{array}$ & $\begin{array}{c}\text { Custos unitários } \\
\text { detalhados, com take- } \\
\text { off detalhado forçado }\end{array}$ & $\begin{array}{c}\mathrm{L}:-5 \% \text { a }-15 \% \\
\mathrm{H}:+5 \% \text { a }+20 \%\end{array}$ & 4 a 20 \\
\hline Classe 1 & $50 \%$ a $100 \%$ & $\begin{array}{c}\text { Estimativa de } \\
\text { Checagem ou } \\
\text { Proposta }\end{array}$ & $\begin{array}{c}\text { Custos unitários } \\
\text { detalhados, com take- } \\
\text { off detalhado }\end{array}$ & $\begin{array}{c}\mathrm{L:}:-3 \% \text { a }-10 \% \\
\mathrm{H}:+3 \% \text { a }+15 \%\end{array}$ & 5 a 100 \\
\hline
\end{tabular}

[a] 0 estado do processo tecnológico e a disponibilidade dos dados de referência de custos afetam o intervalo marcadamente; Os valores +/- representam uma procentagem típica da variação de custos da estimativa de custo, após a aplicação da contingência (tipicamente com um nível de confiança de 50\%), para um dado escopo.

b] Se o índice de "1" representar 0,005\% dos custos do projeto, então um índice de 100 representa $0,5 \%$. 0 esforço requerido na preparação da estimativa é diretamente proporcional ao tamanho do projeto e à qualidade dos dados e ferramentas utilizados na mesma

Fonte: Tradução da prática recomendada AACE 18R-97 (2011).

A partir da Tabela 3, é possível enquadrar estimativas de investimentos de projetos nas classes de 1 a 5 , conforme os seguintes requisitos, que definem o propósito de cada estimativa, detalhando seu uso:

- Nível de definição de projeto requerida, expressa em uma porcentagem da definição completa;

- Uso final, que indica qual a aplicação final da estimativa de custo sendo executada;

- Métodos de estimativa utilizados, listando quais os métodos de estimativa poderiam ser utilizados para o desenvolvimento do custo da classe;

- Nível esperado de precisão, que é a variação típica em níveis baixos e altos, após a aplicação da contingência. Tipicamente, a estimativa tem um nível de $90 \%$ de confiança dentro dos ranges baixo e alto, estabelecidos pela classe.

\subsection{Método de Lang}

O método de Lang sugere uma maneira simplificada para determinação de estimativas de custo de plantas de processo. O mesmo se baseia na aplicação de um fator sobre o custo dos equipamentos de uma planta, que pode ser do tipo: 
- Processamento de sólidos - fator 3,10;

- Processamento de sólidos e fluidos - fator 3,63;

- Processamento de fluidos - fator 4,74.

O custo total instalado seria então obtido a partir da multiplicação do fator apropriado pelo custo total dos equipamentos de uma unidade industrial.

O custo total determinado a partir dos fatores inclui não somente o cálculo dos equipamentos, mas também custo com materiais, mão de obra, estruturas metálicas e de concreto, tubulações, materiais elétricos, sistemas de controle, projeto, construção e despesas gerais. Os custos considerados como "owners cost" não estão incluídos na estimativa.

\subsection{CAPEX e OPEX}

O CAPEX (CAPital EXpenditure) de um projeto se resume basicamente às despesas ou investimentos em capital para a execução do mesmo. Ele é uma metodologia largamente utilizada para determinação de fluxos de caixa e do valor presente líquido, em conjunto com o OPEX (OPeration EXpenditure), que leva em conta aspectos operacionais e consumíveis.

A estimativa de custos na área industrial é particularmente difícil, devido às incertezas relacionadas à área, como a utilização de novas tecnologias, muitas vezes incipientes e não estabilizadas. Ademais, a singularidade de cada projeto ainda limita a curva de aprendizado para estas estimativas (MCMILLAN, apud EMHJELLEN et al., 2002).

\subsection{ASPEN Plus}

O Simulador ASPEN Plus é um software de simulação de processos químicos que possui diversos blocos construtivos, modelos e ferramentas que permitem a 
elaboração e a otimização de sistemas químicos variados. Seu banco de dados inclui propriedades físicas para simulação com sólidos, líquidos, gases e eletrólitos avançados. O mesmo foi utilizado para a simulação do projeto proposto para gaseificação de vinhaça em água supercrítica.

\subsubsection{Bloco RYIELD}

O bloco RYIELD do simulador ASPEN Plus modela um reator especificando os rendimentos de reação para cada componente. Este modelo é utilizado quando a estequiometria da reação e a cinética da mesma não são conhecidas, ou quando os dados de distribuição de rendimento/ correlações estão disponíveis.

\subsubsection{Bloco RGIBBS}

O bloco RGIBBS do simulador ASPEN Plus calcula o equilíbrio químico em uma única fase, ou em fase e equilíbrio simultaneamente.

O modelo RGIBBS minimiza a energia livre de Gibbs, calculando a concentração na saída do reator, eliminando a necessidade dos parâmetros cinéticos, diretos e reversos, das reações. O modelo RGIBBS pode determinar o equilíbrio de fases, sem a especificação da reação química. É permitida a presença de qualquer número de fases líquidas.

Segundo Sandler (2015), o conceito de constantes de equilíbrio foi introduzido em livros por uma conveniência computacional. O princípio fundamental diz que no equilíbrio, à pressão e temperatura constantes, a energia livre de Gibbs deve ter um valor mínimo. Com base nesse princípio, em programas de simulação de processo, é desenvolvida uma expressão genérica para a energia livre de Gibbs de um dado sistema, em termos de número de mols de todas as espécies presentes, reagentes, produtos e materiais inertes, em todas as fases. O cálculo então varia o número de mols de cada espécie em cada fase, sujeitando-o a certas restrições estequiométricas, até descobrir a solução que minimiza a energia livre de Gibbs do sistema. Desta maneira, o problema jaz na minimização de uma única função, independentemente do número de reações ou de fases envolvidas, conforme informado nos estudos de Neveus et al. (2013). A Equação 5.1 representa o cálculo 
da energia mínima. A mesma está sujeita à restrição da equação 5.2 e aos resultados da Equação 5.3.

$$
\min _{n} G=\min \sum_{i=1}^{N_{i}} n_{i} \mu_{i}
$$

para a qual $\mathrm{G}$ é a energia livre de Gibbs, $\mathrm{n}_{i}$ é o número de mols e $\mu_{i}$ é o potencial químico de uma dada espécie.

$$
\mathbf{A} \cdot \mathbf{n}=\mathbf{b}
$$

na qual $\mathrm{A}$ é uma matriz de elementos $\mathrm{N}_{\mathrm{E}}$ x $\mathrm{N}_{\mathrm{C}}$, que também pode ser chamada $A_{k i}$. Nela, k é o número de átomos e $i$ é o índice que indica um componente qualquer. Ainda para a Equação 5.2, $n$ é o vetor de composição $N_{C}$ e b é o vetor $N_{E}$, que representa as quantidades totais de cada elemento na mistura.

$$
\mu_{i}(\mathbf{n}, T)=\mu_{1}^{0}(T)+R T \ln \frac{\gamma_{n}}{n_{t}}
$$

(Equação 5.3)

$\mathrm{Na}$ equação 5.3 é calculado o potencial químico para uma dada espécie, numa condição fixa de temperatura. Nessa equação, $\mu_{i}{ }^{0}$ é o potencial químico de um componente $i$ no estado estacionário, $\mathrm{n}_{t}$ é o número total de mols $\left(n_{t}=\sum_{i=1} N_{C} . n_{i}\right)$ e $\gamma_{i}$ é o coeficiente de atividade para uma dada espécie.

O potencial químico no estado estacionário pode ser calculado pela Equação 5.4, caso não esteja disponível em dados de literatura.

$$
\mu^{0}(T)=-R T\left[\begin{array}{l}
\nu^{T} \\
\mathbf{E}
\end{array}\right]^{-1}\left(\begin{array}{c}
\ln \mathbf{K}(T) \\
\mathbf{0}
\end{array}\right)
$$

onde $v$ é a matriz estequiométrica e $E$ é uma matriz esparsa $\left(N_{C}-N_{R}\right) \times N_{C}$, cheia de elementos zeros, com a exceção de um elemento igual a 1 por linha, que representa o componente básico a ser computado como nulo. 
Com base nos potenciais pode-se então minimizar a energia livre de Gibbs, obtendo-se as composições no equilíbrio químico.

Para as considerações do equilíbrio de fases, o mesmo pode ser descrito por uma relação de igualdade de potenciais para cada componente nas fases líquido e vapor, conforme indicado na Equação 5.5.

$$
\mu_{i}^{\operatorname{lig}}(T, P, \mathbf{n})=\mu_{i}^{\mathrm{ap}}(T, P, \mathbf{n})
$$

Pela escolha do modelo de Gibbs para a determinação do comportamento do sistema, é interessante definir os potenciais em função do coeficiente de atividade, transformando a Equação 5.5 na Equação 5.6.

$$
y_{i}=K_{i}^{\mathrm{VII}} x_{i}
$$

no qual $\mathrm{K}_{\mathrm{i}}^{\mathrm{VLE}}$ é a constante de equilíbrio para espécies voláteis, que pode ser calculada pela Equação 5.7, para o caso de espécies voláteis, e pela Equação 5.8, para solutos (como $\mathrm{CO} 2, \mathrm{O} 2$ e N2) e $x_{i}$ é a fração molar do componente i na fase líquida.

$$
\begin{gathered}
K_{i}^{\text {VLE }}=\frac{\gamma_{i} x_{i} \rho_{i}^{\text {sat }} p_{i}^{\text {stt }}}{\varphi_{i}^{P}} \exp \left[\frac{v_{i}\left(P-P_{i}^{\text {sat }}\right)}{R T}\right] \\
K_{i}^{\text {VLLE }}=\frac{\gamma_{i} x_{i} \mathcal{H}_{i}^{\text {o }}}{\varphi_{i} P \gamma_{i}^{\infty}} \exp \left[\frac{v_{i}^{\infty}\left(P-P_{\mathrm{H}_{0}}^{\text {sat }}\right)}{R T}\right]
\end{gathered}
$$

nas quais $\varphi_{i}$ é 0 coeficiente de fugacidade para o componente i na fase gasosa,

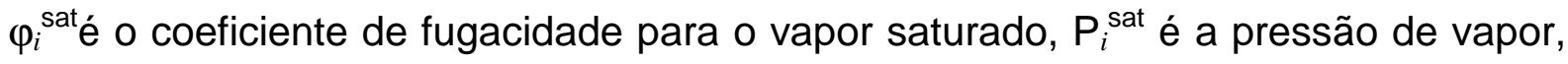
$v_{i}$ é o volume molar parcial e $v_{i}^{\infty}$ é o volume molar parcial para diluição infinita. $O$ fator exponencial da Equação $M$ é o fator de Poynting, que é usado para a correção de pressão, $\mathrm{H}_{i}^{\infty}$ é o coeficiente de Henry da diluição infinita e $\gamma_{i}^{\infty}$ é o coeficiente de atividade a diluição infinita. 


\subsection{Fluxograma de Gaseificação de Vinhaça em Água Supercrítica}

A vazão do sistema como um todo foi determinada com base na produção de vinhaça em uma safra de 167 dias, conforme Wood et al. (2013), de 1,7×106 m³. Considerando-se que as plantas trabalhariam no período de safra 7 dias por semana e 24 horas por dia, teríamos uma vazão aproximada de $450 \mathrm{t} / \mathrm{h}$, que foi adotada como vazão de projeto do módulo de gaseificação.

A vinhaça produzida na usina é geralmente enviada para bacias de vinhaça, que são grandes reservatórios, revestidos com mantas de polietileno de alta densidade, de maneira a evitar a contaminação do solo pelo produto armazenado. Essa vinhaça é então encaminhada para caminhões que transportam o fluido até perto das plantações de cana, onde a mesma é aspergida sobre a terra (fertirrigação). A intervenção do módulo de gaseificação começa nessa bacia, para a qual será construído um reservatório de concreto adjacente, de menor volume e conectado à bacia por um vertedouro. O mesmo servirá para instalação das bombas de alta pressão de vinhaça de primeiro nível. Tais bombas (uma operando e uma reserva) elevam a pressão da vinhaça a $100 \mathrm{kgf} / \mathrm{cm}^{2} \mathrm{~g}$ e bombeiam uma vazão de $450 \mathrm{t} / \mathrm{h}$, suficiente para escoar toda a produção de uma usina padrão de grande porte. Após o primeiro bombeamento, a vinhaça passa pelo primeiro trocador de calor, que permite o aproveitamento do conteúdo energético da água recuperada no final do processo para aquecimento da vinhaça a uma temperatura acima de $100^{\circ} \mathrm{C}$. Em seguida, o fluido é roteado para um segundo trocador de calor, que fornece energia suficiente para que a vinhaça atinja uma temperatura próxima dos $300^{\circ} \mathrm{C}$. O fluido quente do trocador é o gás produto, que já teve parte de sua energia reaproveitada por outros equipamentos do circuito a jusante. Na condição de $300^{\circ} \mathrm{C}$ e $100 \mathrm{~kg} / \mathrm{cm}^{2} \mathrm{~g}$ a água presente na vinhaça (cerca de 93\%) ainda não atingiu o estado supercrítico, ela ainda está no estado líquido, o que ainda permite seu bombeamento. $O$ mesmo é realizado com o auxilio de bombas de alta pressão de segundo nível (uma operando e uma reserva), que elevam a pressão do fluido a $250 \mathrm{~kg} / \mathrm{cm}^{2}$. A pressão atingida pelas bombas de segundo nível já é a máxima alcançada pelo sistema. Após esse estágio a preparação para a gaseificação se dá pelo aumento da temperatura até $\mathrm{o}$ set point de $800^{\circ} \mathrm{C}$ e pela separação dos sais da vinhaça. $\mathrm{O}$ aumento de temperatura até um patamar anterior aos $800^{\circ} \mathrm{C}$ é realizado por dois 
trocadores de calor em série, nos quais a vinhaça passa pelos tubos e pelos cascos é circulado o gás produto exausto do gaseificador. O primeiro trocador de gás eleva a temperatura da vinhaça até que ela atinja a condição supercrítica, assim como a maioria dos seus constituintes, com exceção dos sais. Os mesmos são então capturados em um sistema de deposição de sal, composto por um vaso com recheio. O recheio cerâmico do vaso é uma barreira para a passagem do fluido supercrítico e acaba interceptando as moléculas de sal, que ficam aderidas ao recheio, removendo tais partículas do fluido. Nesse momento o fluido precisa de pouca energia para atingir a condição de gaseificação pré-determinada. Esse calor é obtido ao passar o fluido por uma fornalha de bagaço. Após a fornalha, a vinhaça está a $800^{\circ} \mathrm{C}$ e $230 \mathrm{kgf} / \mathrm{cm}^{2}$, já nas condições previstas para a gaseificação. Ela é roteada até o gaseificador, no qual é gerada uma mistura gasosa de metano, hidrogênio, monóxido de carbono, dióxido de carbono e água. O gás produto passa pelos trocadores de gás em série, para então entrar no ultimo trocador de calor antes do vaso separado. Nele a água já não está mais no estado supercrítico e sim líquido, permitindo a sua separação dos outros gases. Os gases são armazenados pressurizados em um vaso de gás produto, enquanto a água é encaminhada para um vaso de água recuperada, passando antes pelo primeiro trocador de calor, o que permite a redução da sua temperatura.

A partir da definição das etapas do processo e dos equipamentos presentes no mesmo, foi criado o fluxograma de processo simplificado, apresentado na Figura 8.

A partir das definições de projeto, passou-se para a etapa de elaboração dos balanços de massa e energia, que foram executados no software ASPEN Plus. Com os resultados do balanço, foi possível preencher os campos indicados com "HOLD" na Figura 8, o que permitiu o dimensionamento dos equipamentos e sua precificação. 
Figura 8: Fluxograma de Processo do sistema de Gaseificação de Vinhaça em Água Supercrítica proposto.

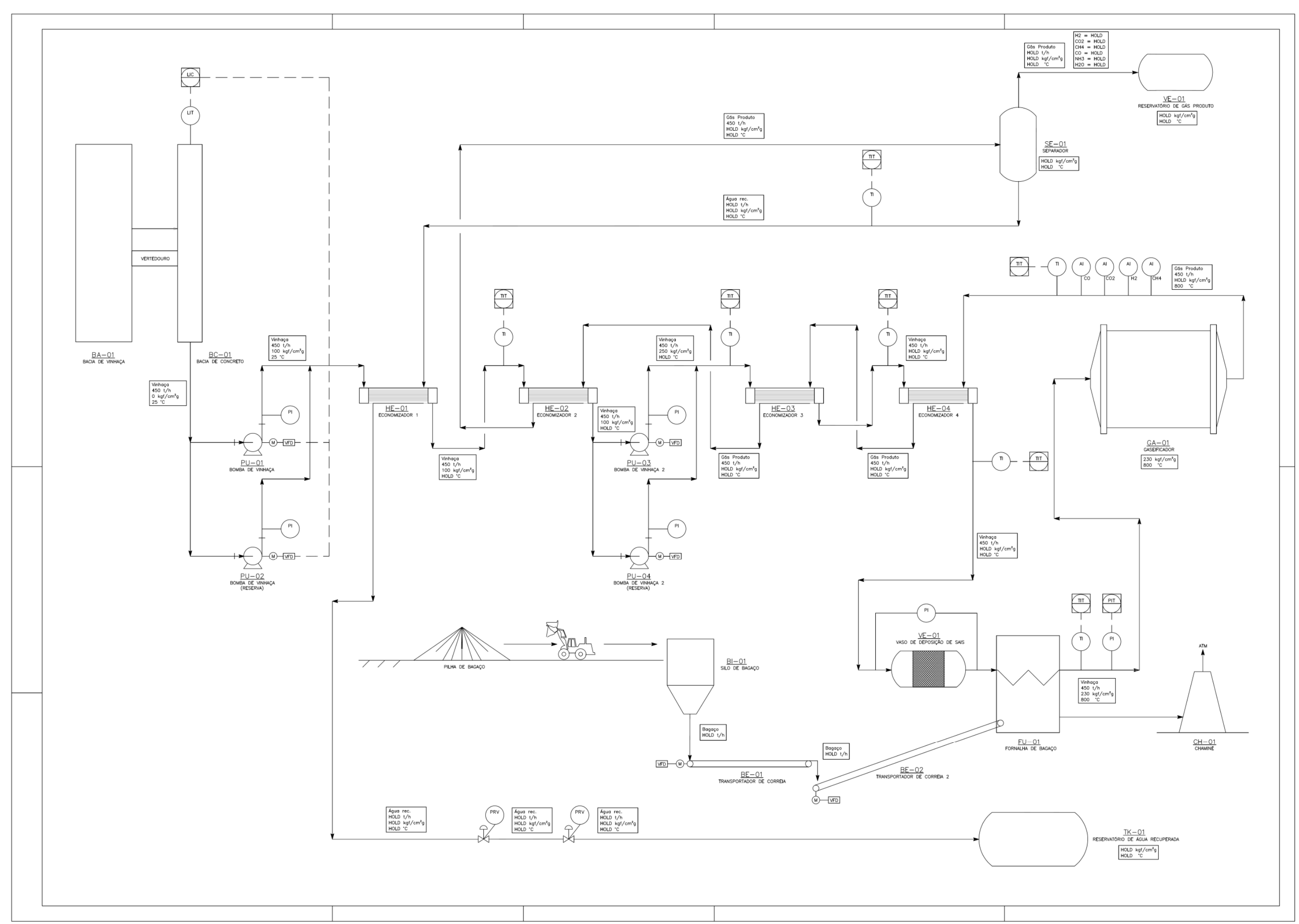




\section{RESULTADOS}

\subsection{Balanço de massa e energia do caso de projeto}

O software ASPEN Plus, utilizado para a simulação dos balanços de massa e energia, não possui um bloco nativo para a operação unitária de gaseificação. A caracterização do gaseificador foi realizada utilizando blocos de processo existentes no software, assim como realizado por Fiori; Valbusa e Castello(2012) e Kumaretal.(2009). O mesmo foi representado por uma combinação de reatores, um RYELD seguido por um RGIBBS. O bloco RGIBBS processa componentes simples, considerando o equilíbrio a partir da minimização da energia livre de Gibbs. Para as condições de operação definidas para o gaseificador $\left(800^{\circ} \mathrm{C}\right.$ e $\left.230 \mathrm{kgf} / \mathrm{cm}^{2} \mathrm{~g}\right)$, o equilíbrio é facilmente atingido em questão de minutos (KAMLER e SORIA, 2012), o que valida a premissa adotada.

Como a vinhaça contém uma fração orgânica, que poderia ser considerada como uma biomassa real, ela não consegue ser processada diretamente pelo bloco RGIBBS, que só funciona com moléculas simples. $O$ processamento da vinhaça para componentes menos complexos é realizado pelo bloco RYIELD, que atua como um reator de separação ou um devolatilizador, possibilitando a atuação do RGIBBS.

A vinhaça foi incluída no programa como um fluído determinado pelo usuário (user defined), já que o banco de dados do ASPEN Plus não possui informações relativas a biomassas em geral. Da mesma maneira que em Tang e Kitagawa (2005), considerou-se que as quantidades das espécies no equilíbrio poderiam ser aproximadas pelas reações 3.8, 3.9 e 3.10, sendo que a fórmula química considerada para a vinhaça em base seca é $\mathrm{C}_{0,0331} \mathrm{H}_{0,0860} \mathrm{~N}_{0,0012} \mathrm{O}_{0,0194}$, com uma massa molecular de $13,431 \mathrm{~g} / \mathrm{mol}$ 
(CORTEZ e PÉREZ, 1997). A contribuição do nitrogênio foi considerada na reação, formando $\mathrm{NH}_{3}$.

O método base selecionado para o modelo foi o de Soave-Redlich-Kwong (RK-SOAVE). Este modelo é geralmente utilizado para substâncias pouco polares, mas é particularmente indicado para altas temperaturas e pressões, como aplicações em estado supercrítico (TISDALE, 2004).

A Figura 9 mostra o esquema do módulo simulado em ASPEN Plus.

Figura 9: Simulação de gaseificação de vinhaça em água supercrítica.

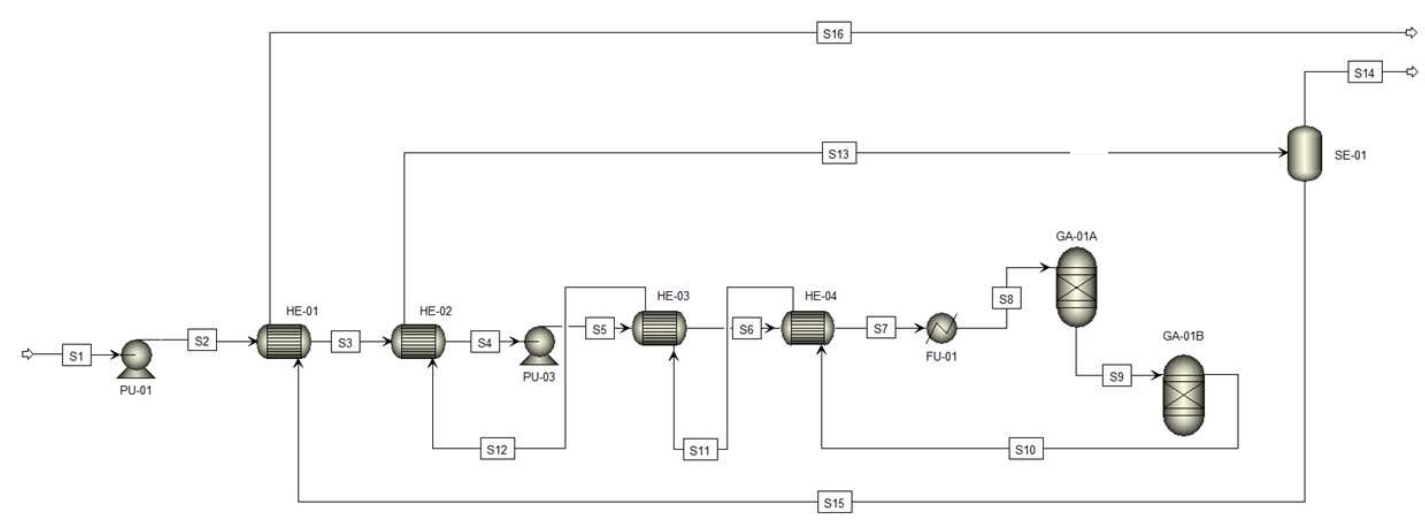

As condições de operação do gaseificador foram pré-determinadas pela autora com base na análise da literatura, de maneira a assegurar que em um pequeno tempo de residência, sem a necessidade de catalisadores, fossem atingidos os rendimentos previstos em literatura.

Para a separação dos componentes no bloco RYIELD foi utilizada a premissa de uma quebra da parte orgânica da vinhaça em $40 \%$ de $\mathrm{H}_{2}, 30 \%$ de $\mathrm{CO}_{2}, 10 \% \mathrm{CH}_{4}$ e $20 \%$ de $\mathrm{CO}$. O bloco RGIBBS, trabalha com a premissa de equilíbrio e foi condicionado a operar a $230 \mathrm{kgf} / \mathrm{cm}^{2}$ e $800^{\circ} \mathrm{C}$. Todos os equipamentos de troca de calor a montante do gaseificador (RYIELD + RGIBBS) foram então dimensionados para permitir que, em operação normal, essa condição fosse atingida. 
Os resultados da simulação, rodada a partir da Figura 8, encontram-se na Tabela 4.

Tabela 4: Resultados da simulação para o módulo de gaseificação de vinhaça em água.

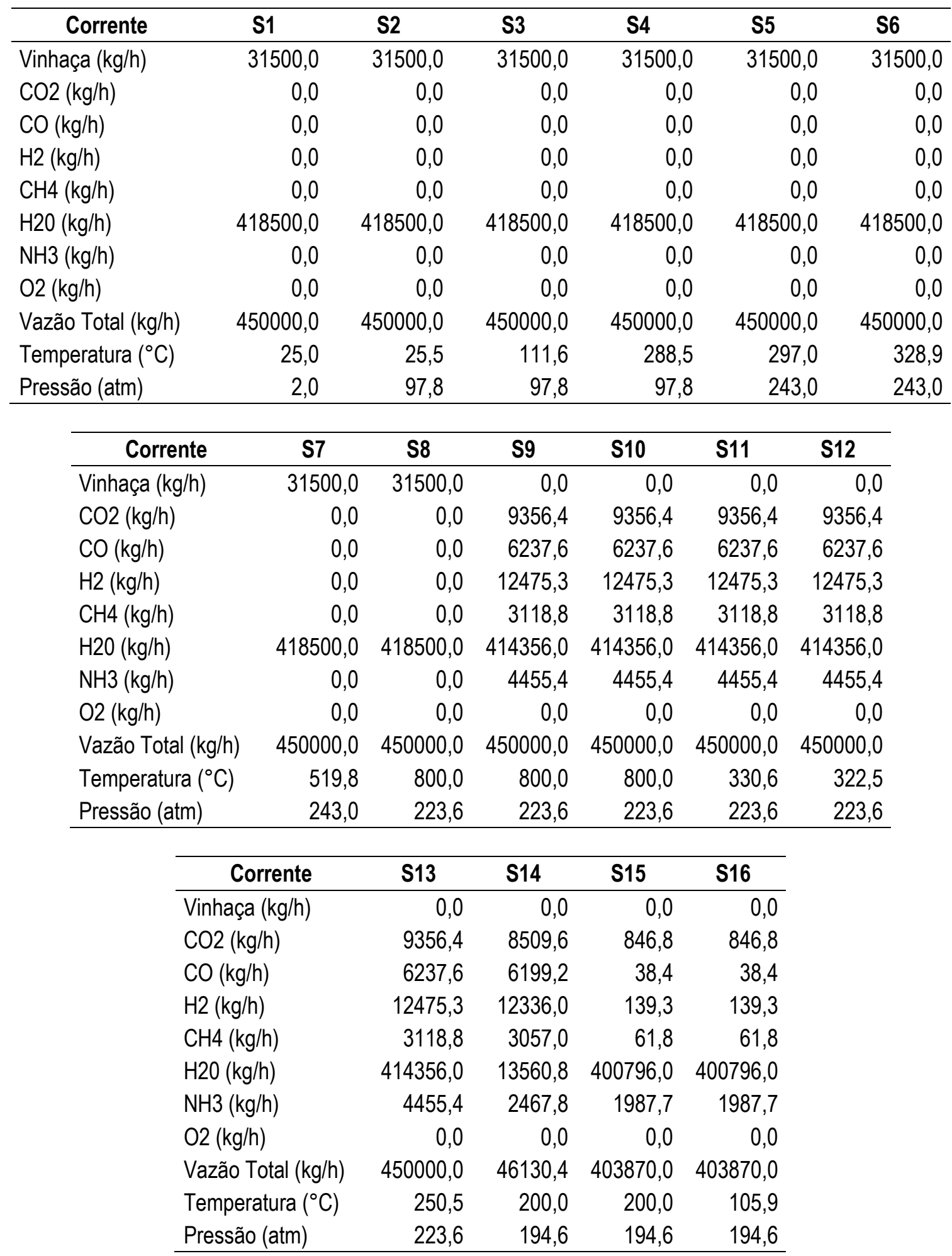


Com base nos resultados foi possível preencher as condições faltantes no fluxograma do módulo, indicadas com HOLD, conforme Figura 10. 
Figura 10: Fluxograma de Processo do sistema de Gaseificação de Vinhaça em Água Supercrítica proposto - completo.

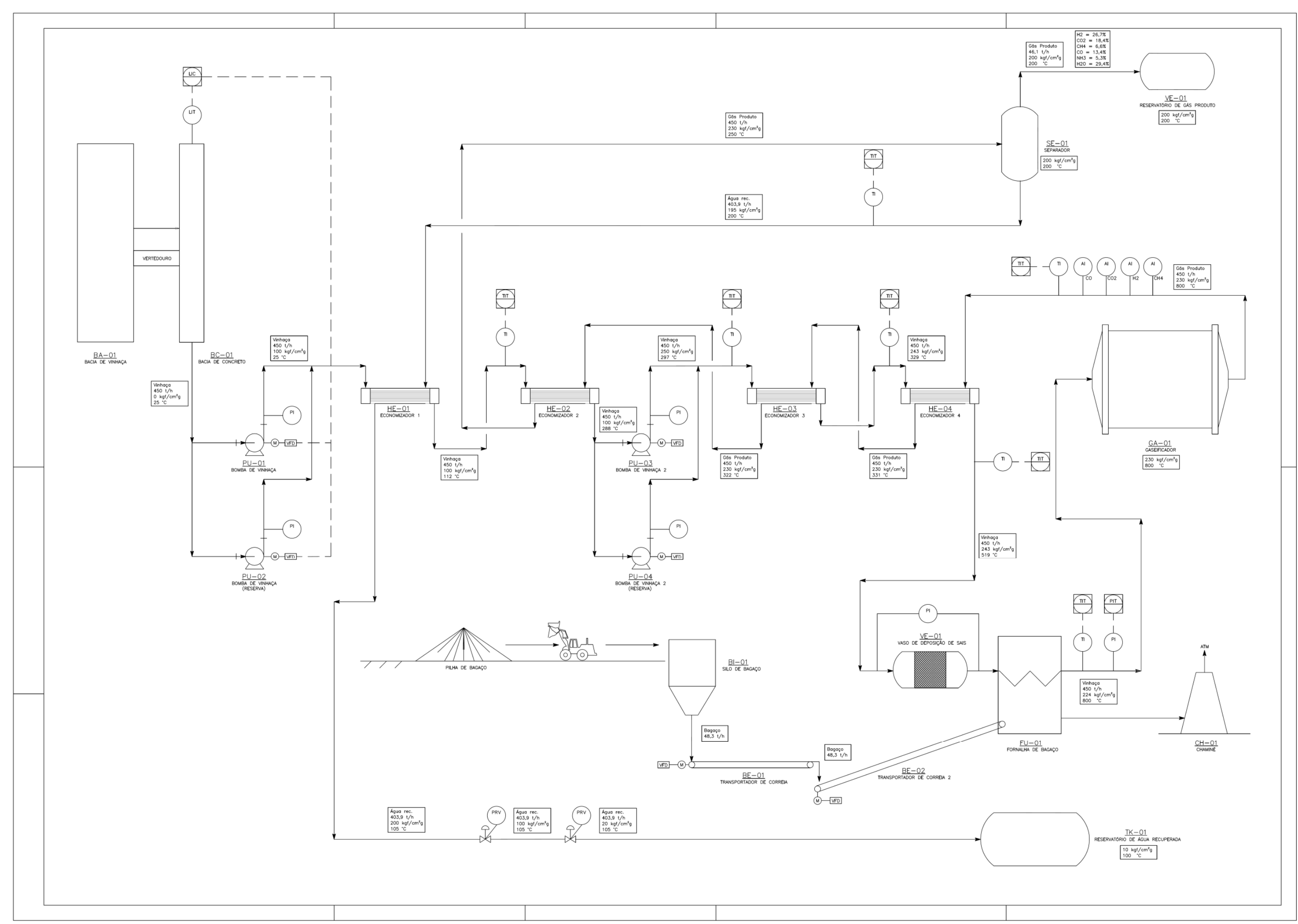




\subsection{Descrição dos equipamentos}

A seguir serão descritos os equipamentos pertencentes ao módulo de gaseificação de vinhaça em água supercrítica, com base nos resultados obtidos com a simulação.

\subsubsection{Bacia de vinhaça BA-01}

A bacia de vinhaça é basicamente uma lagoa de armazenamento revestida com polietileno de alta densidade. O revestimento previne a percolação do fluido pelo solo, o que poderia impactar em contaminação de lençóis freáticos e salinização do solo próximo ao armazenamento do fluido. $O$ volume da bacia foi definido como sendo de $9000 \mathrm{~m}^{3}$, de maneira a represar aproximadamente 20 horas de produção de vinhaça da usina padrão considerada como base para o sistema.

\subsubsection{Bacia de concreto BC-01}

A bacia de concreto consiste em um reservatório adjacente à lagoa, conectado a ela por meio de um vertedouro, de maneira que a vinhaça passe de uma para a outra por gravidade. Esse reservatório abrigará a sucção das primeiras bombas de vinhaça, que deverão ser auto escorvantes para conseguir captar o fluido na bacia e também deverá ser revestido em polietileno de alta densidade.

\subsubsection{Bombas de vinhaça PU-01/02/03/04}

O bombeamento de vinhaça foi dividido em dois estágios, de maneira a possibilitar o seu bombeamento ainda no estado líquido, mesmo com as etapas de aquecimento intermediário entre os estágios. As bombas são do tipo super alta pressão, com vazão determinada a partir da produção de uma usina de referência, de $450 \mathrm{t} / \mathrm{h}$. 
As bombas de vinhaça de primeiro estágio são do tipo auto escorvantes, devido ao posicionamento da sucção abaixo do nível de instalação das mesmas (dentro da bacia de concreto). As mesmas devem possuir uma tela de proteção na sucção, de maneira a evitar a captação de folhas ou sujeiras que possam estar na bacia de vinhaça. A bomba 01 opera e a bomba 02 é reserva. A pressão de descarga foi definida como sendo $100 \mathrm{kgf} / \mathrm{cm}^{2} \mathrm{~g}$, suficiente para que a água não saia do estado líquido após o primeiro estágio de aquecimento, posterior às bombas.

As bombas de vinhaça de segundo estágio são consideradas bombas booster, por complementar a pressão do fluido bombeado, elevando-o ao nível de pressão requerido no gaseificador, definido como $250 \mathrm{kgf} / \mathrm{cm}^{2}$. Essa pressão já contabiliza as perdas de carga do sistema, garantindo a pressão de $230 \mathrm{kgf} / \mathrm{cm}^{2}$ na chegada do gaseificador. A bomba 03 opera e a bomba 04 é reserva.

\subsubsection{Economizador HE-01}

O economizador HE-01 é o primeiro de uma série de economizadores inseridos no processo para aproveitar o calor dos produtos da gaseificação no pré-aquecimento da corrente de alimentação de vinhaça. Ele é um trocador do tipo casco e tubo, que recebe a vazão de 450 t/h de vinhaça nos tubos, em contracorrente com a água separada do gás produto. A alimentação da vinhaça acontece nos tubos por questões de manutenção e limpeza do equipamento, devido à alta concentração de sais presente na mesma. A vinhaça entra no trocador à temperatura ambiente e atinge os $112^{\circ} \mathrm{C}$ na saída do mesmo, trocando um calor de $45573 \mathrm{Gcal} / \mathrm{h}$ com a água sendo passada pelo casco. A água entra no trocador com $200^{\circ} \mathrm{C}$ e sai do mesmo com $106^{\circ} \mathrm{C}$.

\subsubsection{Economizador HE-02}

O economizador HE-02 está à jusante do HE-01 e também é do tipo casco e tubo. Ele eleva a temperatura da vinhaça a $288^{\circ} \mathrm{C}$, reduzindo a temperatura 
do gás produto que passa em contracorrente de $322^{\circ} \mathrm{C}$ para $250^{\circ} \mathrm{C}$. $\mathrm{O}$ gás produto alimentado a este equipamento já teve sua energia recuperada em dois outros estágios anteriores, e após essa etapa é encaminhado para o vaso separador de gás. O calor trocado no trocador é da ordem de $107277 \mathrm{Gcal} / \mathrm{h}$.

O aproveitamento da energia contida no gás produto não pode ser maior devido à necessidade de se manter a vinhaça no estado líquido (um aumento maior de temperatura poderia colocá-la na região gasosa ou até mesmo já na supercrítica).

\subsubsection{Economizadores HE-03/04}

Os economizadores HE-03/04 poderiam ter sido considerados como um único trocador de calor, mas, devido ao tamanho resultante do mesmo, optou-se pela divisão em etapas, obtendo-se assim dois equipamentos de menor porte. Os dois são trocadores de calor casco e tubo em contracorrente.

O economizador HE-03 está posicionado após o bombeamento de segundo estágio, no qual a vinhaça já se encontra na pressão de $250 \mathrm{kgf} / \mathrm{cm}^{2} \mathrm{~g}$. Ele aproveita a energia contida no gás produto logo após o primeiro aproveitamento de calor, possibilitando uma troca térmica de $25166 \mathrm{Gcal} / \mathrm{h}$. O gás produto passa pelo casco, entrando com a temperatura de $331^{\circ} \mathrm{C} \mathrm{e}$ saindo com $322^{\circ} \mathrm{C}$. A vinhaça é alimentada a $296^{\circ} \mathrm{C}$ nos tubos e ganha $32^{\circ} \mathrm{C}$ no percurso do equipamento, atingindo os $322^{\circ} \mathrm{C}$ na saída do mesmo.

O economizador HE-04 foi posicionado a jusante do HE-03, recebendo a vinhaça nos tubos e os gases no casco. A energia trocada corresponde a $176275 \mathrm{Gcal} / \mathrm{h}$, sendo que os gases saem a $331^{\circ} \mathrm{C}$ e a vinhaça a $519^{\circ} \mathrm{C}$. Esse trocador retira a maior parte da energia contida no gás produto, que sai do gaseificador a $800^{\circ} \mathrm{C}$. As etapas subsequentes de aproveitamento de 
energia (HE-03 e HE-02) tentam maximizar a utilização do calor contido no gás produto.

\subsubsection{Sistema de deposição de sais VE-01}

O sistema de deposição de sais está localizado após o último economizador, HE-04. A vinhaça nesse ponto já se encontra no estado supercrítico, o que favorece a deposição dos sais, que não estão no estado supercrítico nessa condição. O equipamento consiste em um vaso de recheio, no qual o recheio cerâmico dificulta a passagem do fluido para a próxima etapa do processo, retendo as partículas de sal em si. O mesmo é dotado de um sistema de medição de pressão diferencial, que alerta para altos níveis de perda de carga no sistema, que implicam em paradas para limpeza do recheio. O sal retirado é armazenado e pode ser vendido posteriormente, por conter altos teores de minerais como potássio, fósforo e magnésio.

\subsubsection{Fornalha de bagaço FU-01}

Após o último estágio de aquecimento, a vinhaça já se encontra na temperatura de $519^{\circ} \mathrm{C}$, restando $281^{\circ} \mathrm{C}$ para que a mesma atinja a temperatura de gaseificação definida, $800^{\circ} \mathrm{C}$. Essa diferença de temperaturas representa uma energia de $87301 \mathrm{Gcal} / \mathrm{h}$, que é obtida na fornalha de bagaço. A mesma queima 48,3t/h de bagaço para fornecer a energia necessária.

\subsubsection{Sistema de alimentação de bagaço e chaminé BI-01, BE-01/02 e $\mathrm{CH}-01$}

A fornalha de bagaço requer uma vazão de 48,3t/h de bagaço para fornecer o calor necessário à vinhaça. Para tal, foi envisionado um sistema simples, contendo uma moega (BI-01) e dois transportadores de correia (BE-01/02) aptos a transportar a quantidade requerida pela fornalha. A moega possui um volume de $400 \mathrm{~m}^{3}$, correspondente a um tempo de residência de 1 hora. 
Na saída da fornalha uma chaminé simples $(\mathrm{CH}-01)$ garante a dispersão dos gases exaustos da queima do bagaço.

\subsubsection{Gaseificador GA-01}

O gaseificador é o equipamento central da planta. Nele ocorrem as reações de pirólise, combustão e gaseificação que irão transformar os orgânicos presentes na vinhaça em uma mistura gasosa contendo monóxido de carbono, dióxido de carbono, metano e hidrogênio. O gaseificador opera a uma pressão de $250 \mathrm{kgf} / \mathrm{cm}^{2} \mathrm{~g}$ e uma temperatura de $800^{\circ} \mathrm{C}$. Ele processa uma vazão de $450 \mathrm{t} / \mathrm{h}$ de vinhaça. Seu comportamento foi determinado com base em um modelo misto, englobando aspectos cinéticos e de equilíbrio citados anteriormente neste trabalho.

\subsubsection{Separador SE-01}

O separador SE-01 está posicionado após o último economizador de gás, o $\mathrm{HE}-02$. Ele opera numa condição de $200 \mathrm{kgf} / \mathrm{cm}^{2}$ e $200^{\circ} \mathrm{C}$. Nessas condições a água está no estado líquido, o que permite a sua separação do gás produto. A vazão de saída de gás é de $46,1 \mathrm{t} / \mathrm{h}$ e a vazão de água recuperada é de 403,9 t/h. Não foi possível separar todo o gás da água, pois uma fração vapor se manteve na corrente gasosa.

\subsubsection{Vaso de armazenamento de gás produto VE-01}

O vaso de armazenamento de gás produto possui uma capacidade de $400 \mathrm{~m}^{3}$, suficiente para armazenar 15 minutos de produção do gás a $200 \mathrm{kgf} / \mathrm{cm}^{2}$ e $200^{\circ} \mathrm{C}$.

\subsubsection{Tanque de água recuperada TK-01 e válvulas redutoras de pressão}

O tanque TK-01 armazena a água recuperada, que pode ser reutilizada na usina. As condições de armazenamento da água no tanque são de $10 \mathrm{kgf} / \mathrm{cm}^{2} \mathrm{~g}$ e $100^{\circ} \mathrm{C}$ e seu volume é de $10000 \mathrm{~m}^{3}$, garantindo um tempo de 
residência de aproximadamente 22 horas. As válvulas redutoras de pressão servem para reduzir a pressão de saída do economizador HE-01 e garantir a chegada da mesma no tanque em níveis de pressão que não impliquem em grandes gastos com material (maiores espessuras), posto que este tanque possui um volume razoável.

\subsection{Lista de equipamentos}

A Tabela 5 mostra uma lista de equipamentos, com todas as características dos equipamentos dimensionados para o módulo de gaseificação de vinhaça em água supercrítica.

Tabela 5: Lista de Equipamentos com as principais características dos equipamentos do módulo de gaseificação de vinhaça em água supercrítica.

\begin{tabular}{ccc}
\hline Tag & Descrição & Características \\
\hline BA-01 & Bacia de Vinhaça & $\begin{array}{c}\text { Revestimento de PEAD } \\
\text { Volume: } 9000 \mathrm{~m}^{3}\end{array}$ \\
\hline BC-01 & Bacia de Concreto & Revestimento de PEAD \\
Volume: $400 \mathrm{~m}^{3}$
\end{tabular}




\begin{tabular}{|c|c|c|}
\hline HE-01 & Economizador 1 & $\begin{array}{l}\text { Carga térmica: } 4,56 \mathrm{e}+07 \mathrm{kcal} / \mathrm{h} \\
\text { Temperatura de entrada - lado casco: } 200^{\circ} \mathrm{C} \\
\text { Temperatura de saída - lado casco: } 105,9^{\circ} \mathrm{C} \\
\text { Temperatura de entrada - lado tubo: } 25,5^{\circ} \mathrm{C} \\
\text { Temperatura de saída - lado tubo: } 111,6^{\circ} \mathrm{C}\end{array}$ \\
\hline HE-02 & Economizador 2 & $\begin{array}{c}\text { Carga térmica: } 1,07 \mathrm{e}+08 \mathrm{kcal} / \mathrm{h} \\
\text { Temperatura de entrada - lado casco: } 322,5^{\circ} \mathrm{C} \\
\text { Temperatura de saída - lado casco: } 250,5^{\circ} \mathrm{C} \\
\text { Temperatura de entrada - lado tubo: } 111,6^{\circ} \mathrm{C} \\
\text { Temperatura de saída - lado tubo: } 288,5^{\circ} \mathrm{C}\end{array}$ \\
\hline HE-03 & Economizador 3 & $\begin{array}{c}\text { Carga térmica: } 2,5 \mathrm{e}+07 \mathrm{kcal} / \mathrm{h} \\
\text { Temperatura de entrada - lado casco: } 330,6^{\circ} \mathrm{C} \\
\text { Temperatura de saída - lado casco: } 322,5^{\circ} \mathrm{C} \\
\text { Temperatura de entrada - lado tubo: } 296,9^{\circ} \mathrm{C} \\
\text { Temperatura de saída - lado tubo: } 328,9^{\circ} \mathrm{C}\end{array}$ \\
\hline HE-03 & Economizador 4 & $\begin{array}{l}\text { Carga térmica: } 1,7 \mathrm{e}+08 \mathrm{kcal} / \mathrm{h} \\
\text { Temperatura de entrada - lado casco: } 800^{\circ} \mathrm{C} \\
\text { Temperatura de saída - lado casco: } 330,6^{\circ} \mathrm{C} \\
\text { Temperatura de entrada - lado tubo: } 328,9^{\circ} \mathrm{C} \\
\text { Temperatura de saída - lado tubo: } 519,8^{\circ} \mathrm{C}\end{array}$ \\
\hline GA-01 & Gaseificador & $\begin{array}{l}\text { Temperatura de operação: } 800^{\circ} \mathrm{C} \\
\text { Pressão de operação: } 230 \mathrm{~kg} / \mathrm{cm}^{2} \mathrm{~g}\end{array}$ \\
\hline SE-01 & Separador & $\begin{array}{l}\text { Temperatura de operação: } 200^{\circ} \mathrm{C} \\
\text { Pressão de operação: } 200 \mathrm{kgf} / \mathrm{cm}^{2} \mathrm{~g}\end{array}$ \\
\hline VE-01 & Reservatório de Gás Produto & $\begin{array}{c}\text { Capacidade: } 400 \mathrm{~m}^{3} \\
\text { Temperatura de operação: } 200^{\circ} \mathrm{C} \\
\text { Pressão de operação: } 200 \mathrm{~kg} / \mathrm{cm}^{2} \mathrm{~g}\end{array}$ \\
\hline TK-01 & Reservatório de Água Recuperada & $\begin{array}{l}\text { Capacidade: } 10000 \mathrm{~m}^{3} \\
\text { Temperatura de operação: } 100^{\circ} \mathrm{C} \\
\text { Pressão de operação: } 10 \mathrm{kgf} / \mathrm{cm}^{2} \mathrm{~g}\end{array}$ \\
\hline $\mathrm{BI}-01$ & Silo de Bagaço & $\begin{array}{c}\text { Capacidade: } 405 \mathrm{~m}^{3} \\
\text { Tempo de residência: } 1 \mathrm{~h}\end{array}$ \\
\hline BE-01 & Transportador de Correia & $\begin{array}{c}\text { Capacidade: } 405 \mathrm{~m}^{3} / \mathrm{h}(48,3 \mathrm{t} / \mathrm{h}) \\
\text { Potência: } 185 \mathrm{~kW} \\
\end{array}$ \\
\hline BE-02 & Transportador de Correia 2 & $\begin{array}{c}\text { Capacidade: } 405 \mathrm{~m}^{3} / \mathrm{h}(48,3 \mathrm{t} / \mathrm{h}) \\
\text { Potência: } 185 \mathrm{~kW}\end{array}$ \\
\hline FU-01 & Fornalha de Bagaço & $\begin{array}{l}\text { Carga térmica: } 8,7 \mathrm{e}+07 \mathrm{kcal} / \mathrm{h} \\
\text { Capacidade: } 405 \mathrm{~m}^{3} / \mathrm{h} \text { (bagaço) }\end{array}$ \\
\hline VE-01 & Vaso de Deposição de Sais & Vazão de operação: 450t/h \\
\hline $\mathrm{CH}-01$ & Chaminé & Altura: $20 \mathrm{~m}$ \\
\hline
\end{tabular}




\subsection{Estimativas de Custo}

\subsubsection{CAPEX}

O levantamento de preços para a estimativa de custo/ composição do CAPEX foi realizado com base em propostas orçamentárias de fornecedores e extrapolações de banco de dados particulares.

A estimativa para o módulo de gaseificação pode ser enquadrada na Classe 4 da AACE, conforme Tabela 3. Podem ser destacadas as seguintes características primárias e secundárias resultantes desta definição:

- Nível de definição do projeto (em termos de definição completa): entre 0 e $2 \%$;

- Propósito da estimativa (uso final): estudo ou viabilidade;

- Metodologia utilizada na estimativa: equipamentos consignados/ modelos paramétricos;

- Range de acurácia esperado na estimativa: no nível baixo de -15\% a $30 \%$, no nível alto de $+20 \%$ a $+50 \%$.

Os valores considerados para cada equipamento encontram-se na Tabela 6. 
Tabela 6: Estimativa de custo para os equipamentos do módulo de gaseificação de vinhaça em água supercrítica.

\begin{tabular}{llr}
\hline Tag & Descrição & Custo Estimado \\
\hline BA-01 & Bacia de Vinhaça & $\mathrm{R} \$ 1.950 .000,00$ \\
\hline BC-01 & Bacia de Concreto & $\mathrm{R} \$ 1.098 .224,00$ \\
\hline PU-01 & Bomba de Vinhaça & $\mathrm{R} \$ 387.000,00$ \\
\hline PU-02 & Bomba de Vinhaça (Reserva) & $\mathrm{R} \$ 387.000,00$ \\
\hline PU-03 & Bomba de Vinhaça 2 & $\mathrm{R} \$ 387.000,00$ \\
\hline PU-04 & Bomba de Vinhaça 2 (Reserva) & $\mathrm{R} \$ 387.000,00$ \\
\hline HE-01 & Economizador 1 & $\mathrm{R} \$ 628.333,00$ \\
\hline HE-02 & Economizador 2 & $\mathrm{R} \$ 1.208 .333,00$ \\
\hline HE-03 & Economizador 3 & $\mathrm{R} \$ 1.450 .000,00$ \\
\hline HE-03 & Economizador 4 & $\mathrm{R} \$ 1.772 .222,00$ \\
\hline GA-01 & Gaseificador & $\mathrm{R} \$ 1.098 .224,00$ \\
\hline SE-01 & Separador & $\mathrm{R} \$ 1.098 .224,00$ \\
\hline VE-01 & Reservatório de Gás Produto & $\mathrm{R} \$ 1.098 .224,00$ \\
\hline TK-01 & Reservatório de Água Recuperada & $\mathrm{R} \$ 1.950 .000,00$ \\
\hline BI-01 & Silo de Bagaço & $\mathrm{R} \$ 148.500,00$ \\
\hline BE-01 & Transportador de Correia & $\mathrm{R} \$ 35.580,00$ \\
\hline BE-02 & Transportador de Correia 2 & $\mathrm{R} \$ 35.580,00$ \\
\hline FU-01 & Fornalha de Bagaço & $\mathrm{R} \$ 500.000,00$ \\
\hline VE-01 & Vaso de Deposição de Sais & $\mathrm{R} \$ 1.000 .000,00$ \\
\hline CH-01 & Chaminé & $\mathrm{R} \$ 200.000,00$ \\
\hline Custo Total com Equipamentos & $\mathrm{R} \$ 16.819 .445,00$ \\
\hline
\end{tabular}

Com base no custo total com equipamentos, foi estimado o custo do projeto como um todo, utilizando o fator de Lang de 4,74, que é comum para plantas de processamento de fluidos. O mesmo resultou em $\mathrm{R} \$ 79.724 .169,00$ ou $\$$ 19.931.042,00 dólares (cotação aproximada de $\$ 4,00$ para cada real), com uma acurácia de $+50 \% /-30 \%$. 


\subsubsection{OPEX}

A estimativa de OPEX para o módulo de gaseificação de vinhaça em água supercrítica foi realizada com base em seis grandes categorias de custos, comumente consideradas em projetos de engenharia. As mesmas englobam custos com funcionários, insumos, energia, manutenção, aluguel de equipamentos e até mesmo serviços terceirizados.

Os valores obtidos para manutenção e serviços terceirizados foram obtidos a partir de percentuais de $0,5 \%$ e $0,1 \%$ do CAPEX ao ano, respectivamente.

O valor obtido para funcionários considerou um operador e um encarregado trabalhando em cada turno, sendo que o módulo operaria em dois turnos. Os valores de salário médio e custo de aluguel da pá carregadeira foram obtidos em um banco de dados particular, atualizado em dezembro de 2015.

Os custos com insumos foram estimados a partir da vazão de bagaço requerida no balanço do módulo, sendo que o valor usado por tonelada de bagaço é o resultado de uma média de três fornecedores do estado de São Paulo. O frete já está incluído no preço.

Os custos com energia foram estimados com base na tarifa obtida pelo governo no leilão de energia existente $(A-1)^{[11]}$, de dezembro de 2015 , e a potência contratada foi extrapolada a partir de uma estimativa de consumo do módulo como um todo.

Todos os custos supracitados estão indicados na Tabela 7, assim como a estimativa de CAPEX obtida para o módulo de gaseificação de vinhaça em água supercrítica.

\footnotetext{
${ }^{11}$ http://economia.uol.com.br/noticias/reuters/2015/12/11/leilao-contrata-1954-mw-medios-e-ajudagoverno-a-reduzir-custos-de-energia.htm
} 
Tabela 7: Estimativa de OPEX do módulo de gaseificação de vinhaça em água supercrítica.

\begin{tabular}{|c|c|c|}
\hline \multirow{5}{*}{ Funcionários } & Número de profissionais trabalhando & 2 \\
\hline & Número de turnos & 2 \\
\hline & $\begin{array}{l}\text { Custo salarial anual médio - operador/ } \\
\text { encarregado }(\mathrm{R} \$)\end{array}$ & 54000,00 \\
\hline & Custo de transporte/ alimentaçãp ( $R \$ / p e s s o a / d i a)$ & 35,00 \\
\hline & Custo total com funcionários (R\$/ano) & 241550,00 \\
\hline Manutenção & Custos com manutenção/ materiais (R\$/ano) & 398620,85 \\
\hline \multirow{3}{*}{ Insumos } & Consumo de bagaço (t/d) & 1159,20 \\
\hline & Custo do bagaço $(\mathrm{R} \$ / \mathrm{t})$ & 50,00 \\
\hline & Custos com insumos (R\$/ano) & 19462968,00 \\
\hline \multirow{3}{*}{$\begin{array}{l}\text { Aluguel de } \\
\text { equipamentos }\end{array}$} & Tempo de aluguel (h) & 8760 \\
\hline & Custo do aluguel + combustível $(R \$ / h)$ & 60,00 \\
\hline & Custo com pá carregadeira (R\$/ano) & 525600,00 \\
\hline $\begin{array}{l}\text { Serviços } \\
\text { terceirizados }\end{array}$ & Custos com serviços terceirizados ( $\mathrm{R} \$ / \mathrm{ano}$ ) & 79724,17 \\
\hline \multirow{4}{*}{ Energia } & Custo da energia (R\$/MWh) & 150,00 \\
\hline & Consumo estimado para a planta (MW) & 6,0 \\
\hline & Demanda contratada da planta (MW) & 10,0 \\
\hline & Custos com energia (R\$/ano) & 12088800,00 \\
\hline OPEX & OPEX total (R\$/ano) & 32797263,00 \\
\hline
\end{tabular}

Temos então que os custos anuais com a operação do módulo de gaseificação de vinhaça em água supercrítica resultariam em aproximadamente 32,8 milhões de reais.

Outro aspecto que poderia ser considerado, é a receita com a venda do gás produto e da água recuperada. O valor usualmente considerado em projetos para a compra/ recuperação simples de água é de $R \$ 3,00 / \mathrm{m}^{3}$, enquanto o preço do gás de síntese pode ser considerado como $R \$ 0,56 / \mathrm{m}^{3[12]}$.

\footnotetext{
12 http://asia-irpr.com/sinocoking-aboveground-facility-operating-at-100-capacity-and-generating25000-cubic-meters-of-syngas-per-hour/
} 


\subsection{Análise de Sensibilidade}

\subsubsection{Impactos no OPEX}

A fim de analisar a sensibilidade das estimativas realizadas para o módulo com relação aos custos de operação (OPEX), foram realizadas duas novas simulações para o módulo, variando os seguintes aspectos operacionais:

- Temperatura de operação no gaseificador;

- Teor de sólidos da vinhaça alimentada no sistema.

Não foi avaliada nenhuma alteração de CAPEX decorrente da modificação das características citadas. Considerou-se que o módulo de gaseificação continuaria projetado para a condição pré-determinada (condição de projeto de $800^{\circ} \mathrm{C}, 230 \mathrm{kgf} / \mathrm{cm}^{2} \mathrm{~g}$ para uma vinhaça alimentada com $7 \%$ de sólidos), mas que o mesmo poderia operar em condições diferentes das projetadas.

Para a primeira simulação foi considerada uma temperatura de operação de $600^{\circ} \mathrm{C}$. A variação na temperatura não implica em modificações nas correntes relacionadas à vinhaça, já que os rendimentos no gaseificador se mantêm. Operacionalmente, tal variação poderia implicar na necessidade de um maior tempo de residência da vinhaça no gaseificador, para garantir que o equilíbrio seja atingido. O maior impacto da diminuição da temperatura se dá no sistema da fornalha e seus componentes. Como a nova requisição de temperatura exige um menor aquecimento na fornalha, os consumos de bagaço diminuirão assim como a potência nos transportadores de correia que alimentam o mesmo à fornalha.

A Tabela 8 mostra os resultados de balanço de massa/ energia para este caso. 
Tabela 8: Resultados da simulação para o módulo de gaseificação de vinhaça em água supercrítica com a temperatura de operação de $600^{\circ} \mathrm{C}$ no gaseificador.

\begin{tabular}{|c|c|c|c|c|c|c|}
\hline Corrente & S1 & S2 & S3 & S4 & S5 & S6 \\
\hline Vinhaça (kg/h) & 31500,0 & 31500,0 & 31500,0 & 31500,0 & 31500,0 & 31500,0 \\
\hline $\mathrm{CO} 2(\mathrm{~kg} / \mathrm{h})$ & 0,0 & 0,0 & 0,0 & 0,0 & 0,0 & 0,0 \\
\hline $\mathrm{CO}(\mathrm{kg} / \mathrm{h})$ & 0,0 & 0,0 & 0,0 & 0,0 & 0,0 & 0,0 \\
\hline $\mathrm{H} 2$ (kg/h) & 0,0 & 0,0 & 0,0 & 0,0 & 0,0 & 0,0 \\
\hline $\mathrm{CH} 4$ (kg/h) & 0,0 & 0,0 & 0,0 & 0,0 & 0,0 & 0,0 \\
\hline $\mathrm{H} 20$ (kg/h) & 418500,0 & 418500,0 & 418500,0 & 418500,0 & 418500,0 & 418500,0 \\
\hline $\mathrm{NH} 3(\mathrm{~kg} / \mathrm{h})$ & 0,0 & 0,0 & 0,0 & 0,0 & 0,0 & 0,0 \\
\hline $\mathrm{O} 2$ (kg/h) & 0,0 & 0,0 & 0,0 & 0,0 & 0,0 & 0,0 \\
\hline Vazão Total (kg/h) & 450000,0 & 450000,0 & 450000,0 & 450000,0 & 450000,0 & 450000,0 \\
\hline Temperatura $\left({ }^{\circ} \mathrm{C}\right)$ & 25,0 & 25,5 & 111,6 & 280,2 & 287,8 & 323,3 \\
\hline Pressão (atm) & 2,0 & 97,8 & 97,8 & 97,8 & 243,0 & 243,0 \\
\hline Corrente & S7 & S8 & S9 & S10 & S11 & $\mathrm{S} 12$ \\
\hline Vinhaça (kg/h) & 31500,0 & 31500,0 & 0,0 & 0,0 & 0,0 & 0,0 \\
\hline $\mathrm{CO} 2(\mathrm{~kg} / \mathrm{h})$ & 0,0 & 0,0 & 9356,4 & 9356,4 & 9356,4 & 9356,4 \\
\hline $\mathrm{CO}(\mathrm{kg} / \mathrm{h})$ & 0,0 & 0,0 & 6237,6 & 6237,6 & 6237,6 & 6237,6 \\
\hline $\mathrm{H} 2$ (kg/h) & 0,0 & 0,0 & 12475,3 & 12475,3 & 12475,3 & 12475,3 \\
\hline $\mathrm{CH} 4(\mathrm{~kg} / \mathrm{h})$ & 0,0 & 0,0 & 3118,8 & 3118,8 & 3118,8 & 3118,8 \\
\hline $\mathrm{H} 20$ (kg/h) & 418500,0 & 418500,0 & 414356,0 & 414356,0 & 414356,0 & 414356,0 \\
\hline NH3 (kg/h) & 0,0 & 0,0 & 4455,4 & 4455,4 & 4455,4 & 4455,4 \\
\hline $\mathrm{O} 2$ (kg/h) & 0,0 & 0,0 & 0,0 & 0,0 & 0,0 & 0,0 \\
\hline Vazão Total (kg/h) & 450000,0 & 450000,0 & 450000,0 & 450000,0 & 450000,0 & 450000,0 \\
\hline Temperatura $\left({ }^{\circ} \mathrm{C}\right)$ & 408,7 & 600,0 & 600,0 & 600,0 & 325,1 & 314,6 \\
\hline Pressão (atm) & 243,0 & 223,6 & 223,6 & 223,6 & 223,6 & 223,6 \\
\hline \multicolumn{2}{|c|}{ Corrente } & $\mathrm{S} 13$ & S14 & S15 & $S 16$ & \\
\hline \multicolumn{2}{|c|}{ Vinhaça (kg/h) } & 0 & 0 & 0 & 0 & \\
\hline \multicolumn{2}{|c|}{ CO2 $(\mathrm{kg} / \mathrm{h})$} & 9356,4 & 8509,6 & 846,8 & 846,8 & \\
\hline \multicolumn{2}{|c|}{$\mathrm{CO}(\mathrm{kg} / \mathrm{h})$} & 6237,6 & 6199,2 & 38,4 & 38,4 & \\
\hline $\mathrm{H} 2(\mathrm{~kg} / \mathrm{h})$ & & 12475,3 & 12336,0 & 139,3 & 139,3 & \\
\hline $\mathrm{CH} 4(\mathrm{~kg} /$ & & 3118,8 & 3057,0 & 61,8 & 61,8 & \\
\hline $\mathrm{H} 20(\mathrm{~kg} / \mathrm{l}$ & & 414356,0 & 13560,8 & 400796,0 & 400796,0 & \\
\hline $\mathrm{NH} 3(\mathrm{~kg} /$ & & 4455,4 & 2467,8 & 1987,7 & 1987,7 & \\
\hline $\mathrm{O} 2(\mathrm{~kg} / \mathrm{h}$ & & 0 & 0 & 0 & 0 & \\
\hline Vazão Tc & $(\mathrm{kg} / \mathrm{h})$ & 450000,0 & 46130,4 & 403870,0 & 403870,0 & \\
\hline Tempera & $\left({ }^{\circ} \mathrm{C}\right)$ & 236,0 & 200,0 & 200,0 & 105,9 & \\
\hline Pressão & & 223,6 & 194,6 & 194,6 & 194,6 & \\
\hline
\end{tabular}


Pela análise da Tabela 8, pode-se confirmar que o balanço de massa não foi alterado, quando em comparação a simulação de projeto (Tabela 4). A principal alteração no circuito se dá na fornalha, que agora precisa elevar a temperatura da vinhaça de $408,7^{\circ} \mathrm{C}$ para $600^{\circ} \mathrm{C}$, o que representa uma carga térmica de 78,1 Gcal/h. Para tal, são alimentadas 43,4 t/h de bagaço ao sistema, aproximadamente $5 \mathrm{t} / \mathrm{h}$ a menos que na condição de projeto. $\mathrm{O}$ OPEX como um todo foi avaliado, resultando em uma diferença de quase 2 milhões de reais por ano, relativa à diminuição do consumo de bagaço. $A$ nova estimativa de OPEX encontra-se na Tabela 9.

Tabela 9: Estimativa de OPEX do módulo de gaseificação de vinhaça em água supercrítica com a temperatura de operação de $600^{\circ} \mathrm{C}$ no gaseificador.

\begin{tabular}{|c|c|c|}
\hline \multirow{5}{*}{ Funcionários } & Número de profissionais trabalhando & 2 \\
\hline & Número de turnos & 2 \\
\hline & $\begin{array}{c}\text { Custo salarial anual médio - operador/ } \\
\text { encarregado (R\$) }\end{array}$ & 54000,00 \\
\hline & Custo de transporte/ alimentaçãp ( $R \$ / p e s s o a / d i a)$ & 35,00 \\
\hline & Custo total com funcionários ( $\mathrm{R} \$ / \mathrm{ano})$ & 241550,00 \\
\hline Manutenção & Custos com manutenção/ materiais (R\$/ano) & 398620,85 \\
\hline \multirow{3}{*}{ Insumos } & Consumo de bagaço $(t / d)$ & 1041,60 \\
\hline & Custo do bagaço $(\mathrm{R} \$ / \mathrm{t})$ & 50,00 \\
\hline & Custos com insumos (R\$/ano) & 17488464,00 \\
\hline \multirow{3}{*}{$\begin{array}{l}\text { Aluguel de } \\
\text { equipamentos }\end{array}$} & Tempo de aluguel $(\mathrm{h})$ & 8760 \\
\hline & Custo do aluguel + combustível $(R \$ / h)$ & 60,00 \\
\hline & Custo com pá carregadeira (R\$/ano) & 525600,00 \\
\hline $\begin{array}{l}\text { Serviços } \\
\text { terceirizados }\end{array}$ & Custos com serviços terceirizados ( $\mathrm{R} \$$ /ano) & 79724,17 \\
\hline \multirow{4}{*}{ Energia } & Custo da energia $(\mathrm{R} \$ / \mathrm{MWh})$ & 150,00 \\
\hline & Consumo estimado para a planta (MW) & 6,0 \\
\hline & Demanda contratada da planta (MW) & 10,0 \\
\hline & Custos com energia (R\$/ano) & 12088800,00 \\
\hline OPEX & OPEX total (R\$/ano) & 30822759,01 \\
\hline
\end{tabular}

Logo, a variação de temperatura para $600^{\circ} \mathrm{C}$ apresenta uma vantagem em termos de OPEX. 
A segunda variação do caso de operação, executada para fins de análise de sensibilidade no OPEX, contou com a variação na porcentagem de sólidos presentes na vinhaça alimentada. A quantidade foi alterada de $7 \%$ para $12 \%$. Essa variação poderia ocorrer por modificações nos parâmetros de processo da usina fornecendo a vinhaça. Os resultados da simulação para a condição de vinhaça mais concentrada encontram-se na Tabela 10.

Tabela 10: Resultados da simulação para o módulo de gaseificação de vinhaça em água supercrítica para vinhaça com $12 \%$ de concentração de sólidos.

\begin{tabular}{|c|c|c|c|c|c|c|}
\hline Corrente & S1 & S2 & S3 & S4 & S5 & S6 \\
\hline Vinhaça (kg/h) & 54000,0 & 54000,0 & 54000,0 & 54000,0 & 54000,0 & 54000,0 \\
\hline CO2 (kg/h) & 0,0 & 0,0 & 0,0 & 0,0 & 0,0 & 0,0 \\
\hline $\mathrm{CO}(\mathrm{kg} / \mathrm{h})$ & 0,0 & 0,0 & 0,0 & 0,0 & 0,0 & 0,0 \\
\hline $\mathrm{H} 2(\mathrm{~kg} / \mathrm{h})$ & 0,0 & 0,0 & 0,0 & 0,0 & 0,0 & 0,0 \\
\hline $\mathrm{CH} 4(\mathrm{~kg} / \mathrm{h})$ & 0,0 & 0,0 & 0,0 & 0,0 & 0,0 & 0,0 \\
\hline H2O (kg/h) & 396000,0 & 396000,0 & 396000,0 & 396000,0 & 396000,0 & 396000,0 \\
\hline $\mathrm{NH} 3(\mathrm{~kg} / \mathrm{h})$ & 0,0 & 0,0 & 0,0 & 0,0 & 0,0 & 0,0 \\
\hline $\mathrm{O} 2$ (kg/h) & 0,0 & 0,0 & 0,0 & 0,0 & 0,0 & 0,0 \\
\hline Vazão Total (kg/h) & 450000,0 & 450000,0 & 450000,0 & 450000,0 & 450000,0 & 450000,0 \\
\hline Temperatura $\left({ }^{\circ} \mathrm{C}\right)$ & 25,0 & 25,5 & 110,5 & 284,2 & 292,6 & 327,6 \\
\hline Pressão (atm) & 2,0 & 97,8 & 97,8 & 97,8 & 243,0 & 243,0 \\
\hline Corrente & S7 & S8 & s9 & S10 & S11 & S12 \\
\hline Vinhaça (kg/h) & 54000,0 & 54000,0 & 0,0 & 0,0 & 0,0 & 0,0 \\
\hline $\mathrm{CO} 2(\mathrm{~kg} / \mathrm{h})$ & 0,0 & 0,0 & 9356,4 & 9356,4 & 9356,4 & 9356,4 \\
\hline $\mathrm{CO}(\mathrm{kg} / \mathrm{h})$ & 0,0 & 0,0 & 6237,6 & 6237,6 & 6237,6 & 6237,6 \\
\hline $\mathrm{H} 2$ (kg/h) & 0,0 & 0,0 & 12475,3 & 12475,3 & 12475,3 & 12475,3 \\
\hline $\mathrm{CH} 4$ (kg/h) & 0,0 & 0,0 & 3118,8 & 3118,8 & 3118,8 & 3118,8 \\
\hline H2O (kg/h) & 396000,0 & 396000,0 & 414356,0 & 414356,0 & 414356,0 & 414356,0 \\
\hline $\mathrm{NH} 3$ (kg/h) & 0,0 & 0,0 & 4455,4 & 4455,4 & 4455,4 & 4455,4 \\
\hline $\mathrm{O} 2(\mathrm{~kg} / \mathrm{h})$ & 0,0 & 0,0 & 0,0 & 0,0 & 0,0 & 0,0 \\
\hline Vazão Total (kg/h) & 450000,0 & 450000,0 & 450000,0 & 450000,0 & 450000,0 & 450000,0 \\
\hline Temperatura $\left({ }^{\circ} \mathrm{C}\right)$ & 527,4 & 800,0 & 800,0 & 800,0 & 329,7 & 320,1 \\
\hline Pressão (atm) & 243,0 & 223,6 & 223,6 & 223,6 & 223,6 & 223,6 \\
\hline
\end{tabular}




\begin{tabular}{lrrrr}
\hline \multicolumn{1}{c}{ Corrente } & \multicolumn{1}{c}{ S13 } & \multicolumn{1}{c}{ S14 } & \multicolumn{1}{c}{ S15 } & \multicolumn{1}{c}{ S16 } \\
\hline Vinhaça $(\mathrm{kg} / \mathrm{h})$ & 0,0 & 0,0 & 0,0 & 0,0 \\
$\mathrm{CO} 2(\mathrm{~kg} / \mathrm{h})$ & 9356,4 & 8509,6 & 846,8 & 846,8 \\
$\mathrm{CO}(\mathrm{kg} / \mathrm{h})$ & 6237,6 & 6199,2 & 38,4 & 38,4 \\
$\mathrm{H} 2(\mathrm{~kg} / \mathrm{h})$ & 12475,3 & 12336,0 & 139,3 & 139,3 \\
$\mathrm{CH} 4(\mathrm{~kg} / \mathrm{h})$ & 3118,8 & 3057,0 & 61,8 & 61,8 \\
$\mathrm{H} 20(\mathrm{~kg} / \mathrm{h})$ & 414356,0 & 13560,8 & 400796,0 & 400796,0 \\
$\mathrm{NH} 3(\mathrm{~kg} / \mathrm{h})$ & 4455,4 & 2467,8 & 1987,7 & 1987,7 \\
O2 $(\mathrm{kg} / \mathrm{h})$ & 0,0 & 0,0 & 0,0 & 0,0 \\
Vazão Total $(\mathrm{kg} / \mathrm{h})$ & 450000,0 & 46130,4 & 403870,0 & 403870,0 \\
Temperatura $\left({ }^{\circ} \mathrm{C}\right)$ & 243,9 & 200,0 & 200,0 & 105,6 \\
Pressão $(\mathrm{atm})$ & 223,6 & 194,6 & 194,6 & 194,6 \\
\hline
\end{tabular}

A nova condição de concentração da vinhaça não apresenta impacto expressivo no balanço de massa do módulo, como esperado, já que não foram modificadas as conversões previstas no bloco do gaseificador (RYELD/ RGIBBS). O aumento da concentração da vinhaça tem também impacto no consumo energético das bombas, que precisam exercer uma força maior para bombear o fluido com menor quantidade de água. A análise dos novos consumos, em comparação com os consumos da simulação de projeto, indica uma diferença de menos de $2 \%$ na potência.

A modificação no balanço de energia tem como principal modificação a fornalha, que passa a aquecer a vinhaça de $527,4^{\circ} \mathrm{C}$ para $800^{\circ} \mathrm{C}$. A carga térmica neste equipamento é reduzida para $84791 \mathrm{Gcal} / \mathrm{h}$. As novas condições de operação da fornalha implicam em uma alimentação de $47,1 \mathrm{t} / \mathrm{h}$ de bagaço ao sistema; $1,2 \mathrm{t} / \mathrm{h}$ a menos que no sistema com vinhaça contendo $7 \%$ de sólidos.

As descrições citadas foram sumarizadas na estimativa de OPEX para a alternativa, apresentada na Tabela 11. 
Tabela 11: Estimativa de OPEX do módulo de gaseificação de vinhaça em água supercrítica para vinhaça com $12 \%$ de concentração de sólidos.

\begin{tabular}{|c|c|c|}
\hline \multirow{5}{*}{ Funcionários } & Número de profissionais trabalhando & 2 \\
\hline & Número de turnos & 2 \\
\hline & $\begin{array}{c}\text { Custo salarial anual médio - operador/ } \\
\text { encarregado (R\$) }\end{array}$ & 54000,00 \\
\hline & Custo de transporte/ alimentaçãp ( $R \$ / p e s s o a / d i a)$ & 35,00 \\
\hline & Custo total com funcionários (R\$/ano) & 241550,00 \\
\hline Manutenção & Custos com manutenção/ materiais ( $\mathrm{R} \$$ /ano) & 398620,85 \\
\hline \multirow{3}{*}{ Insumos } & Consumo de bagaço $(t / d)$ & 1130,4 \\
\hline & Custo do bagaço (R\$/t) & 50,00 \\
\hline & Custos com insumos (R\$/ano) & 18979416,00 \\
\hline \multirow{3}{*}{$\begin{array}{l}\text { Aluguel de } \\
\text { equipamentos }\end{array}$} & Tempo de aluguel $(h)$ & 8760 \\
\hline & Custo do aluguel + combustível (R\$/h) & 60,00 \\
\hline & Custo com pá carregadeira (R\$/ano) & 525600,00 \\
\hline $\begin{array}{c}\text { Serviços } \\
\text { terceirizados }\end{array}$ & Custos com serviços terceirizados ( $\mathrm{R} \$$ /ano) & 79724,17 \\
\hline \multirow{4}{*}{ Energia } & Custo da energia (R\$/MWh) & 150,00 \\
\hline & Consumo estimado para a planta (MW) & 6,1 \\
\hline & Demanda contratada da planta (MW) & 10,0 \\
\hline & Custos com energia ( $\mathrm{R} \$ / \mathrm{ano})$ & 12088800,00 \\
\hline OPEX & OPEX total (R\$/ano) & 32313711,01 \\
\hline
\end{tabular}

A diferença do OPEX da condição de projeto (Tabela 4) para o caso de maior concentração de vinhaça foi de 0,5 milhão de reais, mostrando que a sensibilidade do sistema para a temperatura é maior do que para a variação de concentração na vinhaça sendo alimentada ao processo.

\subsubsection{Impactos no CAPEX}

O conteúdo energético do fluido supercrítico na saída do gaseificador é aproveitado pelo módulo de gaseificação a partir do uso de trocadores de calor, que pré-aquecem a vinhaça que será alimentada no próprio gaseificador. O gás produto, após a etapa de separação, é mantido pressurizado a $200 \mathrm{kgf} / \mathrm{cm}^{2}$. Nesta faixa de pressão ele pode ser transportado e vendido. Esse valor de pressão vai ao encontro do que é aplicado para o gás natural veicular, por exemplo, que segundo o inciso III, 
Art. 14, da Portaria ANP no 32, de 6 de março de 2001, estabelece que o revendedor varejista de GNV deve disponibilizar GNV ao consumidor final a pressão máxima de abastecimento de $220 \mathrm{kgf} / \mathrm{cm}^{2}$.

Para a avaliação de sensibilidade de CAPEX foi adotada uma alternativa de aproveitamento da energia contida no fluido supercrítico exausto do gaseificador. Considerou-se um conjunto turbina/ gerador a jusante do gaseificador, de maneira a gerar energia a partir da redução de pressão do fluido. Tal alteração implicou em uma nova pressão de operação no separador, gerando um gás produto com $100 \mathrm{kgf} / \mathrm{cm}^{2} \mathrm{~g}$, ao invés dos $200 \mathrm{kgf} / \mathrm{cm}^{2}$ previamente definidos. A alteração também tem impacto no OPEX, já que a temperatura na entrada da fornalha é reduzida devido à menor temperatura da corrente de entrada, o que impacta diretamente no consumo de bagaço pela operação. A Tabela 12 mostra os resultados de balanço de massa encontrados para o caso, enquanto a Figura 10 mostra 0 novo circuito, conforme rodado em Apen Plus.

Figura 11: Módulo de gaseificação de vinhaça em água supercrítica, com a inclusão da turbina.

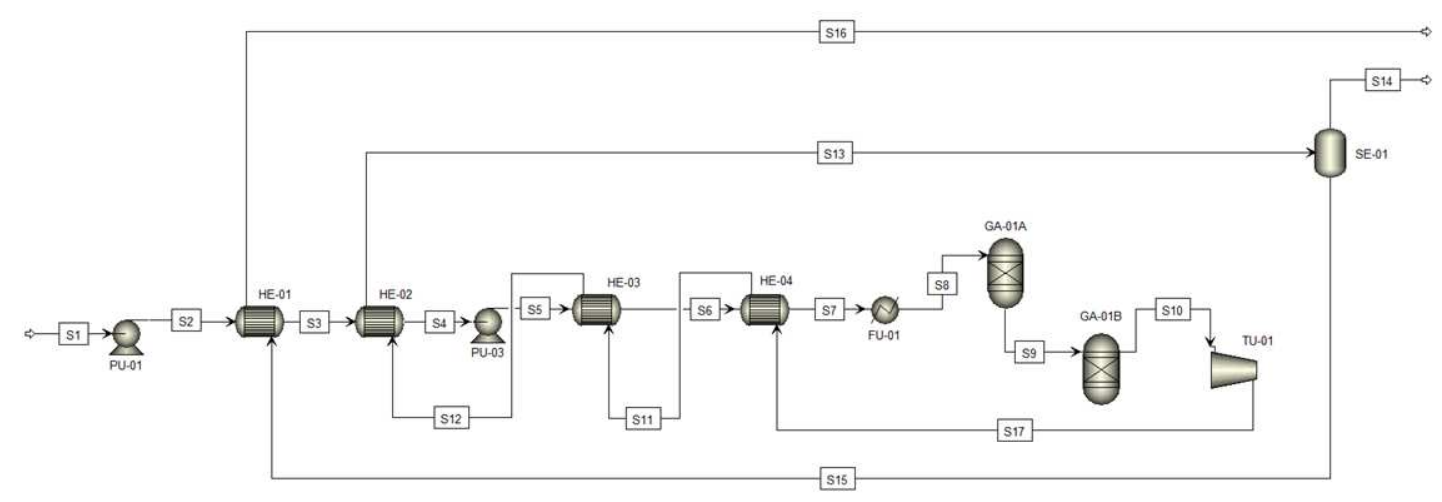


Tabela 12: Resultados da simulação para o módulo de gaseificação de vinhaça em água supercrítica, com a inclusão da turbina.

\begin{tabular}{|c|c|c|c|c|c|c|}
\hline Corrente & S1 & S2 & S3 & S4 & S5 & S6 \\
\hline Vinhaça (kg/h) & 31500,0 & 31500,0 & 31500,0 & 31500,0 & 31500,0 & 31500,0 \\
\hline $\mathrm{CO} 2(\mathrm{~kg} / \mathrm{h})$ & 0,0 & 0,0 & 0,0 & 0,0 & 0,0 & 0,0 \\
\hline $\mathrm{CO}(\mathrm{kg} / \mathrm{h})$ & 0,0 & 0,0 & 0,0 & 0,0 & 0,0 & 0,0 \\
\hline $\mathrm{H} 2(\mathrm{~kg} / \mathrm{h})$ & 0,0 & 0,0 & 0,0 & 0,0 & 0,0 & 0,0 \\
\hline $\mathrm{CH} 4(\mathrm{~kg} / \mathrm{h})$ & 0,0 & 0,0 & 0,0 & 0,0 & 0,0 & 0,0 \\
\hline $\mathrm{H} 20$ (kg/h) & 418500,0 & 418500,0 & 418500,0 & 418500,0 & 418500,0 & 418500,0 \\
\hline $\mathrm{NH} 3(\mathrm{~kg} / \mathrm{h})$ & 0,0 & 0,0 & 0,0 & 0,0 & 0,0 & 0,0 \\
\hline $\mathrm{O} 2$ (kg/h) & 0,0 & 0,0 & 0,0 & 0,0 & 0,0 & 0,0 \\
\hline Vazão Total (kg/h) & 450000,0 & 450000,0 & 450000,0 & 450000,0 & 450000,0 & 450000,0 \\
\hline Temperatura $\left({ }^{\circ} \mathrm{C}\right)$ & 25,0 & 25,5 & 110,7 & 264,4 & 270,7 & 293,1 \\
\hline Pressão (atm) & 2,0 & 97,8 & 97,8 & 97,8 & 243,0 & 243,0 \\
\hline Corrente & S7 & S8 & S9 & S10 & S11 & S12 \\
\hline Vinhaça (kg/h) & 31500,0 & 31500,0 & 0,0 & 0,0 & 0,0 & 0,0 \\
\hline $\mathrm{CO} 2(\mathrm{~kg} / \mathrm{h})$ & 0,0 & 0,0 & 9356,4 & 9356,4 & 9356,4 & 9356,4 \\
\hline $\mathrm{CO}(\mathrm{kg} / \mathrm{h})$ & 0,0 & 0,0 & 6237,6 & 6237,6 & 6237,6 & 6237,6 \\
\hline $\mathrm{H} 2$ (kg/h) & 0,0 & 0,0 & 12475,3 & 12475,3 & 12475,3 & 12475,3 \\
\hline $\mathrm{CH} 4(\mathrm{~kg} / \mathrm{h})$ & 0,0 & 0,0 & 3118,8 & 3118,8 & 3118,8 & 3118,8 \\
\hline $\mathrm{H} 20$ (kg/h) & 418500,0 & 418500,0 & 414356,0 & 414356,0 & 414356,0 & 414356,0 \\
\hline $\mathrm{NH} 3(\mathrm{~kg} / \mathrm{h})$ & 0,0 & 0,0 & 4455,4 & 4455,4 & 4455,4 & 4455,4 \\
\hline $\mathrm{O} 2(\mathrm{~kg} / \mathrm{h})$ & 0,0 & 0,0 & 0,0 & 0,0 & 0,0 & 0,0 \\
\hline Vazão Total (kg/h) & 450000,0 & 450000,0 & 450000,0 & 450000,0 & 450000,0 & 450000,0 \\
\hline Temperatura $\left({ }^{\circ} \mathrm{C}\right)$ & 377,8 & 800,0 & 800,0 & 800,0 & 295,7 & 282,2 \\
\hline Pressão (atm) & 243,0 & 223,6 & 223,6 & 223,6 & 97,8 & 97,8 \\
\hline
\end{tabular}

\begin{tabular}{lrrrrr}
\hline \multicolumn{1}{c}{ Corrente } & \multicolumn{1}{c}{ S13 } & \multicolumn{1}{c}{ S14 } & \multicolumn{1}{c}{ S15 } & \multicolumn{1}{c}{ S16 } & \multicolumn{1}{c}{ S17 } \\
\hline Vinhaça $(\mathrm{kg} / \mathrm{h})$ & 0,0 & 0,0 & 0,0 & 0,0 & 0,0 \\
$\mathrm{CO} 2(\mathrm{~kg} / \mathrm{h})$ & 9356,4 & 8942,1 & 414,4 & 414,4 & 9356,4 \\
$\mathrm{CO}(\mathrm{kg} / \mathrm{h})$ & 6237,6 & 6220,0 & 17,7 & 17,7 & 6237,6 \\
$\mathrm{H} 2(\mathrm{~kg} / \mathrm{h})$ & 12475,3 & 12412,2 & 63,1 & 63,1 & 12475,3 \\
$\mathrm{CH} 4(\mathrm{~kg} / \mathrm{h})$ & 3118,8 & 3089,9 & 28,9 & 28,9 & 3118,8 \\
H20 $(\mathrm{kg} / \mathrm{h})$ & 414356,0 & 27724,5 & 386632,0 & 386632,0 & 414356,0 \\
$\mathrm{NH} 3(\mathrm{~kg} / \mathrm{h})$ & 4455,4 & 3236,8 & 1218,7 & 1218,7 & 4455,4 \\
O2 $(\mathrm{kg} / \mathrm{h})$ & 0,0 & 0,0 & 0,0 & 0,0 & 0,0 \\
Vazão Total (kg/h) & 450000,0 & 61625,4 & 388375,0 & 388375,0 & 450000,0 \\
Temperatura $\left({ }^{\circ} \mathrm{C}\right)$ & 262,3 & 200,0 & 200,0 & 103,5 & 668,9 \\
Pressão (atm) & 97,8 & 97,8 & 97,8 & 97,8 & 97,8 \\
\hline
\end{tabular}


Os resultados da nova simulação indicam que o sistema turbina/ gerador seria capaz de fornecer 40MW de energia elétrica, somente pela redução de pressão do fluido supercrítico (considerada uma eficiência isentrópica de $72 \%$ ). Essa modificação também tem impacto na fornalha, que passa a aquecer a vinhaça de $377,6^{\circ} \mathrm{C}$ para $800^{\circ} \mathrm{C}$, e também no sistema de alimentação de bagaço, que passa a operar com uma vazão de $101 \mathrm{t} / \mathrm{h}$. Para atender à nova demanda de bagaço, mantendo o mesmo tempo de residência, o silo de bagaço também foi impactado, dobrando de tamanho. $O$ trocador de calor HE-04, tem a sua área de troca térmica reduzida, devido à menor troca térmica exercida por ele na nova configuração. $O$ vaso separador, que nessa configuração opera em uma condição mais branda de pressão também tem seu custo reduzido. Todas as alterações citadas tem impacto direto nas estimativas de CAPEX e OPEX, que podem ser observadas nas Tabelas 12 e 13, respectivamente.

Tabela 13: Estimativa de custo dos equipamentos do módulo de gaseificação de vinhaça em água supercrítica com turbina.

\begin{tabular}{llr}
\hline Tag & Descrição & Custo Estimado \\
\hline BA-01 & Bacia de Vinhaça & $\mathrm{R} \$ 1.950 .000,00$ \\
BC-01 & Bacia de Concreto & $\mathrm{R} \$ 1.098 .224,00$ \\
PU-01 & Bomba de Vinhaça & $\mathrm{R} \$ 387.000,00$ \\
PU-02 & Bomba de Vinhaça (Reserva) & $\mathrm{R} \$ 387.000,00$ \\
PU-03 & Bomba de Vinhaça 2 & $\mathrm{R} \$ 387.000,00$ \\
PU-04 & Bomba de Vinhaça 2 (Reserva) & $\mathrm{R} \$ 387.000,00$ \\
HE-01 & Economizador 1 & $\mathrm{R} \$ 628.333,00$ \\
HE-02 & Economizador 2 & $\mathrm{R} \$ 1.208 .333,00$ \\
HE-03 & Economizador 3 & $\mathrm{R} \$ 1.450 .000,00$ \\
HE-03 & Economizador 4 & $\mathrm{R} \$ 1.611 .111,00$ \\
GA-01 & Gaseificador & $\mathrm{R} \$ 1.098 .224,00$ \\
SE-01 & Separador & $\mathrm{R} \$ 768.757,00$ \\
VE-01 & Reservatório de Gás Produto & $\mathrm{R} \$ 1.098 .224,00$ \\
TK-01 & Reservatório de Água Recuperada & $\mathrm{R} \$ 1.950 .000,00$ \\
BI-01 & Silo de Bagaço & $\mathrm{R} \$ 297.000,00$ \\
BE-01 & Transportador de Correia & $\mathrm{R} \$ 60.486,00$ \\
BE-02 & Transportador de Correia 2 & $\mathrm{R} \$ 60.486,00$ \\
FU-01 & Fornalha de Bagaço & $\mathrm{R} \$ 850.000,00$ \\
VE-01 & Vaso de Deposição de Sais & $\mathrm{R} \$ 1.000 .000,00$ \\
CH-01 & Chaminé & $\mathrm{R} \$ 200.000,00$ \\
\hline
\end{tabular}


Com base no custo total com equipamentos, foi estimado o custo do projeto como um todo para este caso, utilizando novamente o fator de Lang de 4,74, que é comum para plantas de processamento de fluidos. O mesmo resultou em $\mathrm{R} \$ 278.410 .247,0$ ou $\$ 69.602 .562,00$ dólares (cotação aproximada de $\$ 4,00$ por cada real).

Tabela 14: Estimativa de OPEX do módulo de gaseificação de vinhaça em água supercrítica com turbina.

\begin{tabular}{|c|c|c|}
\hline \multirow{5}{*}{ Funcionários } & Número de profissionais trabalhando & 2 \\
\hline & Número de turnos & 2 \\
\hline & $\begin{array}{c}\text { Custo salarial anual médio - operador/ } \\
\text { encarregado (R\$) }\end{array}$ & 54000,00 \\
\hline & Custo de transporte/ alimentação ( $\mathrm{R} \$ /$ pessoa/dia) & 35,00 \\
\hline & Custo total com funcionários (R\$/ano) & 241550,00 \\
\hline Manutenção & Custos com manutenção/ materiais ( $\mathrm{R} \$$ /ano) & 398620,85 \\
\hline \multirow{3}{*}{ Insumos } & Consumo de bagaço $(t / d)$ & 2424 \\
\hline & Custo do bagaço $(\mathrm{R} \$ / \mathrm{t})$ & 50,00 \\
\hline & Custos com insumos (R\$/ano) & 40698960,00 \\
\hline \multirow{3}{*}{$\begin{array}{c}\text { Aluguel de } \\
\text { equipamentos }\end{array}$} & Tempo de aluguel (h) & 8760 \\
\hline & Custo do aluguel + combustível ( $R \$ / h)$ & 60,00 \\
\hline & Custo com pá carregadeira (R\$/ano) & 525600,00 \\
\hline $\begin{array}{c}\text { Serviços } \\
\text { terceirizados }\end{array}$ & Custos com serviços terceirizados ( $\mathrm{R} \$ /$ ano) & 79724,169 \\
\hline \multirow{4}{*}{ Energia } & Custo da energia (R\$/MWh) & 150,00 \\
\hline & Consumo estimado para a planta (MW) & 6,09144 \\
\hline & Potência instalada na planta (MW) & 40 \\
\hline & Custos com energia $(\mathrm{R} \$ /$ ano) & $(-40991380,01)$ \\
\hline OPEX & OPEX total $(\mathrm{R} \$ / a n o)$ & 953075,00 \\
\hline
\end{tabular}

A estimativa de CAPEX para este caso apresenta maiores incertezas que a estimativa do módulo sem a turbina, pois não foi possível obter cotações para a turbina supercrítica, e não existem equipamentos semelhantes no banco de dados da autora. Logo, seu custo foi determinado a partir da 
extrapolação do preço de uma turbina subcrítica de $40 \mathrm{MW}$ (65 bar, $485^{\circ} \mathrm{C}$ ), considerando-se a utilização de materiais mais nobres, para resistir não somente às condições de temperatura e pressão, mas também à corrosão. A partir da comparação com o CAPEX obtido para o sistema sem a turbina, podemos dizer que o CAPEX é três vezes e meia maior do que o da alternativa sem turbina.

Para o caso do OPEX, passa a ser considerado o ganho com a produção de energia pelo conjunto turbina/ gerador, o que representa aproximadamente $34 \mathrm{MW}$, que poderiam ser vendidos para a rede integrada. Para simplificação dos cálculos, foi considerado que essa energia seria vendida pelos mesmos $\mathrm{R} \$ 150,00 / \mathrm{MWh}$ que ela poderia ser comprada. Com isso tem-se uma redução significativa de OPEX, mesmo com o aumento expressivo no consumo de bagaço para atendimento da nova carga térmica da fornalha.

\subsection{Análise Geral da Sensibilidade}

Para testar a robustez do projeto, ou seja, para demonstrar que o mesmo é pouco sensível a variações de premissas de projeto, foram analisados três casos: o primeiro variando uma condição de operação, o segundo alterando as características da matéria-prima e o terceiro modificando o parte do conceito de aproveitamento energético.

Para o primeiro caso, a variação da condição de operação se deu pela seleção de um novo valor de temperatura de operação para o gaseificador. A temperatura de $600^{\circ} \mathrm{C}$ foi escolhida por estar em um patamar relativamente seguro, já que a maioria das literaturas indica que este valor resulta nas melhores condições para a SCWG de biomassas, mesmo que não existam dados referentes a essa sensibilidade para vinhaça, especificamente. Esse caso considera também a premissa de que o 
dimensionamento do gaseificador e do sistema de deposição de sais do reator não seria afetado por essa mudança operacional (condição de projeto $x$ condição de operação). A diminuição das entalpias das correntes após o segundo economizador (HE-02), devido ao menor calor trocado pelas correntes de entrada e de retorno, é compensada globalmente pela economia de biomassa de aquecimento, neste caso, do bagaço de cana para a fornalha. O comportamento térmico das correntes produto de água e de gases (correntes $\mathrm{S} 14$ e S16) se mantém o mesmo, pois as características do primeiro trocador (HE-01), se mantém. Conforme esperado, o comportamento térmico global do processo foi alterado, refletindo em uma diminuição de OPEX para $\mathrm{R} \$ 30.822 .759,01$, mas de modo percentual negligenciável em frente ao valor total. Naturalmente, o processo é termicamente mais eficiente quando o gaseificador opera em temperaturas menores, uma vez que o processo não é energeticamente eficiente. No entanto, uma otimização de processo dessa natureza é um esforço que deve ser conduzido em conjunto com uma estimativa/ projeto de Classe 3, com balanços e cotações mais precisos.

Para o caso de variação na matéria prima, foi variada a concentração da vinhaça saindo da usina, em faixa plausível sem a necessidade de grandes alterações no projeto, tal como inclusão de equipamentos de filtração e/ ou secagem da água contida na vinhaça. Era esperado que o projeto suportasse a mudança nas condições da matéria-prima, sem grandes alterações, diferentemente de sistemas com gaseificadores tradicionais. Neles, o material gaseificado tem sua umidade obrigatoriamente removida, sendo por alguma operação anterior ao gaseificador (equipamento específico), ou dentro do próprio equipamento, o que consome grandes quantidades de energia para a evaporação dessa umidade. Nos gaseificadores supercríticos, essa mudança de fase, seja de líquido para vapor, ou diretamente de líquido para fluido supercrítico, não se configura como uma perda da entalpia de evaporação. Portanto, uma vez que a massa de vinhaça se mantém constante, a diminuição da água que vem junto com 
matéria-prima não reflete em demasia no OPEX do processo, e a entalpia das correntes na saída do gaseificador (correntes de S11 a S16), disponíveis para integração energética, se mantêm dentro de faixa do caso de projeto (com variações percentuais menores que $0,5 \%$ ).

Para o terceiro caso, foi considerada uma modificação do conceito global do projeto. A inclusão de uma turbina para extrair a energia contida no produto da gaseificação configura uma mudança substancial de projeto. O resultado almejado com uma variação desta natureza não foi o de descobrir qual seria a melhor opção com relação ao aproveitamento energético da planta (recuperação interna x geração de energia elétrica), mas sim demonstrar que o sistema é robusto o suficiente para suportar mudanças de grande porte, sem modificações nas operações unitárias principais. A alteração realizada no projeto afetou diretamente o valor de CAPEX, entretanto compensada pelos ganhos em OPEX. A inclusão da turbina altera 0 comportamento térmico global do projeto, e é compensada por um aumento no consumo de bagaço de cana, mas essa alteração é percentualmente menor do que o ganho em geração de energia elétrica, reduzindo assim significativamente OPEX. Do ponto de vista do projeto, a inclusão da turbina não impactou no conceito principal da gaseificação, e por ter maior impacto nos equipamentos/ correntes à jusante do gaseificador, teria sua implementação facilitada. Outras alternativas de modificação no CAPEX, tais como:

- Limpeza e purificação dos gases produto (remoção de CO2 e do vapor de água remanescente) por membranas ou por lavagem em água fria;

- Purificação da água recuperada, para reuso na usina, através de injeção de ar; 
se enquadram no mesmo caso da turbina, não requerendo uma análise maior de sensibilidade do projeto, e por isso não foram testados neste estudo.

\subsection{Análise Geral do Projeto}

Como usualmente praticado em projetos de processos industriais, o presente trabalho pré-especifica os produtos desejados no gaseificador, assumindo a hipótese de equilíbrio termodinâmico. Os detalhes e a capacidade de previsão dos modelos termodinâmicos em relação aos modelos cinéticos são discutidos em outro trabalho[13].

Ao avaliar de modo geral o projeto desenvolvido, diante das várias considerações e alternativas de projeto conceitual que foram criadas e descartadas ao longo do desenvolvimento do estudo, considera-se aqui que os projetos futuros de gaseificação de vinhaça em água supercrítica não se afastarão do projeto conceitual apresentado neste estudo. A não existência de propostas semelhantes na literatura, voltadas para a vinhaça[14], corroboram com essa afirmação.

Os refinamentos do projeto apresentado provavelmente virão de um aumento na integração energética das correntes finais do processo, às

\footnotetext{
13 trabalho submetido: F.Gonçalves Souza, S.C. Felix da Silva, S.W.Park. Modelos Cinéticos de Gaseificação em Água Supercrítica das Biomassas. COBEQ 2016. XXI Congresso Brasileiro de Engenharia Química. Fortaleza, CE. 25-29 Setembro 2016.

${ }^{14}$ Tem-se uma publicação de M.Gassner, F.Vogel, G.Heyen, F. Marechal. Optimal process design for the polygeneration of SNG. Energy and Environmental Science vol. 4 pp. 1726-1741, 2011 onde se busca análise de projeto para biomassa sólida, não se tratando de vinhaça, e, apesar de buscar técnicas sistemáticas de otimização e integração de processos, não há analise de fonte de aquecimento e custos de equipamentos estão genericamente citados. Por conseguinte, não há análise de CAPEX e de robustez de projeto, enquanto a integração se refere à múltipla geração de energia térmica, SNG e eletricidade. A análise de custos de operação não demonstra claramente que o balanço de energia nesse caso é deficitário. M. Brandenberger, J. Matzenberger, F. Vogel, Ch. Ludwig. Producing synthetic natural gas from microalgae viasupercritical water gasification. Biomass and Bioenergy vol 51, p. 26-34 propõe a queima do $\mathrm{CH} 4$ produzido para o uso da energia, o que é desfavorável para geração global de gases, e ainda assim energeticamente desfavorável. O custo de construção de SWGC está genericamente alocado, sem maiores discussões.
} 
custas de um maior CAPEX, ou da integração mais completa com a usina, em termos de correntes de processo. Aqui, a usina foi considerada como um limite de bateria, do qual era recebida a matéria-prima e para a qual eram enviados os produtos, sem consideração pelos valores advindos da sua integração ao processo (upsides).

Alguns valores internos às estimativas de CAPEX e de OPEX foram superestimados por segurança, mas deve-se lembrar de que não existe nenhuma base de dados similar na literatura, para se ter uma dimensão do investimento de projetos desta natureza.

Considerando os ganhos em termos de:

- Custos evitados com a destinação final da vinhaça, como bombeamento, frete, aspersão;

- Custos evitados com compra de água da concessionária (pela utilização da água recuperada da vinhaça);

- Venda ou consumo interno do gás produto, ou até mesmo a produção de energia elétrica (para o caso de utilização da turbina);

é demonstrado que o investimento é promissor e que o melhor desenvolvimento da tecnologia/ detalhamento do projeto terá retorno em termos financeiros e ambientais.

Diferentemente de projetos com gaseificadores tradicionais, que são engessados com a necessidade de uma etapa de secagem adicional ao aquecimento para a obtenção da condição de gaseificação, este projeto comporta pequenas alterações que modificam radicalmente o processo, sem modificar a filosofia supercrítica. Para exemplificar mais uma alteração possível no projeto, poderia ser considerada a inclusão de um reator de água em estado subcrítico $\left(200-300^{\circ} \mathrm{C}\right)$ antes do gaseificador, para que na primeira unidade seja possível fazer extração de produtos químicos de 
cadeias maiores, ainda não processadas. Tais produtos poderiam ser a matéria-prima de uma plataforma química paralela ao módulo de gaseificação (building blocks). Para este caso há necessidade de obtenção de modelos cinéticos na etapa subcrítica. Outra possibilidade seria a adição de uma etapa de fracionamento de sais, no processo de precipitação de sais, a montante do gaseificador. Essa etapa poderia contar com uma lixiviação, ou separação osmótica, recuperando minerais de interesse. Os aspectos citados reforçam ainda mais a característica de flexibilidade do projeto.

Apesar de no presente trabalho ser sistematicamente declarado que não existem publicações sobre gaseificação de vinhaça como um processo completo, com a exceção de poucos trabalhos de prospecção e teste laboratorial, não é somente preencher esse espaço vazio que o torna inovador. Considera-se que este trabalho será o precursor de muitos outros trabalhos similares de gaseificação de vinhaça em água supercrítica, abordando os aspectos gerais de matérias primas proteicas, incluindo desde a pesquisa básica de mecanismos e testes laboratoriais até propostas de unidades de demonstração. A vinhaça por si só já possui um apelo interessante para pesquisas, por ser uma matéria-prima abundante, de fácil acesso e que não necessita de pré-condicionamento custoso (como outros materiais lignocelulósicos sólidos) para ser alimentada em reatores supercríticos. Logo, a previsão de aumento dos estudos com vinhaça significa um horizonte otimista de obtenção informações mais detalhadas sobre o processo e, consequentemente, muitos dos aspectos hoje considerados desafios para tecnologia de SCWG serão aos poucos solucionadas.

Portanto, retomando a ideia descrita inicialmente no capítulo de Materiais e Métodos, o presente trabalho analisa uma tecnologia emergente, ou seja, uma tecnologia para a qual têm-se demonstrações de bancada, mas não existem unidades em escala comercial, para demonstração da tecnologia. Assim, um projeto de unidade industrial passa a ser um objeto de pesquisa 
importante, por integrar processos, detectar uma estrutura de investigação e ser impulsionador de desenvolvimento de tecnologia. Esta é razão pela qual grande parte dos trabalhos enumerados no capítulo de Revisão Bibliográfica aborda parcialmente um ou outro aspecto de fluxograma e projeto, mas enfrentam enormes dificuldades de levantamento de base de dados.

Esta análise é mais bem ilustrada ao se utilizar a estrutura de referencial teórico de inovação, para demonstrar a capacidade impulsionadora de um projeto de tecnologia emergente.

Tabela 15: Estratégia Tradicional versus Inovação Estratégica.

\begin{tabular}{|c|c|}
\hline Abordagem Tradicional & $\begin{array}{c}\text { Abordagem de Inovação } \\
\text { Estratégica }\end{array}$ \\
\hline $\begin{array}{l}\text { Adota a orientação de presente para futuro e } \\
\text { toma o atual como ponto de partida }\end{array}$ & $\begin{array}{c}\text { Inicia com o fim como objetivo, } \\
\text { identifica oportunidades de longo } \\
\text { prazo e assim traz uma ponte para o } \\
\text { presente }\end{array}$ \\
\hline $\begin{array}{l}\text { Assume postura de seguidor de tecnologia e } \\
\text { conserva regras }\end{array}$ & Assume postura de ruptura de regras \\
\hline $\begin{array}{l}\text { Aceita contornos de negócios estabelecidos e } \\
\text { categoria de produtos }\end{array}$ & $\begin{array}{c}\text { Procura criar novos espaços } \\
\text { competitivos e novos campos de } \\
\text { ação }\end{array}$ \\
\hline $\begin{array}{c}\text { Segue modelos de planos de negócios linear e } \\
\text { tradicional }\end{array}$ & $\begin{array}{l}\text { Acopla disciplina em processo com } \\
\text { inspiração criativa }\end{array}$ \\
\hline Procura entradas de fontes óbvias e tradicionais & $\begin{array}{c}\text { Procura inspiração de fontes não- } \\
\text { convencionais }\end{array}$ \\
\hline $\begin{array}{c}\text { Pesquisa as necessidades articuladas do } \\
\text { consumidor }\end{array}$ & $\begin{array}{l}\text { Pesquisa as necessidades não- } \\
\text { articuladas do consumidor }\end{array}$ \\
\hline $\begin{array}{l}\text { Impulsionado pela tecnologia (procura a } \\
\text { satisfação do cliente) }\end{array}$ & $\begin{array}{l}\text { Inspirado pelo consumidor (procura } \\
\text { encantar cliente) }\end{array}$ \\
\hline $\begin{array}{c}\text { Pode ter modelo organizacional único para } \\
\text { encaixar tudo }\end{array}$ & $\begin{array}{l}\text { Pode experimentar novos } \\
\text { empreendimentos ou outras } \\
\text { estruturas organizacionais }\end{array}$ \\
\hline
\end{tabular}

Fonte: adaptado de Palmer e Kaplan (2013)

Um setor tradicional como o sucro-alcooleiro deve combinar uma abordagem tradicional de tecnologia e modelo de negócios, mas permitir "trazer uma ponte do futuro para o presente". Nesses termos, deve ser capaz de fazer inovação, envolvendo todos os interessados, desde clientes internos e externos da demanda tecnológica, fornecedores de materiais e 
equipamentos, investidores, novos consumidores de novos produtos. Para isso, é necessário ver além do óbvio e das práticas costumeiras. Mas a questão é como fazer desse conceito bem abordado (Frishammar et al., 2012) uma ação palpável

Dificilmente apenas a partir das ideias surgidas por seremdipidade, em laboratórios (abordagem tradicional), seria gerada uma força motriz suficiente para formar um grupo de interessados. Assim, os próprios acadêmicos assumem a tarefa lenta de testar uma tecnologia qualquer em unidades piloto, fazer demonstrações e anotações tecnológicas, de modo lento e linear, até os interessados a considerarem como uma tecnologia razoavelmente comprovada. Afirma-se aqui que a outra forma que combina a abordagem estratégica com a tradicional é definir e propor um projeto de nova unidade industrial, sem referências passadas. Isso o torna uma força impulsionadora de resolução de desafios tecnológicos em escala comercial, somando esforços de todos os interessados. Naturalmente, entre essa etapa e a fase de partida de produção, são envolvidas outras considerações organizacionais (Lager, 2012).

Explica-se a seguir porque o projeto de uma unidade industrial de tecnologia emergente é uma força impulsionadora de pesquisas e desenvolvimento, sendo ela por si própria um objeto de pesquisa. Como não existe uma unidade industrial que deva ser melhorada, não há garantia de que a tecnologia adequada esteja disponível pelos fornecedores. Portanto, este empreendimento requer um forte comprometimento de pesquisadores para levantar informações relevantes para a tecnologia, e de fornecedores para desenvolver equipamentos compatíveis em nível pré-competitivo e colaborativo. Assim, o próprio projeto se torna objeto de novas inspirações, integração de equipamentos e melhorias de processos. A estrutura teórica desse conceito pode ser vista no trabalho de Lager e Frishammar (2012), com suas implicações para a indústria e academia. Não é do presente escopo de trabalho discutir detalhadamente essa conceituação teórica. llustram-se aqui essas inspirações, de modo prático. 
A corrosão devido à operação com fluidos em estado supercrítico é um desafio tecnológico, mas não é uma restrição ou impedimento para a aplicação futura do projeto. A construção de caldeiras de vapor supercrítica é comprovadamente possível, com a utilização de uma tecnologia corrente. Motivado pelo horizonte de que SCWG será uma tecnologia adotada no futuro, existe uma intensa pesquisa sobre esse assunto (KRITZER, 2004; MARRONE e HONG, 2009).

A baixa solubilidade de sais em SCWG (SKERGET, KNEZ e KNEZHRNCIC, 2011) torna necessária a pesquisa em separadores desses sais. Esses estudos em equipamentos e mecanismos de formação de sais só se justificam dentro do contexto de projeto de unidades industriais, e impulsionando cada vez mais a sua publicação na literatura, como em Xu et al. (2015) e Xu et al. (2010).

$O$ presente projeto assumiu, para efeito de custos de equipamentos, que 0 reator seria fluidizado (FREMAUX et al., 2015; LU et al., 2015). Mas a SCWG é uma intensificadora de processos, reduzindo o tempo de reação para segundos, eliminado restrições de mistura e difusão, reduzindo drasticamente a energia mecânica necessária para o escoamento, entre outros. Por isso, existe uma intensa pesquisa em concepções, desde permeação cerâmica, banco de série de tubos com catalisadores em leito fixo e vários outros, para os quais não se discute aqui as referências bibliográficas completas, ver Puig-Arvanat et al. (2013). Portanto, dentro do conceito de intensificador de processos, o presente projeto superestima os valores de custo de capital, que tem potencial de ser reduzido.

Já existem turbinas comerciais para produção de eletricidade diretamente de água supercrítica, uma vez que caldeiras supercríticas e reatores nucleares fornecem uma forte motivação para aplicação direta desses fluidos em turbinas apenas com expansão. A SCWG será beneficiária do maior desenvolvimento dessa tecnologia. 
O gaseificador foi dimensionado apenas com a consideração de uma possível ação catalítica dos sais que se encontram junto com vinhaça, mas sem conceituação de modelos para tal. Logo, os pontos ótimos de gaseificação, e da seletividade $\mathrm{H}_{2} / \mathrm{CH}_{4}$ dependem do reator e das variáveis operacionais que devem ser estudadas. Entretanto, a pesquisa em catalisador heterogêneo para SCWG é extensa e contínua, devido às vantagens para o projeto do reator (AZADI e FARNOOD (2011); GUO et al., (2010)).

Estudos de engenharia de sistemas de processos químicos, tais como a integração energética através de programação numérica de otimização, análise de riscos e sua sensibilidade, análise de superestruturas em blocos de processos, e outros que usualmente são utilizados em projetos petroquímicos tradicionais onde se busca ganhos através de resolução sistemática de integração de processos, são prematuros no projeto de unidade de SCWG, devido ao alto grau de incerteza no banco de dados. Mas, dentro do espírito de trazer o futuro para o presente, o desenvolvimento e a aplicação desses estudos irá aumentar consistentemente.

De modo similar, a aplicação de indicadores energéticos ainda é prematura para o uso em engenharia de sistemas de processos químicos aplicados em SCWG, e vale o mesmo propósito enunciado anteriormente. Pelo fato de a SCWG trabalhar com expansão de fluido e com a perda de exergia química, a aplicação de análise termo econômica baseada em exergia é promissora para este projeto de vinhaça e será assunto de trabalho futuro.

Com essa enumeração, demonstra-se assim a capacidade impulsionadora de pesquisa de um projeto de tecnologia emergente em SCWG de vinhaça. Todas essas aplicações de estudos são familiares, apenas explicaram-se dentro da estrutura teórica de inovação os trabalhos que poderiam parecer mero fast-followers de estudos originais, sem motivação de estudos colaborativos. 


\section{CONCLUSÃO E RECOMENDAÇÕES}

Este trabalho compreende uma análise sistemática para preencher um espaço de conhecimento aberto entre as pesquisas laboratoriais/ teóricas e as unidades reais de produção de gases por SCWG (Supercritical Water Gasification), que sejam comercialmente atrativas de ponto de vista da eficiência energética.

O trabalho englobou o projeto de um módulo de gaseificação de vinhaça em água supercrítica, a ser instalado como uma unidade anexa a usinas de açúcar e álcool. Este projeto conceitual e de viabilidade, enquadrado na Classe 4 da classificação da AACE (Association for the Advancement of Cost Engineering), apresenta fluxograma, requisitos dos equipamentos projetados e os custos de capital e de operação.

Para testar a robustez do projeto, ou seja, para demonstrar que o mesmo é pouco sensível a variações de premissas de projeto, foram analisados três casos: o primeiro variando uma condição de operação, o segundo alterando as características da matéria-prima e o terceiro modificando a parte do conceito de aproveitamento energético. $O$ projeto se mostrou robusto $o$ suficiente para os três casos.

Ao avaliar de modo geral o projeto desenvolvido, diante das várias considerações e alternativas de projeto conceitual que foram criadas e descartadas ao longo do desenvolvimento do estudo, considera-se aqui que os projetos futuros de gaseificação de vinhaça em água supercrítica não se afastarão do projeto conceitual apresentado neste estudo.

Considerando os ganhos em termos de:

- Custos evitados com a destinação final da vinhaça, como bombeamento, frete, aspersão; 
- Custos evitados com compra de água da concessionária (pela utilização da água recuperada da vinhaça);

- Venda ou consumo interno do gás produto, ou até mesmo a produção de energia elétrica (para o caso de utilização da turbina);

É demonstrado que o investimento é promissor e que o melhor desenvolvimento da tecnologia/ detalhamento do projeto terá retorno em termos financeiros e ambientais.

Como sugestões para o desenvolvimento de próximos trabalhos, podem ser mencionados os exemplos citados no próprio estudo, que envolveriam:

- A melhor análise dos aspectos de limpeza e purificação dos gases produto (remoção de $\mathrm{CO} 2$ e do vapor de água remanescente) por membranas ou por lavagem em água fria;

- A purificação da água recuperada, para reuso na usina, através de injeção de ar;

- O estudo do sistema de deposição de sais, incluindo o fracionamento dos mesmos de maneira seletiva. Essa etapa poderia contar com uma lixiviação, ou separação osmótica, recuperando minerais de interesse. 


\section{REFERÊNCIAS BIBLIOGRÁFICAS}

AACE International Recommended Practice No. 18R-97. COST ESTIMATE CLASSIFICATION SYSTEM -AS APPLIED IN ENGINEERING, PROCUREMENT, AND CONSTRUCTIONFOR THE PROCESS INDUSTRIES. TCM Framework: 7.3 - Cost Estimating and Budgeting. 2011.

AHMED, T.; AHMAD, M.; YUSUP, S.; INAYAT, A.; KHAN, Z. "Mathematical and computational approaches for design of biomass gasification for hydrogen production: A review". Renewable and Sustainable Energy Reviews, v. 16, n. 4, p. 2304-2315, May 2012.

BAEZ-SMITH, C."Anaerobic Digestion of Vinasse for Production of Methane in the Sugar Cane Distillery". Sugar Processing Research Conference. September 17-20, 2006. Águas de São Pedro, S. P., Brazil.

BARATIERI, M.; BAGGIO, P.; FIORI, L. GRIGIANTE, M. "Biomass as an energy source: Thermodynamic constraints on the performance of the conversion process". Bioresource Technology, v. 99, n. 15, p. 7063-7073, Oct 2008.

BASU, P. "Biomass Gasification and Pyrolysis: practical design and theory". Elsevier Inc., 2010.

BASU, P. "Combustion and gasification in fluidized beds". Taylor and Francis Group, 2006.

BASU, P.; METTANANT, Biomass Gasification in Supercritical Water -- A Review. International Journal of Chemical Reactor Engineering vol 7, num. 1, 60p. 2009

BROCK, E.E.; SAVAGE, P.E. "Detailed chemical kinetics model for supercritical water oxidation of $\mathrm{C} 1$ compounds and H2". AIChE Journal, v. 41, n. 8, p. 1874-1888, Aug 1995.

CASTELLO, D.; FIORI, L. "Kinetics modeling and main reaction schemes for the supercritical water gasification of methanol". Journal of Supercritical Fluids, v. 69, p. 64-74, Sep 2012.

CHRISTOFOLETTI, C.; ESCHER, A.; CORREIA, J.; MARINHO, J.; FONTANETTI, C. "Sugarcane vinasse: Environmental implications of its use". Waste Management, v. 33, n. 12, p. 2752-2761, Dec 2013.

CORTEZ, L. A. B.; PÉREZ, L. E. B.; "Experiences on vinasse disposal. Part III: combustion of vinasse - \#6 Fuel oil emissions". Braz, J. Chem. Engineering, v. 14, n 1, 1997. 
EMHJELLEN, K.; EMHJELLEN, M.; OSMUNDSEN, P.; "Investment Cost Estimates and Investment Decisions". Energy Policy, v. 30, n. 2, p. 91-96, Jan 2002.

FIORI, L.; VALBUSA, M.; CASTELLO, D. "Supercritical water gasification of biomass for H2 production: Process design”. Bioresource Technology, v. 121, p. 139-147, Oct 2012.

FREITAS, A. C. D.; GUIRARDELLO, R. "Supercritical water gasification of glucose and cellulose for hydrogen and syngas production". Ibic2012: International Conference on Industrial Biotechnology, v. 27, p. 361-366, 2012.

FREMAUX, S.; BEHESHTI, S-M.; GHASSEMI, H.; SHAHSAVANMARKADEH, R. An experimental study on hydrogen-rich gas production via steam gasification of biomass in a research-scale fluidized bed. Energy Conversion and Management. V. 91, p. 427-432, 2015.

FRISHAMMAR, J.; KURKKIO, M.; ABRAHAMSSON, L.; LICHTENTHALER, $U$. Antecedents and consequences of firms process innovation capability. A literature reviews and a conceptual framework. IEEE Trans. On Engineering Management, v. 59, n. 4, p. 519-529. 2012.

FRISHAMMAR, J.; LAGER, T. . J. of Business Chemistry, v. 9, n.2, p. 67-84, 2012.

GARCÍA-JARANA, M.B.; SÁNCHEZ-ONETO, J.; PORTELA, J. R.; NEBOTSANZ, E.; MARTÍNEZ DE LA OSSA, E. J. "Supercritical water gasification of industrial organic wastes". Journal of Supercritical Fluids, v. 46, n. 3, p. 329334, 2008.

GOODWIN, A. K.; RORRER, G. L. "Reaction rates for supercritical water gasification of xylose in a micro-tubular reactor". Chemical Engineering Journal, v. 163, n. 1-2, p. 10-21, Sep 2010.

GOODWIN, A. K.; RORRER, G. L. "Modeling of supercritical water gasification of xylose to hydrogen-rich gas in Hastelloy microchannel reactor". Industrial \& Engineering Chemistry Research, v. 50, n. 12, p. 71727182, Jun 2011.

GUALBERTO, L; "Comparação entre Tecnologias de Gaseificação de Biomassa Existentes no Brasil e no Exterior e Formação de Recursos humanos na região norte. -Estado da Arte da Gaseificação", Relatório CENBIO CONVÊNIO FINEP / CETERNERG 23.01.0695.00 Set. 108p.São Paulo . 2002.

GUAN, Q.; SAVAGE, P. E.; WEI, C.; "Gasification of alga Nannochloropsis sp. in Supercritical Water". Journal of Supercritical Fluids, v. 61, p. 139-145, Jan 2012. 
GUAN, Q.; WEI, C.; SAVAGE, P. E.; "Kinetic model for supercritical water gasification of algae". Physical Chemistry Chemical Physics, v. 14, n. 9, p. 3140-3147, 2012.

HIGMAN, C; VAN DER BURGT, M., "Gasification". Elsevier Publishing, Burlington, MA, 2003.

HUELSMAN, C. M. "Phenol Gasification in Supercritical Water: Chemistry, Byproducts and Toxic Impacts". PhD Thesis. University of Michigan, 2014.

KAMLER, J.; SORIA, J. A. "Supercritical Water Gasification of Municipal Sludge: A Novel Approach to Waste Treatment and Energy Recovery". Gasification for Practical Applications, InTech. 2012. http://www.intechopen.com/books/gasification-for-practicalapplications/supercritical-water-gasification-of-municipal-sludge-a-novelapproach-to-waste-treatment-and-energy.

KAMM, B.; GRUBER, P.; KAMM, M. "Biorefineries - Industrial Processes and Products. Status Quo and Future Directions. Vol. 1". WILEY-VCH Verlag GmbH \& Co. KgaA, Weinheim, 2006.

KRITZER, P. Corrosion in high-temperature and supercritical water and aqueous solutions: a review. The Journal of Spercritical Fluids, v. 29, n.1-2, p. 1-29. 2004

KUMAR, A.; NOUREDDINI, H.; DEMIREL, Y.; JONES, D.; HANNA, M.; "Simulation of Corn Stover and Distillers Grains Gasification with Aspen Plus" Transactions of the Asabe, v. 52, n. 6, p. 1989-1995, Nov-Dec 2009.

LAGER, T. "Managing process innovation: from idea generation to implementation”. Series on Technology Management, v. 17, p.160-186, 2011.

LAGER, T. Startup of new plants and process tecnology in the process industries: organizing for na extreme event. J. of Business Chemistry, v. 9, n.1, p. 1-18, 2012.

LAKSHMANAN, V.I.; ROY, R.; RAMACHANDRAN, V. "Innovative Process Development in Metallurgical Industry". Springer. 2016.

LETELLIER, S.; MARIAS, F.; CEZAC, P.; SERIN, J. "Gasification of aqueous biomass in supercritical water: A thermodynamic equilibrium analysis" Journal of Supercritical Fluids, v. 51, n. 3, p. 353-361, Jan 2010.

LIM, M.; ALIMUDDIN, Z. "Bubbling fluidized bed biomass gasification Performance, process findings and energy analysis". Renewable Energy, v. 33 , n. 10, p. 2339-2343, Oct 2008. 
LU, Y. J.; GUO, L. J.; JI, C. M.; ZHANG, X. M.; HAO, X. H.; YAN, Q. H. "Hydrogen production by biomass gasification in supercritical water: a parametric study". International Journal of Hydrogen Energy, v. 31, n. 7, p. 822-831, Jun 2006.

LU, Y.; HUANG, J.; ZHENG, P.; JING, D. Flow structure and bubble dynamics in supercritical water fluidized bed and gas fluidized bed: A comparative study. International Journal of Multiphase Flow. v. 73, p. 130-141. 2015.

MAGDELDIN, M.; KOHL, T.; DEBLASIO, C.; JÄRVINEN, M.; PARK, S.W.; GIUDICI, R. The Bio-SCWG Project: Integration of biomass supercritical water gasification with CHP units. The Joint Held Congresses $3^{\text {rd }}$ Congreso latinoamericano sobre biorrefierías/ $2^{\text {nd }}$ International Symposium on Lignocelulosic Materials. November , 23-25 Concepción. Chile. 2015.

MAGNUSSON, H. "Process Simulation in AspenPlus of an Integrated Ethanol and CHP Plant". Umea University. Sweden. 2005.

MANZOUR, P. A. "Hydrogen Production Using Catalytic Supercritical Water Gasification of Lignocellulosic Biomass". PhD Thesis. University of Toronto, 2012.

MARRONE, P.A.; HONG, G.T. "Corrosion control methods in supercritical water oxidation and gasification processes". The Journal of Spercritical Fluids v. 51, n.2, p. 83-103. 2009

MATSUMURA, Y.; MINOWA, T. Fundamental design of a continuous biomass gasification process using a supercritical water fluidized bed. International Journal of Hydrogen Energy Vol. 29, num. 7, p. 701-707, 2004

MCMILLAN, J. "Games, Strategies \& Managers". Oxford University Press, Oxford. 1992.

MELO, A. S. S. A; SILVA, M. P. "Estimando o valor da "externalidade positiva" do uso da vinhaça na produção de cana de açúcar: um estudo de caso". IV Encontro da Sociedade Brasileira de Economia Ecológica, Belém, 2001. http://www.ecoeco.org.br/publicacoes/encontros .

MORAES, B. S.; JUNQUEIRA, T. L; PAVANELLO, L. G.; CAVALETT, O.; MANTELATTO, P. E.; BONOMI, A.; MORAES, M. Z. "Anaerobic digestion of vinasse from sugarcane biorefineries in Brazil from energy, environmental, and economic perspectives: Profit or expense?". Applied Energy, v. 113, p. 825-835, Jan 2014.

NAQVI, M.; YAN, J.; FRÖLING, M. "Biorefinery system of DME or $\mathrm{CH} 4$ production from black liquor gasification in pulp mills". Bioresource Technology, v. 101, p. 937-944, 2009. 
NIKOO, M. B; MAHINPEY, N.; "Simulation of biomass gasification in fluidized bed reactor using Aspen Plus". Biomass \& Bioenergy, v. 32, n. 12, p. 12451254, Dec 2008.

"Plano decenal de expansão de energia 2022". Ministério de Minas e Energia. Empresa de Pesquisa Energética. Brasília. MME/EPE, 2013.

NEVEUX; T.; LE MOULLECT, Y.; CORRIOU, J. P.; FAVRE, E. "Modeling CO2 Capture in Amine Solvents: Prediction of Performance and Insights on Limiting Phenomena". . Industrial \& Engineering Chemistry Research, v. 52, n. 11, p. 4266-4279, Mar 2013.

PALMER, D.; KAPLAN, S. A framework for strategic innovation. San Francisco Innovation. LLC. 24p. 2013.

PERTIWI, D.S.; WEBB, C.; SHARRATT,P.N. Conceiving process synthesis methods for biorefineries. The $13^{\text {th }}$ Asia-pacific Confederation of Chemical Engineering Congress, Oct, 5-8, Taipei.2010

PRADA, S. M.; GUEKEZIAN, M.; SUÁREZ-ILHA, M. E. V.; "Metodologia analítica para a determinação de sulfato em vinhoto". Química Nova, v. 21, n.3, p. 249-252. 1998.

PREVITALI, R. N.; "Uso de vinhaça para fertirrigação". Fatec. Araçatuba, 2011.

PUIG-ARVANAT, M.; TORA, E.A.; BRUNO, J.C.; CORONAS, A. State of the art on reactor designs for solar gasification of carbonaceous feedstock. Solar energy v. 97, p. 67-84. 2013.

RIBAS, M. M. F.; "Tratamento de vinhaça em reator anaeróbio operado em batelada sequencial contendo biomassa imobilizada sob condições termofílicas e mesofílicas”. Universidade de São Paulo, São Carlos. 2006.

RESENDE, F. L. P; SAVAGE, P. E. "Kinetic Model for Noncatalytic Supercritical Water Gasification of Cellulose and Lignin". Aiche Journal, v. 56, n. 9, p. 2412-2420, Sep 2010.

ROCHA, M. H. "Uso da Análise do Ciclo de Vida para d Comparação do DesempenhoAmbiental de Quatro Alternativas para Tratamento da Vinhaça". Dissertação de Mestrado. Itajubá, Maio de 2009.

RÖNNLUND, I; MYRÉEN, L.; LUNDQVIST, K.; AHLBECK, J.; WESTERLUND, T. "Waste to energy by industrially integrated supercritical water gasification - Effects of alkali salts in residual by-products from the pulp and paper industry". Energy, v. 36, n. 4, p. 2151-2163, Apr 2011. 
SANDLER, S. I. "Using Aspen Plus in Thermodynamics Instruction: A Stepby-Step Guide". Wiley. 2015

ŠKERGET, M.; KNEZ, Ž.; KNEZ- HRNČIČ. M. Solubility of Solids in Sub- and Supercritical Fluids: a Review. J Chemical and Engineering Data. V. 54, n. 4, p. $694-719.2011$

SMITH, G.P.; GOLDEN, D.M.; FRENKLACH, M.; MORIARTY, N.W.; EITENEER, B.; GOLDENBERG, M.; BOWMAN, T.; HANSON, R.K.; SONG, S. , GARDINER, W.C.; LISSIANSKI, V.V.; QIN, Z. "GRI-Mech 3.0", http://www.me.berkeley.edu/gri_mech/, 2000.

SMITH W. R., MISSEN R. W.;"Chemical reaction equilibrium analysis: theory and algorithms". New York: Wiley; 1982.

TANG, H.; KITAGAWA, K. "Supercritical water gasification of biomass: thermodynamic analysis with direct Gibbs free energy minimization". Chemical Engineering Journal, v. 106, n. 3, p. 261-267, Feb 2005.

TIAN, Z.; MOHAN, G.; INGRAM, L; PULLAMMANAPPALLIL, P. "Anaerobic digestion for treatment of stillage from cellulosic bioethanol production". Bioresource Technology, v. 144, p. 387-395, Sep 2013.

TISDALE, J. "Simulations and Modeling of Biomass Gasification Processes". Msc Thesis. Massachusetts Institute of Technology, 2004.

TURTON, R.; BAILIE, R.C.; WHITING, W.B.; SHAEIWITZ, J.A.;. BHATTACHARYYA, D. "Analysis, Synthesis, and Design of Chemical Processes". Prentice Hall. 2012.

YAN, Q.; GUO, L.; LU, Y. "Thermodynamic analisys of hydrogen production from biomass gasification in supercritical water". Energy Conversion and Management, v. 47, n. 11-12, p. 1515-1528, Jul 2006.

XU, D.H.; WANG, S.Z.; GING, Y.M.; GUO, Y.; TANG, X.Y.; MA, H.H. A novel concept reactor design for preventing salt deposition in supercritical water. Chemical Engineering Research and Design,v. 88, n.11, p. 1515-1522. 2010.

XU, D.; HUANG, SC.; WANG, S.; LIN, G.; GUO, Y.; Salt deposition problem in supercritical water. Chemical Engineering Journal, v. 279, p. 1010-1022. 2015.

YANIK, J.; EBALE, S.; KRUSE, A.; SAGLAM, M.; YUKSEL, M. "Biomass gasification in supercritical water: II. Effect of catalyst". International Journal of Hydrogen Energy, v. 33, n. 17, p. 4520-4526, Sep 2008.

YAKABOYLU, O.; HARINCK, J.; SMIT, K. G.; JONG, W. " Supercritical water gasification of manure: $A$ thermodynamic equilibrium modeling approach". Biomass \& Bioenergy, v. 59, p. 253-263, Dec 2013. 
YAKABOYLU, O.; HARINCK, J.; SMIT, K.G. G.; JONG, W. "Supercritical water gasification of biomass: A literature and technology overview" Energies vol. 8, Num. 2, p.859-894. 2015.

YOSHIDA, A.; OSHIMA, Y. MATSUMURA, C. "Gasification of biomass model compounds and real biomass in supercritical water". Biomass \& Bioenergy, v. 26, n. 1, p. 71-78, 2004.

WEBLEY, P.; TESTER, J. "Fundamental kinetics of methane oxidation in supercritical water". Energy \& Fuels, v. 5, n. 3, p. 411-419, May-Jun 1991.

WITHAG,J.; SMEETS, J.; BRAMER, E.; BREM, G. "System model for gasification of biomass model compounds in supercritical water - A thermodynamic analysis". Journal of Supercritical Fluids,v. 61, p. 157-166, Jan 2012.

WOOD, C; ROSENTRATER, K. A.; MUTHUKUMARAPPAN, K. GU, Z. "Quantification of Physical and Chemical Properties, and Identificationof Potentially Valuable Components from Fuel Ethanol Process Streams". Cereal Chemistry, v. 90, n. 1, p. 70-79, Jan-Feb 2013.

ZHANG, J. "Hydrogen Production by Biomass Gasification in Supercritical Water". Energeia vol. 19, No. 6, p.1-6. (CAER - University of Kentucky, Center for applied Energy Research) 2008. 